L1brary, N.W. BIdg

\title{
NBS
}

SEP 91963

Eechnical Note No.179

CHOKING TWO-PHASE FLOW LITERATURE SUMMARY AND IDEALIZED DESIGN SOLUTIONS FOR HYDROGEN, NITROGEN, OXYGEN, AND REFRIGERANTS 12 AND 11

R. V. SMITH

U. S. DEPARTMENT OF COMMERCE NATIONAL BUREAU OF STANDARDS 


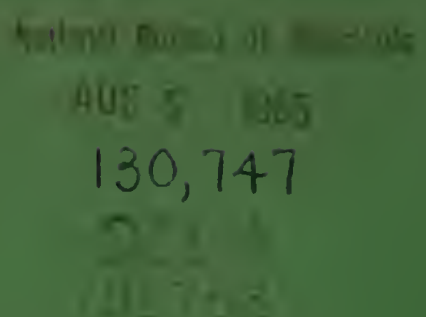

THE NATIONAL BUREAU OF STANDARDS

\section{Functions and Activities}

The functions of the National Bureau of Standards are set forth in the Act of ('ongress, March 3, 1901, as amended by Congress in Public Law 619, 1950. These include the development and maintenance of the national standards of measurement and the provision of means and methods for making measurements consistent with these standards; the determination of physical constants and properties of materials; the development of methods and instruments for testing materials, devices, and structures; advisory services to government agencies on scientific and technical problems; invention and development of devices to serve specinl needs of the Government; and the development of standard practices, codes, and specifications. The work includes basic and applied research, development, engineering, instrumentation, testing, evaluation, calibration services, and various consultation and information services. Research projects are also performed for other government agencies when the work relates to and supplements the basic program of the Bureau or when the Bureau's unique competence is required. The scope of activities is suggested by the listing of divisions and sections on the inside of the back cover.

\section{Publications}

The results of the Bureau's research are published either in the Bureau's own series of publications or in the journals of professional and scientific societies. The Bureau publishes three periodicals available from the Government Printing Office: The Journal of Research, published in four separate sections, presents complete scientific and technical papers; the Technical News Bulletin presents summary and preliminary reports on work in progress; and the Central Radio Propagation Laboratory Ionospheric Predictions provides data for determining the best frequeneies to use for radio communications throughout the world. There are also five series of nonperiodical publications: Monographs, Applied Mathematies Series, Handbooks, Miscellaneous Publications, and Technical Notes.

A complete listing of the Bureau's publications can be found in National Bureau of Standards Circular 460, Publications of the National Bureau of Standards, 1901 to June 1947 (\$1.25), and the Supplement to National Bureau of Standards Circular 460, July 1947 to June 1957 (\$1.50), and Miscellaneous Publication 240, July 1957 to June 1960 (includes Titles of Papers Published in Outside Journals 1950 to 1959) (\$2.25); available from the Superintendent of Documents, Government Printing Office, Washington D.C. 20402. 


\title{
NATIONAL BUREAU OF STANDARDS \\ Eechnical Mote 179 \\ August 3,1963
}

\section{CHOKING TWO-PHASE FLOW LITERATURE SUMMARY AND \\ IDEALIZED DESIGN SOLUTIONS FOR hYDROGEN, NITROGEN, OXYGEN, AND REFRIGERANTS 12 AND 11}

\author{
R. V. Smith \\ Cryogenic Engineering Laboratory \\ National Bureau of Standards \\ Boulder, Colorado
}

NBS Technical Notes are designed to supplement the Bureau's regular publications program. They provide a means for making available scientific data that are of transient or limited interest. Technical Notes may be listed or referred to in the open literature.

For sale by the Superintendent of Documents, U. S. Government Printing Office Washington, D.C. 20402

Price 75 cents 
This paper is a collection of the author's study on two-phase, choking flow. Although all sections are related to this area, specific parts of the report may be read without reference to the other sections.

Section 2. 0 presents a rather detailed description of reported work, divided with respect to theoretical models and experimental flow systems.

Section 3. 0 presents most of the data of Section 2 in graphical form, and these results may be used as a design guide, separately, or with the idealized solutions of Section 6 .

Sections 4.0 and 5. 0 present the author's discussion and evaluation of the reported work.

Section 6. 0 presents idealized solutions recommended by the author for use as a design guide. For specific design recommendations, without the detailed development of the equations, the designer may make use of Section 6.4 only.

Section 7. 0 presents a discussion of proper mathematical expressions for the choking phenomena. 
2. 0 A SUMMARY OF REPORTED WORK

2. 1 Theoretical Analyses....... 6

2. 1. 1 Theoretical Analyses which Predict Choking from Initial Flow Conditions, Horrogeneous, Thermal Equilibrium Model

2. 1.2 Theoretical Analyses which Predict Choking from Initial Flow Conditions; Separated-Phase, Thermal Equilibrium Model........ 10

2. 1. 3 Theoretical Analyses which Predict Choking from Initial Flow Conditions; Separated Phase, Metastable Model

2. 1.4 Theoretical Analyses which Predict Critical Flow at the Point of Choking; Homogeneous Model._._._._._._._._. 14

2. 1.5 Theoretical Analyses which Predict Critical Flow at the Point of Choking; Separated, Thermal Equilibrium Model............. 16

2. 2 Semi-Empirical Relationships .

2. 2. 1 Semi-Empirical Relationships for Adiabatic, Constant-Area Flow Systems........ 19

2. 2. 2 Semi-Empirical Relationships for Adiabatic, Variable-Area Flow Systems

2. 2. 2. 1 Semi-Empirical, Adiabatic, Variable-Area Flow Systems with Superheated or Saturated Vapor or High Quality Fluid Entering

2. 2. 2. 2 Adiabatic, Variable-Area Flow Systems with Subcooled or Saturated Liquid or Low Quality Fluid Entering. . . . _ 21

2. 2. 3 Semi-Empirical Relationships for Constant-Area Flow Systems with Heat Added or Removed

3. 0 GRAPHICAL COMPARISONS OF REPORTED THEORETICAL AND

EXPERIMENTAL DATA

4. 0 DISCUSSION OF REPORTED WORK $\ldots \ldots$

4. 1 Discussion of Reported Experimental Data_.

4.1.1 Instrumentation and Data Reduction... 32

4. 1. 1. 1 Pressure Measurements_. 32

4. 1. 1.2 Critical Quality Determinations - 34

4.1.2 Discussion of Experimental Data as Related to Systems and Fluid Properties -......... 35 
4. 2 Discussion of Predictive Equations and Correlations

4. 2. 1 Predictive Equations and Correlations for Adiabatic,

Constant-Area Systems

4.2.2 Predictive Equations and Correlations for Adiabatic, Variable-Area Systems......

4. 2. 3 Predictive Equations and Correlations for Non-Adiabatic Systems - -

4. 2. 4 Critical Flow Predictions from Upstream Flow Conditions_._._... 41

0 FUR THER DESIRABLE ENGINEERING DATA

0 .IDEALIZED SOLUTIONS FOR CHOKING FLOW

6. 1 Introduction

6. 2 Mass Limiting Flow Flux in Terms of Properties at the Point of Choking -

6. 2. 1 Homogeneous, Thermal Equilibrium Model _............... 43

6. 2. 2 Separated-Phase, Thermal Equilibrium Model_._. 44

6. 2. 3 Homogeneous, Metastable (Equivalent, Two-Component) Model_.. 45

6. 3 Quality as a Function of Pressure

6.3.1 Fanno Flow $1 . . .66$

6. 3. 2 Isentropic Flow

6. 4 Critical Pressure Predictions for Idealized Flow Processes_._._._._. 47

6.4.1 Homogeneous, Thermal Equilibrium Model; Fanno Flow Process _ 47

6. 4.2 Homogeneous, Thermal Equilibrium Model; Isentropic Flow Process ...

6. 4.3 Homogeneous, Metastable (Equivalent of Two-Component) Model; Isentropic Flow Process.

6.4.4 Separated-Phase, Thermal Equilibrium Model; Fanno or Isentropic Flow Process

6. 4. 5 Separated-Phase, Metastable (Equivalent of Two-Component) Model; Isentropic Flow Process

6. 5 The Use of Idealized Solutions in Design Problems

7. 0 TWO-PHASE CHOKING AND RELAXATION PHENOMENA

7. 1 Homogeneous Mixture Flow Model

7. 2 Acoustic Velocity

7. 3 Choking Flow and the Second Law of Thermodynamics

7. 4 Discussion of Methods of Approach 107

7. 5 Non-Homogeneous Models _. 108

7. 6 Qualitative Solutions_. 109

7. 7 Qualitative Solutions: Thermal Equilibrium

7. 8 Qualitative Solutions: Relaxation Considered

7. 9 Conclusions 
ACKNOWLEDGMENTS

AUTHOR BIBLIOGR APHY

SUBJECT BIBLIOGRAPHY FOR LITERATURE SUMMARY 118 NOTATION

ADDENDUM 



\title{
CHOKING TWO-PHASE FLOW LITERATURE SUMMARY AND IDEALIZED DESIGN SOLUTIONS FOR HYDROGEN, NITROGEN, OXYGEN, AND REFRIGERANTS TWELVE AND ELEVEN
}

\author{
R. V. Smith
}

The literature summary presents a brief description and discussion of papers on choking, two-phase flow. These papers are arranged with respect to analysis methods and experimental systems. The idealized solutions utilize models intended to provide upper and lower limits for the actual flow cases. Charts are preserted to provide for rapid determination of choking flow for the choking point condition and for Fanno and isentropic flow for the fluids $\mathrm{H}_{2}, \mathrm{~N}_{2}$, $\mathrm{O}_{2}, \mathrm{CCl}_{2} \mathrm{~F}_{2}$, and $\mathrm{CCl}_{3} \mathrm{~F}$. A discussion of choking flow and relaxation phenomena is included.

\section{0 INTRODUCTION}

Choked flow refers to the Mach one condition, or, flow at the discharge of a constant area or converging area device such that a further reduction in downstream pressure will not increase the mass rate of flow. This is often called critical or mass-limiting flow. Choking flow can occur in any fluid generally regarded as compressible, so choking flow occurs in the gas phase and in the liquid-gas mixtures considered in this paper.

Mass-limiting flow for the gas phase is well understood for some ideal flow cases and has been treated in many texts $[60,11]$. For one dimensional, steady, adiabatic, horizontal flow one may write:

Momentum equation

$$
u d u+v d p+\frac{f u^{2}}{2 D} d \ell=0
$$

Continuity equation

$$
\dot{\mathrm{m}}=\mathrm{Au} / \mathrm{v}=\text { constant }
$$

or

$$
\mathrm{G}=\frac{\dot{\mathrm{m}}}{\mathrm{A}}=\mathrm{u} / \mathrm{v}
$$

Energy equation

$$
h_{0}=h+\frac{u^{2}}{2}=\text { constant. }
$$

In developing equations to predict choking flow, one may assume that the acoustic or small pressure wave velocity is equal to the choking velocity or, from the initial definition, that when choking occurs, $(\mathrm{dG} / \mathrm{dp})=0$. Both treatments result in the same final expressions, which are:

$$
a^{2}=\left(\frac{\partial p}{\partial p}\right)_{s} .
$$


and

$$
G_{c}^{2}=-(\partial p / \partial v)_{s}
$$

For the designer, it is usually desirable to be able to determine choking flow conditions from upstream conditions. For isentropic flow, a ratio between the choking, or critical, pressure and the stagnation pressure is usually developed. This ratio is generally known as the critical pressure ratio which is

$$
\frac{p_{c}}{p_{0}}=\left(\frac{2}{\gamma+1}\right)^{\frac{\gamma}{\gamma-1}}
$$

for an ideal gas. Similar relationships may be developed for fluids which do not follow the ideal gas relationship, if the equation of state is known. Experimental data, however, do not indicate that isentropic flow relationships can be extended to all variable-area, adiabatic flow. For example, Ducoffe, et al. [17], used a general relationship that

$$
G_{c} \frac{\sqrt{T_{o}}}{P_{o}}=\text { constant, }
$$

for a specific ideal gas, isentropic flow using (1) through (5). They compared their data for air flow through typical variable area flow devices by plotting

$$
\left.G_{c} \frac{\sqrt{T_{0}}}{P_{0}} \text { vs } \frac{P_{\ell}}{P_{0}} \text {. (See figure } 1\right) \text {. }
$$

Their data indicate slightly less than ideal-mass critical flow for an AN straight-through fitting and tee, with the critical pressure ratio $\left(\mathrm{p}_{\mathrm{c}} / \mathrm{p}_{\mathrm{o}}\right)$ occurring somewhat lower than 0.53 as predicted by (6) for air, assumed to be an ideal gas. These data are much as would be expected for this case where the difference may be accounted for by deviations from the ideal gas and isentropic flow assumption. However, for an orifice and an elbow, the mass rate of flow continues to increase at downstream pressures far below the predicted choking pressures. This behavior cannot be explained as a small deviation from the theory. The author suggests the differences between the ideal and the actual data may be attributed to deviations from the ideal nozzle assumption of uniform flow properties across any cross section, that is, the assumption of one dimensional flow.

For the Fanno flow (adiabatic, constant area, one dimensional flow with the equation of state known) case, the stagnation pressure does not remain constant, so a general expression for the critical pressure ratio cannot be developed. However, it may be shown that for a given system, flow will proceed to the mass limiting case (which is the maximum entropy case) if the term (fL/D) is equal to a predictable value for a chosen value of $G_{c}$ (see figure 2 ). In the 


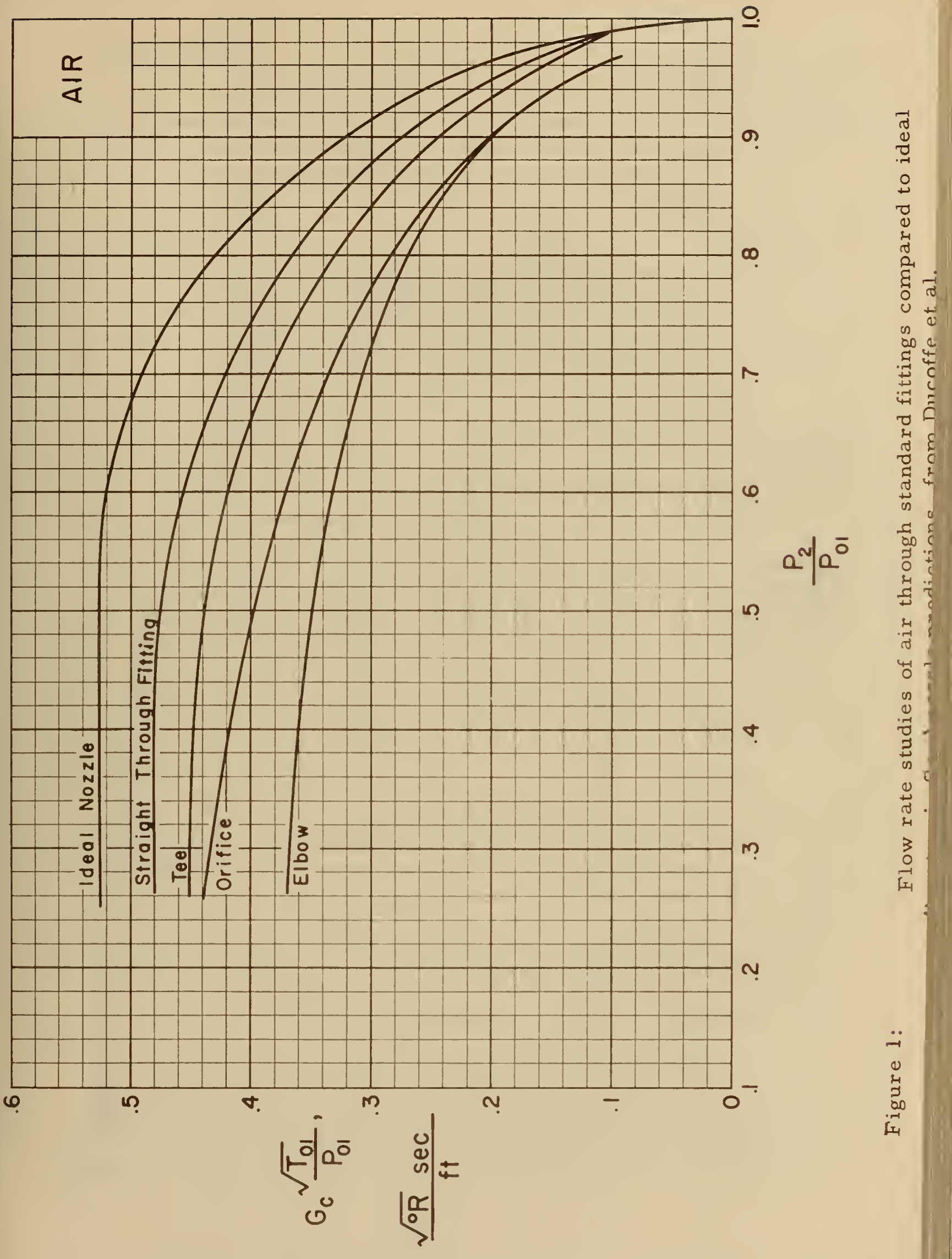




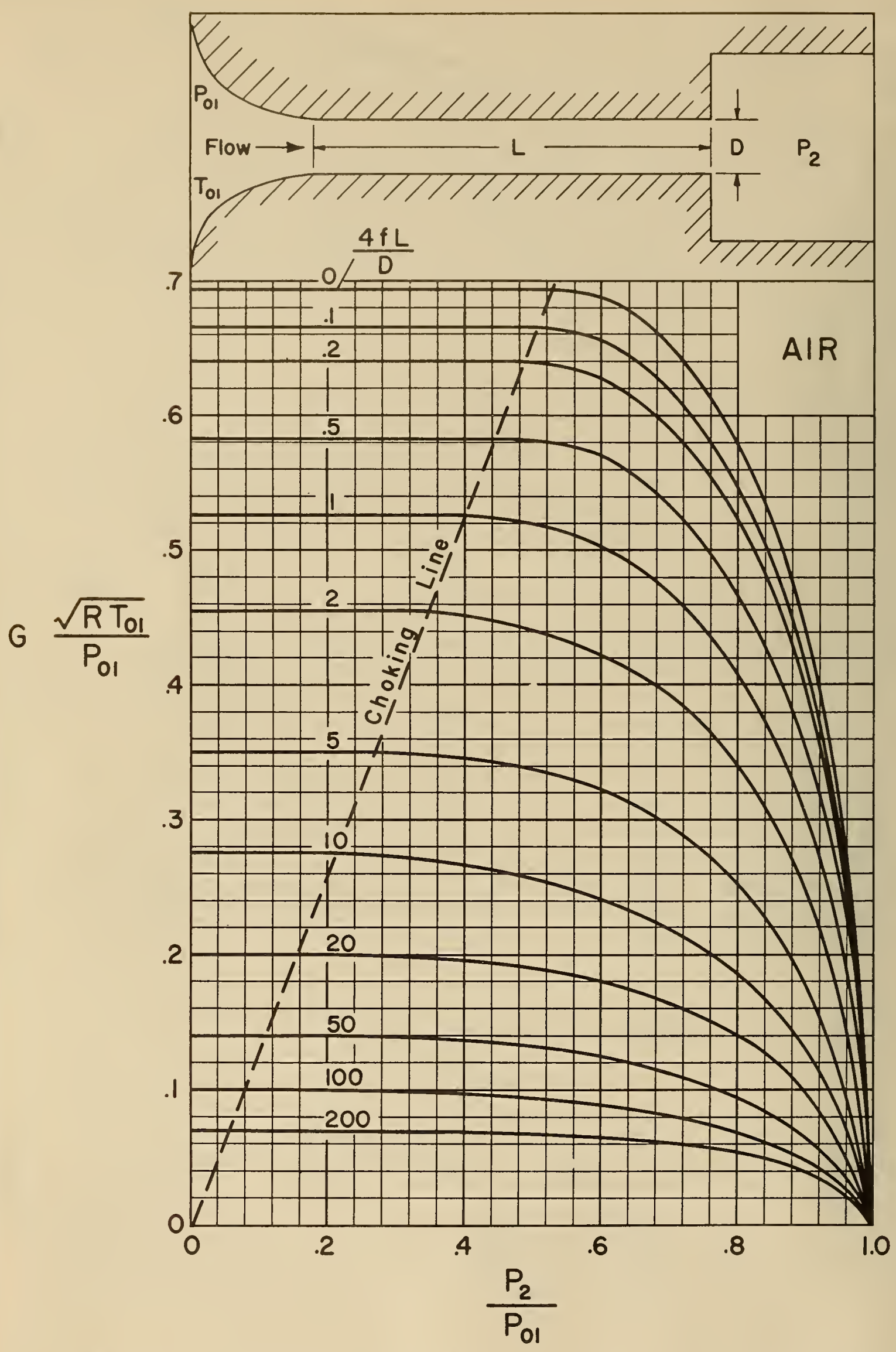

Figure 2: Choking predictions for Fanno flow of air, from Shapiro 
choking region, if the inlet and discharge pressures are held constant, and the length increased, the maximum flow will be reduced. Also, holding the inlet pressure constant and reducing the discharge pressure will not increase the mass rate of flow per unit area. Equations have been developed for other cases of one dimensional flow (for example, isothermal flow) and are treated in many papers and texts $[60,11]$.

For the two-phase, single-component flow, several additional degrees of freedom exist to further complicate the problem. These degrees of freedom occur as a result of the possibilities of mass, momentum and energy transport at the liquid-vapor interface. In order to write a flow equation including these additional degrees of freedom, one must have an accurate flow model. Here, to approximate the actual flow pattern, one is faced with a variable density model because of variable quality in the flow section and with the possibilities of different phase velocities (slip velocity).

Some limited success has been achieved in correlating relationships for two-phase flow patterns, for example the work of Baker [5], but reliable and general predictive relationships are almost entirely lacking. Essentially no work has been done for the case where flow patterns are changing, which is the probable case for some mass-limiting flow systems.

As for mass, momentum, and energy transport, at the liquid-vapor interface, all these are rate processes which require time to reach a steady or equilibrium state. Even if an accurate flow pattern is known, process rates and times are necessary for correct predictive solutions. Very little has been reported regarding these transport rates, however, data do indicate their importance. For example, in the case of mass transfer, many instances of metastable (vapor and liquid not in thermal equilibrium) flow have been observed and reported. So the assumption of liquid-vapor equilibrium is not always correct, and one must consider the mass transfer rate process.

In view of these two-phase complexities and knowledge limitations, one would not expect to find general and reliable mass limiting flow relationships. One finds, instead, theoretical solutions similar to single phase solutions with assumptions of rather simple flow patterns, such as homogeneous mixtures or separated phases. These solutions are obviously limited in accuracy by deviations of the actual case from the assumptions. There are also many reported empirical and semi-empirical approaches to the problem, again, often related to simplified or single phase solutions. As usual, these approaches are essentially limited to systems and ranges of variables similar to the system and range of variables for the experimental work.

It is the purpose of this report to bring all these works together and to examine the state and reliability of knowledge for various flow cases, particularly those cases nearest to engineering application. Areas requiring further investigation will then be indicated. Finally, some idealized solutions intended to provide upper and lower limits for choking flow will be presented. 


\section{0 A SUMMARY OF REPORTED WORK}

The work reported generally divides itself into theoretical analyses and empirical and semi-empirical approaches to the problem. These two approaches represent the major divisions of this section. Further subdivisions will be made and discussed at the time of introduction of the topic subdivision. Papers that cover more than one subject area will be discussed in each subject area with which they are concerned.

\section{1 Theoretical Analyses}

A major division in the theoretical models is whether critical flow is predicted with reference to a point in the flow system (for example, critical pressure ratio) or if critical flow is predicted at the choking point. Further divisions in treatment are in the choice of flow models and whether the critical flow is represented by (5) for the mixture or by some other flow condition.

If the homogeneous model is chosen, assuming thermal equilibrium, then the additional degrees of freedom mentioned in the introduction may be considered because, when the liquid ard vapor are completely mixed, the momentum transport at the interface is zero and energy transport at the interface may be generally considered sufficient to produce essentially the same temperature throughout the fluid. In addition, if thermal equilibrium is assumed, the energy conservation equation may be used to determine the required mass transport at the liquid-vapor interface. Then, solutions may be obtained which predict choking in the same general way critical flow is predicted for the single phase case, either from upstream conditions or at the choking point. Similar solutions are also possible for some separated flow models if certain transport relationships and a choking condition are assumed. The remainder of the solutions predict choking flow at the choking point only.

\section{1. 1 Theoretical Analyses which Predict Choking from Initial Flow} Conditions, Homogeneous, Thermal Equilibrium Mode1

Bridge ${ }^{[9]}$, in 1949, wrote a paper primarily for the purpose of guiding designers of steam-water systems, using a homogeneous, thermal equilibrium model. For pressure drop computations he develops from (1)

$$
-d p=\frac{f u^{2}}{2 v D} d \ell+\frac{u d u}{v} *
$$

* Friction factor, $f$, is defined by (1). Bridge used a friction factor, $f_{\text {Bridge }}=f / 4$ in his paper. 


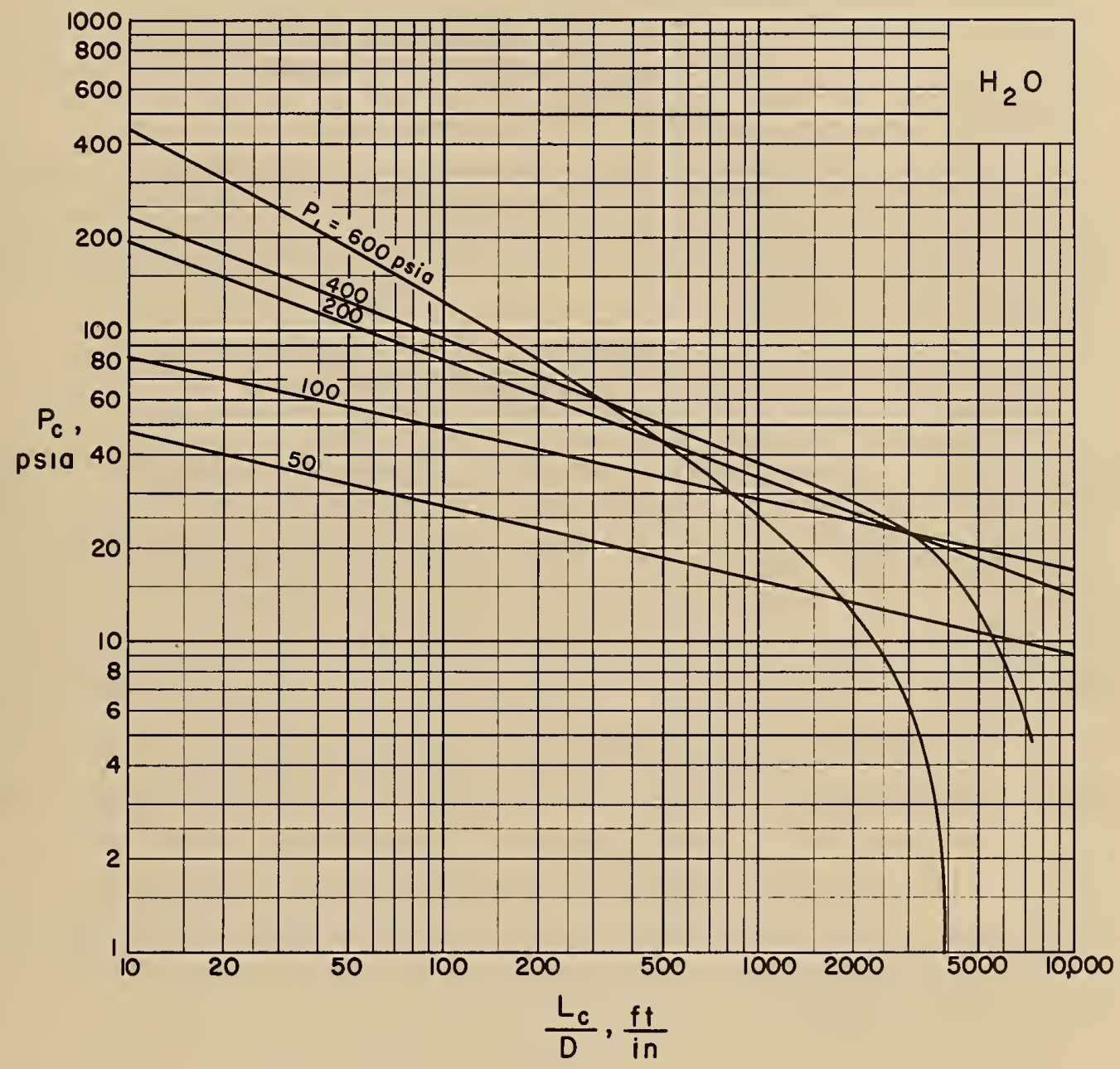

Figure 3: Steam-water choking flow predictions from Bridge (isentropic flow) (HO)(TH 


$$
\frac{1}{G^{2}} \int \frac{d p}{v}=\frac{f L}{2 D}+\ln \frac{v}{v_{l}}
$$

To aid the computation, he plotted a series of solutions for $\int \frac{\mathrm{dp}}{\mathrm{v}}$ and $\ln \frac{\mathrm{v}}{\mathrm{v}_{\mathrm{l}}}$, assuming an isenthalpic process. To predict critical flow, he plotted a series of curves, each with a constant $G$ for $P$ versus $L / D$ to determine $L_{\text {max }}$ or the necessary length to achieve critical flow. From these curves he produced further curves which predicted the critical pressure ratio as a function of inlet pressure and $L_{c} / D$. These results are shown as figure 3 .

Allen [2], in 1951, also used the homogeneous, thermal equilibrium model, the conservation equations $(1,2,3)$ and (5), and assumed isenthalpic expansion to predict pressure drop for a steam-water mixture flow through constant area pipes. For a critical pressure ratio, he derived the expression

$$
P_{C}=G_{C} C_{A l} P_{1}
$$

where $\mathrm{C}_{\mathrm{Al}}$ is a function of saturation enthalpy and specific volume and the inlet and exit pressures. For mass flow through a variable area, flow-control device, he assumed isentropic rather than isenthalpic expansion and the general assumptions as above, and wrote an expression for mass-limiting flow per unit area as a function of the same variables as for the critical pressure ratio. Using average values of the thermodynamic properties at saturation, which are functions of pressure only, allows trial and error solutions for critical mass flow.

Allen found his solutions for maximum mass flow rate and critical pressures to be in generally good agreement with experimental data of Benjamin and Miller [6] and Bottomley, [8] which involved actual drain piping arrangements. He also found his predictions to be reasonably accurate for data on a two-inch regulating valve in a steam plant. His prediction equations were not in agreement with the data of Burnell [10] for short, straight pipes. He explained this discrepancy by the increased probability of large values for slip velocity in the Burnell experimental system.

Using the general model for this section, Love [39], in 1960, developed critical flow relationships for the isentropic flow of steam-water mixtures using $(1,2,3$, and 5$)$, and a previously formulated equation of state for steam-water mixtures. A typical solution of his treatment is shown in figure 4. His values of $G_{c}$ versus stagnation enthalpy with pressure and quality as parameters are similar to those shown in figure 4. Love does not compare his critical flow solutions with experimental data. 


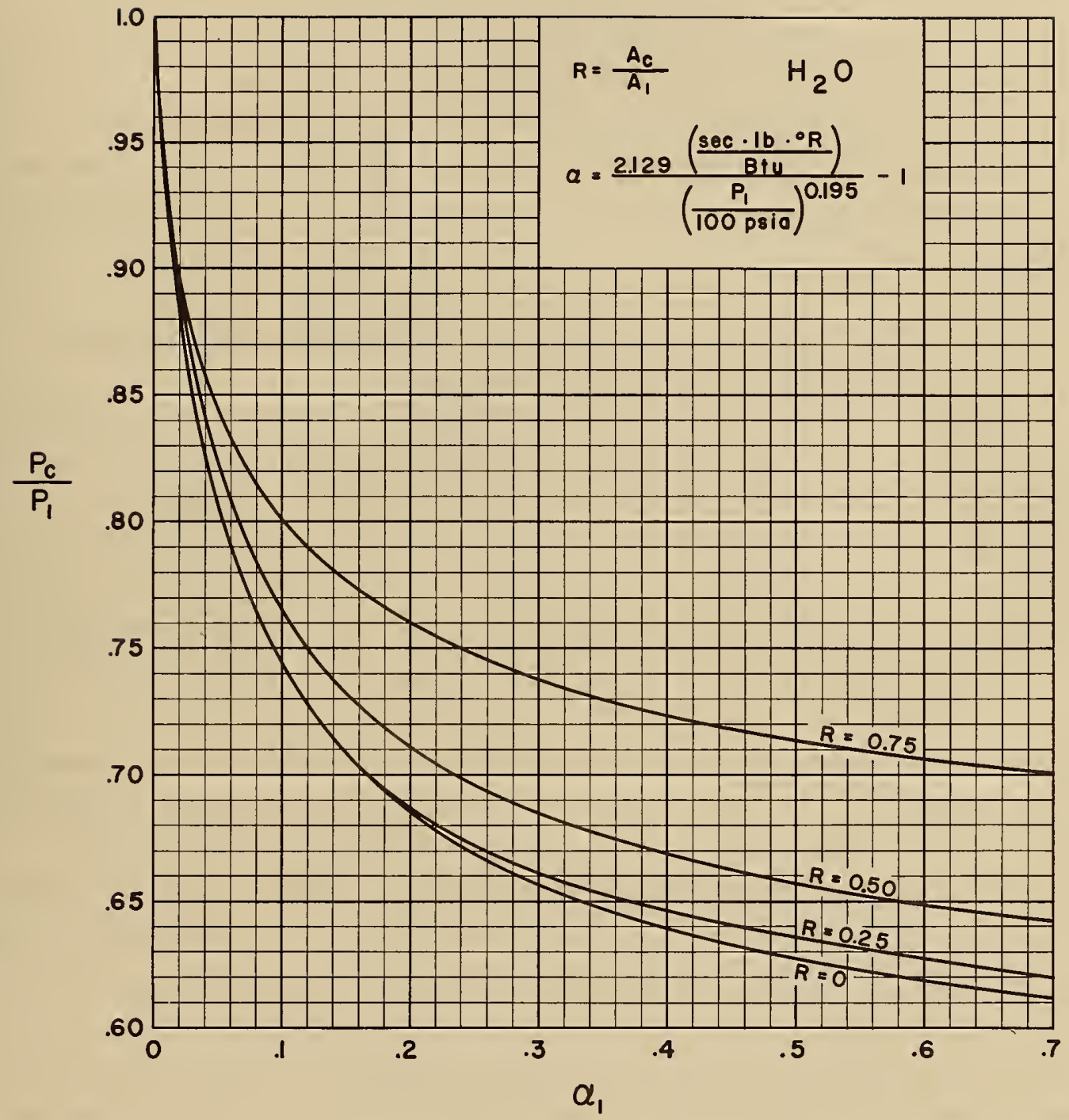

Figure 4: Steam-water choking flow predictions from Love (isentropic flow) (HO)(TH 
A computer solution for isentropic flow of superheated steam and steam and water mixtures entering a flow system and expanding, which used the general model of this section, was obtained by Steltz ${ }^{[67]}$ in 1961. He made further simplifying assumptions that the fluid behaves as an ideal gas in the single-phase and two-phase regions and checked his results at several points using tabular properties of steam. His predictive critical flow results are shown in figure 5.

Sajben [57], in 1961, reported a computer solution for steam-water, Fanno flow, assuming a homogeneous and thermal equilibrium model. He applied $(1,2,3$, and 5$)$ and developed relationships for predictions of mass flow rate, critical flow rate, and outlet quality, if the saturation pressure and point of zero quality flow and two-phase friction factor are known. A critical flow predictive plot for Fanno flow is shown in figure 6. By Sajben's definition, $G_{o(S a)}$ is the zero quality mass-limiting flow rate evaluated at $P_{s(S a)}$, the zero quality flow pressure.

2. 1.2 Theoretical Analyses which Predict Choking from Initial Flow Conditions; Separated-Phase, Thermal Equilibrium Model

Using the general model of this section, Linning [37] , in 1952, developed expressions for predictive critical flow for annular and parallel-separated flow models [5]. His solution considered slip velocity between the phases. The treatment was somewhat empirical as the solution of his equations was dependent on the interface velocity ratio which was determined by experimental measurements of the outlet momentum. He also assumed that the ratio of phase velocities varies linearly from the point of incipient vaporization. Linning predicted critical flow when $\partial G / \partial\left(u_{g} / u_{f}\right)=0$, rather than by the use of (5). In his final solution, he used a single term for the equivalent specific volume for the separated-phase mixture. His predictive results for critical temperature ratios (which are a function of critical pressure ratios for the thermal equilibrium model in the two-phase region) agreed reasonably well with his and Burnell's [10] experimental data, but did not agree with the data of Bottomley [8]. Linning's ${ }^{[37]}$ predictive critical mass flows at the critical point are shown in figure $8 \mathrm{~b}$. Stuart and Murphy, ${ }^{[68]}$ in 1958, developed a critical pressure prediction using thermodynamic reasoning. First, they developed a correlating relationship between Reynold's and Euler's numbers for the critical flow state using the data of Benjamin and Miller, Burnell and Linning. They used this relationship to conclude that the vapor velocity is at, or near, the velocity of sound at the critical point and that the kinetic energy of the liquid phase does not change appreciably from the zero quality point to the critical point. These conclusions, along with the conservation of energy equation, allowed them to draw isenthalpic and sonic gas velocity curves on a pressure-versus-quality plot for any incipient vaporization (saturation) pressure. 


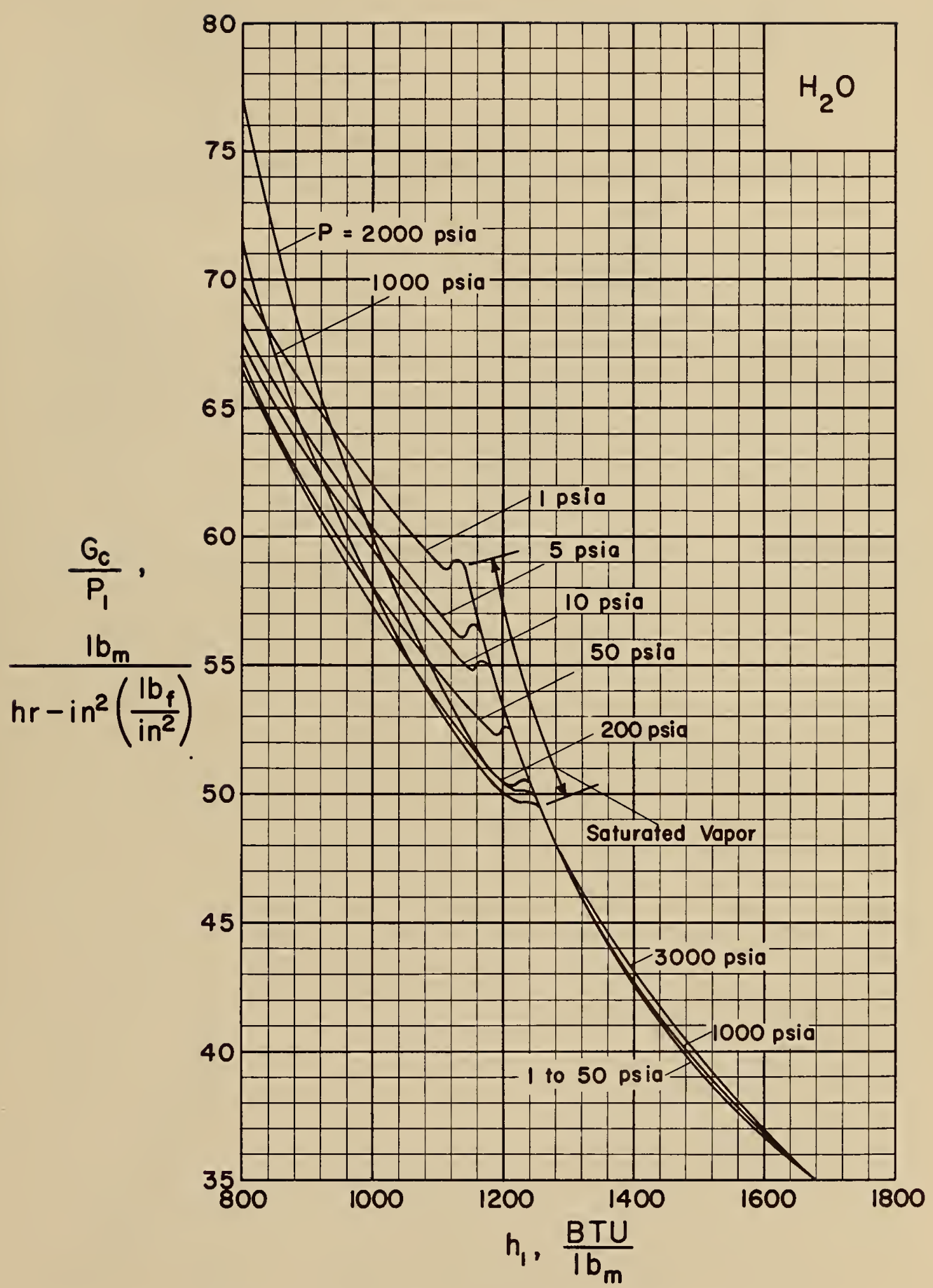

Figure 5: Steam-water, choking-flow predictions from Steltz (isentropic flow)(HO)(TH) 


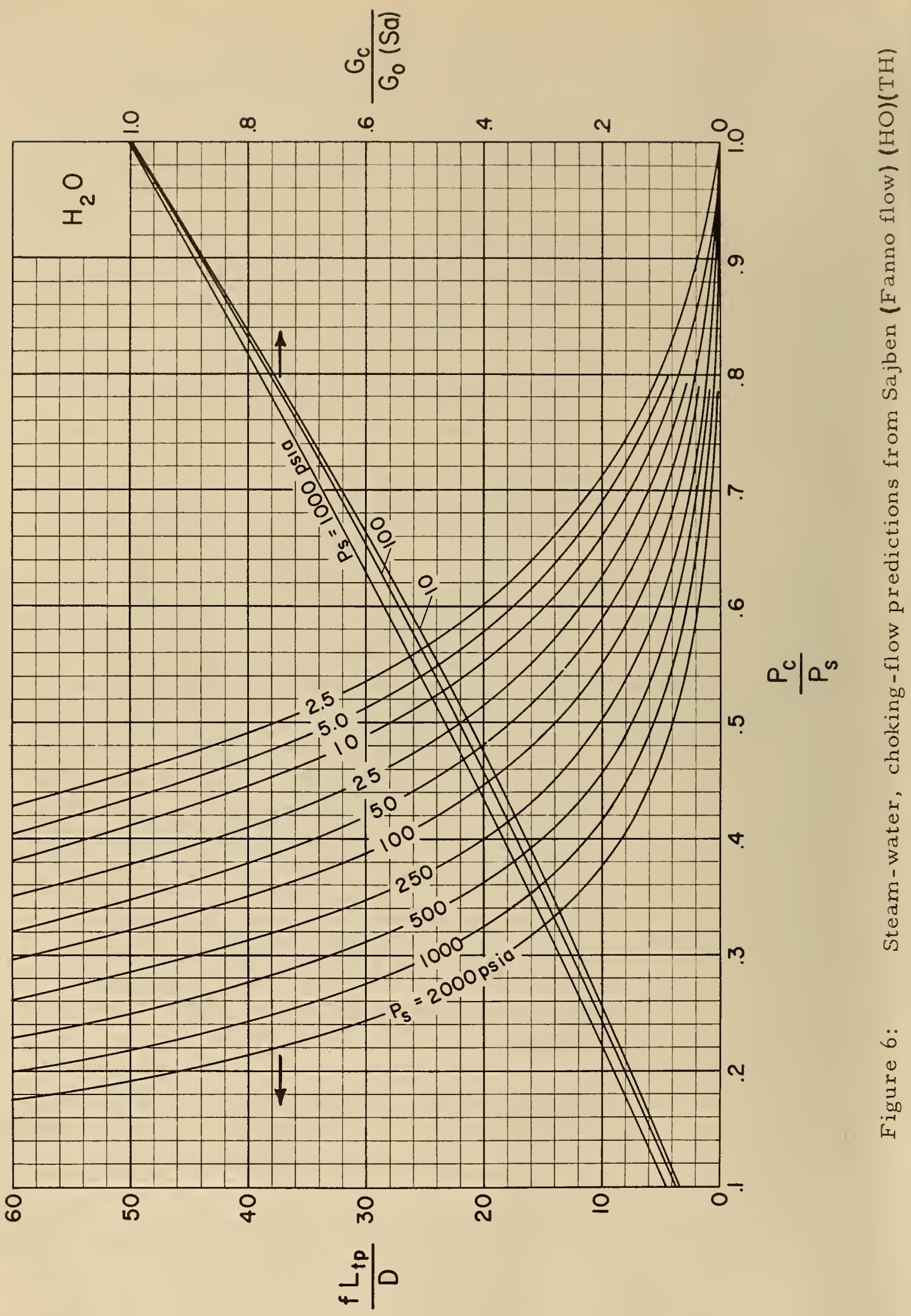


They then further concluded that the critical point must lie near the intersection of the isentropic expansion curve and the vapor acoustic velocity curve on the previously mentioned plot. Using this system, they predicted a critical pressure as a function of incipient evaporation pressure. While their predictions of critical pressure showed fair agreement with Benjamin and Miller, Burnell and Linning, the agreement with the experimental data of Faletti [19] was poor, as shown in Table $38, \mathrm{p}$. 149, of the Faletti dissertation.

2. 1.3 Theoretical Analyses which Predict Choking from Initial Flow Conditions; Separated Phase, Metastable Model

Silver and Mitchell [61], 1945, and Silver ${ }^{[62]}, 1948$, approached the problem of predicting mass flow and critical mass flow for a saturated liquid entering a nozzle. They proposed that thermal equilibrium would not be present in the flow in the nozzle but that the amount of vapor formed would be limited by the rate of heat transfer to and at the liquid-vapor interface. They assumed an annular flow model with no slip velocity, and applied the conservation equations and a form of (5). They were then able to develop predictive equations to compute critical pressures and critical mass flows as a function of nozzle length. For the longer nozzles, the vaporization process occurred over a greater length of time and the fluid tends toward a state of thermal equilibrium. Their results show reasonably good agreement with their experimental data, and their experimental critical mass flows are much greater for the shorter nozzles than predicted by equations which used the thermal equilibrium (Clausius-Clapeyron) relationships and the assumption of no-slip flow. Figure 8 shows some mass flow rate data, from Silver, at the critical point. Two other points were of interest regarding the experimental test results. One was the fact that introduction of very small amounts of steam at the entrance drastically reduced the maximum mass flow rate. The other was that $G_{c}$ was affected appreciably by the addition of a small pressure tap at the exit of the nozzle.

Bailey ${ }^{[4]}$, in 1951, studied the flow of subcooled and saturated water entering a nozzle. He developed a predictive theory based on the assumptions that vaporization will occur around a liquid core at saturation pressure and that the vaporization rate may be computed by the use of an experimentally determined coefficient of evaporation rather than by using the thermal equilibrium assumption. He predicted critical flow when his proposed annulus around the liquid core is completely filled with moving vapor. When the vaporization rate is sufficient to fill this annulus, critical flow is reached and the predicted critical pressure may be computed for this point. Since the annulus to be filled with vapor is large and the vaporization time is short for orifices and short nozzles, the theory predicted flow essentially as though liquid were flowing with no vaporization for the short flow sections, and, therefore, agreed with previous investigators. His theory predicted his experimental nozzle flow rate within 10 percent. 


\section{1. 4 Theoretical Analyses which Predict Critical Flow at the Point of Choking; Homogeneous Model}

Most authors who worked with a homogeneous, thermal equilibrium model extended their solutions to predict critical flow from some point upstream in the flow system, and have been reported in an earlier section. The flow-rate values at the choking point for the homogeneous, thermal equilibrium model have significance, however, as many authors used this model as a basis for correlations and comparisons. Designers, too, may find these data and solutions a useful guide because $\mathrm{G}_{\mathrm{c}(\mathrm{HO})(\mathrm{TH})}$ is a part of a correlating parameter, often used, which is shown in figure 8 of this report. For this reason, some of the treatments to obtain values of $G_{c(H O)(T H)}$ are reported here.

The solutions all involve some assumptions or approximations in the solution of (5). All, or nearly all, of the solutions reported in the last few years have been programmed for solution on the computer. Faletti ${ }^{[19]}$ found he could approximate

$$
G_{c}=-\left(\frac{\partial p}{\partial v}\right)_{s}^{1 / 2}
$$

by

$$
G_{c}=96.2604\left[6.1602 \mathrm{p}^{-1.974} \mathrm{x}_{\mathrm{c}}+17.198 \mathrm{p}^{-1.684}\right]^{-1 / 2} \frac{1 \mathrm{~b} \mathrm{~m}}{\mathrm{ft}^{2}-\mathrm{sec}}
$$

for water-steam systems for a pressure range from 28 to 100 psia.

Sajben ${ }^{[57]}$ suggests a solution which uses the approximation of $\frac{d a}{d p}$ and $\frac{d \beta}{d p}$ as finite differentials.

Love ${ }^{[39]}$ and Steltz ${ }^{[67]}$ used an approximate equation of state to provide a relationship between the variables in (5). Other investigators $[1,20,29,75]$ also showed solutions for this case. All solutions for steam-water systems show reasonably good agreement with each other. Figure 7 from Zaludek ${ }^{[75]}$ shows numerical solutions presented in a very usable chart form.

Another type of homogeneous solution for two components was reported by Holtzman ${ }^{\text {[27] }}$ and Tangren, et al. ${ }^{[70]}$ Both of these solutions used (1) through (5) and considered the gas phase an ideal gas. From this they developed a relationship for

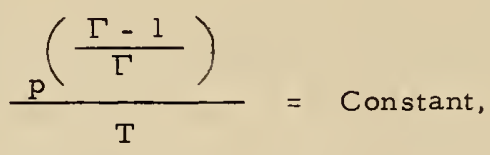

for the isentropic process, where 


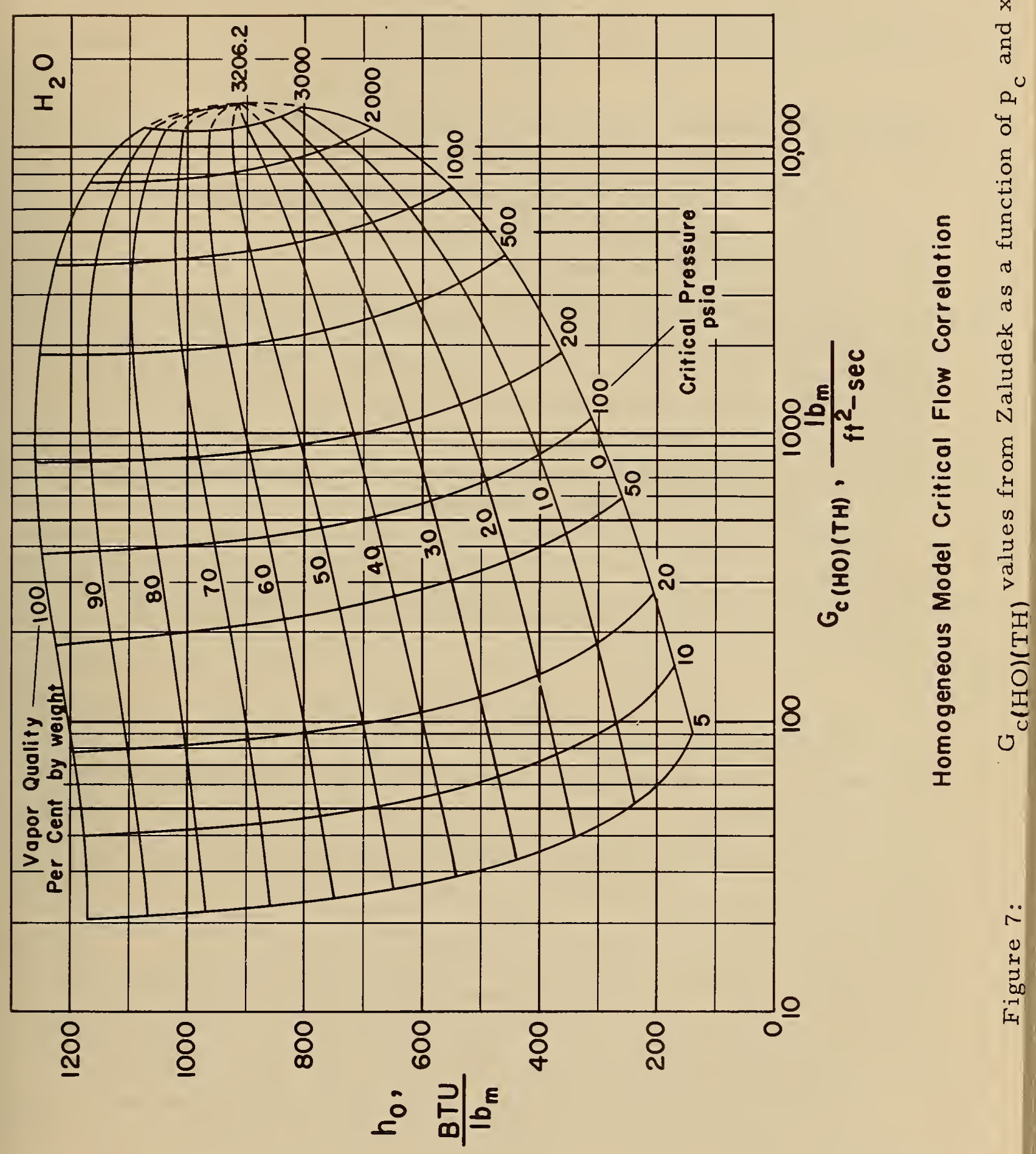




$$
\Gamma=\frac{\frac{\dot{m}_{g}}{\dot{m}_{f}} C_{p g}+C_{f}}{\frac{\dot{m}_{g}}{\dot{m}_{f}} C_{v g}+C_{f}}
$$

and is obviously similar to the specific heat ratio $\left(C_{p} / C_{v}\right)$ used, for example, in the isentropic critical pressure ratio equation for the single phase, single component studies (equation 6).

Holtzman [27] showed that neglecting the compressibility of the liquid, which was another assumption of Tangren, may introduce a considerable error for high-pressure, lowvapor-to-liquid-ratio, air-water systems.

These equations represent the extreme case for metastability (no phase change) for the single-component fluid. The results of this solution are shown in figure $8 \mathrm{~b}$, for water at a reduced pressure of 0.01 . The results using this model show some pressure and fluid dependence when plotted on the correlation shown in figure 8 .

\section{1. 5 Theoretical Analyses which Predict Critical Flow at the Point of Choking;} Separated, Thermal Equilibrium Model

Ryley ${ }^{[56]}$, in 1952, worked with an isentropic model and the conservation equations. He developed an expression for the mass flow rate in terms of the slip ratio, stagnation properties, and critical properties. He then showed that $G$ will be a maximum when

$$
\frac{u_{f}}{u_{g}}=\sqrt[3]{\frac{v_{f}}{v_{g}}} .
$$

The theory showed reasonably good agreement with his own experimental data with steamwater flowing in nozzles.

Isbin, et al. ${ }^{[29]}$, in 1957, employed the momentum balance of Linning with some simplifying assumptions. They also used the Martinelli [41] correlation in the analysis. Agreement with their experimental constant-flow area, steam-water data was good only at higher qualities. Further comparisons with this theory are shown in figure $8 \mathrm{~b}$. In a later study, Isbin, et al. [29], found that slight changes in the void fraction curves from the Martinelli values would improve the predictions of maximum mass flow rates considerably. These void fraction relationships based on critical flow data are shown in their paper.

Massena [42], in 1960, showed an expression for density in terms of the quality and the vapor flow-section-area fraction. Figure $8 \mathrm{~b}$ shows the comparative results of his expression. 
Several investigators assumed that the vapor velocity was at the velocity of sound. Some void fraction or vapor velocity relationship must be assumed to allow predictive solution of maximum mass flow rate. Using the void fraction prediction of Martinelli, Firey computed values of $G_{c}$ which were reported by Faletti ${ }^{[19]}$, p. 150.

In further work, Firey and Collingham [14] measured the velocity of a pulse created by a ruptured diaphragm in a steam-water flow system. They found the pressure wave travelled at a velocity very near the velocity of sound in dry steam in flow with "core qualities" as low as 26.6 percent. Core qualities were measured with a probe and calorimeter device. They then proposed the calculation of a critical mass velocity by the vapor choking model. This model assumes complete metastability for the pressure wave in the gas and also assumes slip velocity is zero. They then compared this critical mass velocity with the work of Faletti. They found reasonably good agreement at higher qualities.

To correct for the deviation of the Faletti experimental data from the homogeneous, thermal equilibrium model at 100 percent quality, the authors proposed a "metastability of the third kind" which involves a molecular combination in a supersaturated vapor which involves molecular groups of sufficient size to change the vapor density but not sufficient in size to sustain growth of a liquid droplet to provide a net condensation. If this deviation is assumed constant, then this correction may be made to the proposed model results and a further correction assuming a slip velocity may be computed. The authors used the data of Faletti to compute a slip velocity $\left(u_{g} / u_{f}\right)$ correction. This slip velocity value increased somewhat parabolically with decreasing quality to a value of 61.5 at 20 percent quality.

Zaloudek [75] also showed a simple vapor-choking model curve for comparison. The agreement is fairly good at high qualities, but the method markedly overpredicts at lower qualities. This predictive curve is shown on figure $8 \mathrm{~b}$ for further comparison. The flow rate versus quality shown by this curve is essentially independent of fluid pressure or fluid material for a reduced pressure range of $0.6>\mathrm{P}_{\mathrm{R}}>0.01$ for $\mathrm{H}_{2} \mathrm{O}, \mathrm{CCl}_{2} \mathrm{~F}_{2}, \mathrm{CCl}_{3} \mathrm{~F}, \mathrm{H}_{2}, \mathrm{~N}_{2}$, and $\mathrm{O}_{2}$

Fauske [20], in 1961, used the separated model of this section with the added assumptions that the pressure gradient $(\partial \mathrm{p} / \partial \ell)$ attained a maximum, finite value at the critical point and that this maximization was achieved by variation in the slip ratio. The latter assumption followed the same general reasoning as Linning and Ryley.

Neglecting frictional forces, Fauske wrote a force balance across a differential element, which finally produced an expression for density as

$$
\frac{1}{\rho} \equiv \frac{x^{2}}{\rho_{g}^{R}}+\frac{(1-x)^{2}}{\rho_{f}\left(1-R_{g}\right)}
$$


Then, differentiating the terms with respect to the slip ratio, and setting this expression equal to zero (initial as sumption), he arrived at

$$
\frac{u_{g}}{u_{f}}=\sqrt{\frac{\rho_{f}}{\rho_{g}}}
$$

and

$$
R_{g}=\left[\left(\frac{1-x}{x}\right)\left(\sqrt{\frac{\rho_{g}}{\rho_{f}}}\right)+1\right]^{-1} .
$$

The maximum mass flow rate was found from manipulation of his initial force-balance equation to be:

$$
G=\left[\frac{g_{c}}{\frac{d(1 / p)}{d p}}\right]^{1 / 2}
$$

which is the same form as (5). However, this $\rho$ is an equivalent density for the separatedphase case, determined by the previously developed relationships.

This predictive expression showed reasonably good agreement with his own higher pressure, lower quality, steam-water experimental data and the experimental data of Faletti ${ }^{[19]}$, and Isbin, et al. ${ }^{[29]}$ Further comparisons are shown in figure $8 \mathrm{~b}$.

\section{2 Semi-Empirical Relationships}

The lack of basic knowledge with respect to the two-phase systems regarding slip velocity, flow patterns, and mass and heat transfer between the phases would not appear to allow general and reliable predictions of the flow model necessary for an optimum theoretical treatment. Therefore, many semi-empirical relationships have been developed to predict critical flow. The predictive treatments are arranged with respect to the experimental systems.

Although the assumption of thermal equilibrium may not be immediately apparent in the data or relationships developed, this assumption was often used in two parts of the studies. The thermal equilibrium assumption was usually used in computing quality, and, often, the homogeneous model was used with this assumption to compute kinetic energy. These assumptions are examined in detail in the section on discussion of reported work.

There are three major divisions of flow systems in this section which represent somewhat idealized engineering situations. These systems are: constant-area adiabatic flow, variable-area adiabatic flow, and constant-area flow with heat added or removed. 


\section{2.1 Semi-Empirical Relationships for Adiabatic, Constant-Area Flow Systems}

Benjamin and Miller [6], in 1942, made a study of saturated water entering a heater drain line with elbows and valves in the system. Treating the fluid as homogeneous, they arrived at a relationship predicting critical flow when the energy made available by a pressure drop is equal to the change in kinetic and frictional energy terms which from (1) is,

$$
G^{2} / 2 g_{c} \ln \left(\frac{\rho_{1}}{\rho_{c}}\right)+G^{2} / 2 g_{c}\left(\frac{f L}{D}\right)=\int_{p_{1}}^{p_{c}} \rho d p .
$$

For a solution of this equation an experimental evaluation of the two-phase friction factor was required. The authors found "f" to vary from 0.0116 to 0.0131 which is in general agreement with Bottomley ${ }^{[8]}$ and represents values which have been used by several subsequent investigators. The process for the integral of $\rho d p$ was considered isentropic. Their equation was found to predict critical pressures in their system reasonably well. Further comparisons of the Benjamin and Miller data may be found in figure 8a. Burnell [10], in 1947, found that in experimental runs of steam and water in straight pipes, his critical mass flow exceeded the values predicted by Benjamin and Miller by a factor of 1.5 to 2.0. Burnell suggested that a slip velocity between the phases may explain this deviation from the homogeneous model.

Several authors have chosen to express critical flow at the critical point as an empirical function of the homogeneous prediction for constant area, steam-water systems. The results are a correlating plot of the observed value $G_{c}$ divided by $G_{c(H O)}(T H)$ versus the quality as shown in figure 8. The relationship shows reasonably good agreement and a lack of pressure dependence, at least for lower pressures. The first to suggest this general relationship was Isbin, et al. [29]

Later, in an extensive test program and with a thorough analysis of his flow system, Faletti [19], in 1960, reported his data in a plot of $G_{C} / G_{c(H O)(T H)}$ versus $x$. His data were for a constant area, steam-water system with relatively low pressures. Also, Zaloudek ${ }^{[75]}$, in 1961, made another thorough constant-area, steam-water experimental study at lower pressures. He reported his data as comparative to many others' experimental data and theoretical predictions on a $G_{c} / G_{c(H O)(T H)}$ versus x plot. In general, the Zaloudek and Faletti data were in good agreement. Further comparisons of Isbin, et al., Faletti, and Zaloudek may be found in figure $8 \mathrm{a}$.

Agnostinelli and Salemann [1], 1957, studying steam-water flow in a fine annulus, computed and plotted values of $G$ versus the downstream and upstream pressure ratio, $P_{2} / P_{1}$, for water subcooled and saturated entering a constant-area test section. They chose two rather extreme cases: one for thermal equilibrium and a homogeneous fluid with a two-phase friction factor and another case of extreme metastability with no vaporization in the flow. Then, by use of (5), a plot of critical points was placed on the chart intersecting both $G$ versus 
$\mathrm{P}_{2} / \mathrm{P}_{1}$ curves. The authors recommended the use of the average of the intersection values to predict the critical flow. Their results showed relatively good agreement for lower entering water temperatures $\left(400-450^{\circ} \mathrm{F}\right)$ and somewhat poorer agreement for higher entering water temperatures $\left(500-600^{\circ} \mathrm{F}\right)$. Entering water pressure was varied.but was not reported as a factor influencing this error of prediction. The test section was l" O. D. with the annulus thickness varying from 0.006 to $0.017 \mathrm{in}$.

\section{2. 2 Semi-Empirical Relationships for Adiabatic, Variable-Area Flow Systems}

Studies in these systems differ from those in the constant-area flow section, primarily, because the tendency for metastability is increased. The probability of the metastable state is increased because the short sections and steep pressure gradients allow less time for the vaporization, or condensation, processes to occur, which are necessary to produce thermal equilibrium. Metastability is even more likely when a single phase enters the variable area section because of the additional time required for the formation of initial vapor bubbles or condensation droplets.

2. 2. 2. 1 Semi-Empirical, Adiabatic, Variable-Area Flow Systems with Superheated or Saturated Vapor or High Quality Fluid Entering

Mellanby and Kerr [43], 1922, Goodenough [23], 1927, Yellot [74], 1934, Retalliatta[51] 1936, and Binnie and Woods [7], 1938, did studies, each of which extended knowledge beyond that previously reported.

From the first papers it was recognized that the isentropic, thermal equilibrium model underpredicted the critical mass flow for superheated steam entering a nozzle or Venturi tube and expanding into the two-phase region. The explanation for the flow being greater than the "ideal" model flow was postulated and later proven to be resulting from metastability. It was found condensation did not occur at the point of the crossing of the saturation line as indicated by an assumed flow process shown on an h-s diagram.

The papers established the Wilson line or Wilson zone at about three to four percent moisture on a thermal-equilibrium, h versus s plot for steam-water systems, which represented the region where condensation would first occur. This concept will generally explain experimental data by treating the gas and two-phase fluids as ideal gases with different specific heat ratios. Finally, the concept of a condensation shock was advanced and shown to further explain some erratic pressure behavior. Thus, critical flow for superheated steam expanding into the two-phase zone has been predicted within most engineering requirements for some time.

Goglia and Van Wylen [22], in 1961, found the behavior of expanding gaseous nitrogen in a nozle was similar to that found in the water studies. 
2. 2. 2. 2 Adiabatic, Variable-Area Flow Systems with Subcooled or Saturated Liquid or Low Quality Fluid Entering

The development of reliable predictions for maximum flow for liquid and low quality fluid entering a variable-area flow system has not been as orderly as for the vapor. Very early investigators recognized that an orifice flow could exceed the maximum flow predicted by the homogeneous, thermal equilibrium model by, at least, a factor of 4 or 5 . Many authors reported that, for entering liquid flow in a short variable area flow system such as an orifice, the flow was free of vaporization in the system even though the discharge pressure was considerably below the saturation pressure. Thus, it was reported that a critical pressure does not exist for such a system. For this reason, several papers which do not find choking flow, but which are variable-area, adiabatic-flow, pressure-drop studies for mass flow rates where some models may predict choking, are summarized in this section also.

Metastability and slip velocity have been advanced as the explanation for the deviation from the homogeneous, thermal equilibrium flow model prediction. Most authors, however, considered only one of the deviations as producing the major effect and regarded the other as negligible.

In one of the earlier papers, Bottomley [8], in 1937, suggested metastability as the prominent factor in explaining his measured discharge coefficients (ratio of maximum flow to the homogeneous, thermal equilibrium model prediction) which had values up to five. He further stated his belief that the metastability resulted from the surface tension effects of small bubbles. He presented a theory for critical flow, based on the assumption that critical pressure is reached when the work available balances the kinetic energy increase. This treatment was suggested as a design guide for typical steam plant units. He also proposed the use of orifice plates instead of ball-float traps in feed-water heater drains. In a later discussion of the paper by Kinderman and Wales [34], he reported that these installations have operated satisfactorily. Finally, he presented some experimental data and design recommendations for constant-area flow systems.

Benjamin and Miller [6], in 1941, presented a paper on the flow of saturated water through orifices, and found results comparable to that of Bottomley [8]. They also reported that when very small steam fractions entered the orifice with the saturated liquid a marked drop in the maximum flow was noted. As in the case of Bottomley, the authors suggest the use of an orifice plate as a drain trap.

Stuart and Yarnall [69], in 1944, studied the flow of water and steam through two orifices in series. They reported metastable flow in the jet of the second orifice which was indicated, in one case, by a measured water temperature of $314.4^{\circ} \mathrm{F}$ when the saturation temperature was $213.0^{\circ} \mathrm{F}$. Also, they observed the jets discharging into the atmosphere. Up to a liquid inlet temperature of $280^{\circ} \mathrm{F}$, only surface vaporization occurred. Above $280^{\circ} \mathrm{F}$, explosive 
boiling occurred three inches downstream from the orifice plate. As the entrance temperature was raised further, the explosive boiling point moved upstream, closer to the orifice. When saturated water was supplied to the orifice at $327.8^{\circ} \mathrm{F}$, the "explosion" occurred very near the orifice discharge. Flow through rounded entrance orifices showed metastability when the orifices were thin, but approached thermal equilibrium, homogeneous predictions for thicker orifices. Kennan questioned some of the metastable measurements in a discussion of the paper; however, he agreed metastability did exist in the tests.

Burnell ${ }^{[10]}$, in 1947, studied flow in nozzles and orifices and presented a theory similar to Bottomley. His nozzle and orifice flow predictions for entering saturated water were based on flow with no vaporization, modified by a correction factor which is a function of the surface tension of the liquid and experimentally determined values for $\mathrm{C}_{(\mathrm{Bu})}$. His equation was

$$
G_{c}=\sqrt{2 g_{c} C_{B u} P_{1} \rho_{1}} .
$$

Burnell also suggested that slip velocity may effect the results in a constant area flow section. In a later paper, published in 1955, Burnell [10] studied the flow of boiling water entering and flowing through a Venturi tube. He found he could predict flow quite well with a conventional Venturi tube equation for single-phase flow and his experimentally determined critical pressure ratio. He found that both a Venturi tube and a nozzle reached a critical pressure at $P_{C} / P_{1} \approx$ 0.663 for $\mathrm{H}_{2} \mathrm{O}$ flow. The nozzle, however, showed a lower mass flow than the Venturi tube at discharge pressures higher than the critical. Burnell's explanation for this was that the Venturi tube flashed further downstream. He found that a throat tap in the Venturi tube reduced the maximum flow rate which was similar to Silver's ${ }^{[50]}$ previous findings with rounded orifices. Burnell's explanation for this reduced mass flow was that the throat tap caused flashing in the throat. Burnell's theoretical and experimental results are shown in figures $8 \mathrm{a}$ and $8 \mathrm{~b}$.

Pasqua [49], in 1953, studied the flow of saturated and subcooled CCl ${ }_{2} F_{2}$ through orifices, short tubes, and nozzles. He found that, while the predictions from the work of Bailey and Silver agreed with the flow more closely than the homogeneous, thermal equilibrium model, these predictions were considerably in error for nozzles with large length-todiameter ratios. By observing the pressure-gradient behavior, he concluded that, for the subcooled liquid entering a short tube, the flow was full-tube flow until saturation pressure was reached, and then an orifice-type flow developed followed by a mass-limiting flow. For an entering saturated liquid, the flow was an orifice-type of flow to the mass limiting point. His empirical, critical-pressure ratio equation,

$$
P_{c} / P_{s}=0.37(L / D)^{0.2}
$$


indicated a very low critical pressure for short nozzles and orifices. Therefore, for almost all cases, the short flow sections would behave as single phase liquid flow, which would be in agreement with previous investigators using water. His proposed mass flow equations were of the form for incompressible liquid flow, modified by a coefficient of contraction to account for the vaporization effect, $C_{c(P a)}$, and the single phase discharge coefficient $C_{d(P a)}$. His equation was

$$
G=C_{c(P a)} C_{d(P a)} \sqrt{2 g_{c} \rho\left(P_{s}-P_{c}\right)}
$$

Monroe ${ }^{[45]}$, in 1956, studied the flow of saturated water through one to four, knifeedge orifices arranged in series. He correlated the data of his work,together with that of Benjamin and Miller, Stuart and Yarnall, and Bottomley and Burnell, with a dimensional-analysis type of approach. He did not discuss the critical flow case,but did conclude that the effects of the type of orifice or of solids in solution in the flowing fluid were not significant.

Kinderman and Wales ${ }^{[34]}$, in 1957, studied the flow of subcooled water entering a system of two orifices in series. Their critical pressure and mass flow predictions were from the use of equations proposed by Burnell, but they suggested the use of surface tension values reported by Zemansky, rather than those of Hall which were used by Burnell. There is a significant difference in these values.

Hoopes [28], in 1957, studied the flow of two-phase water through orifices. He found no critical flow or critical pressure ratio with flow rates up to four times the predictions of the homogeneous, thermal equilibrium models, in agreement with previous investigators. For his study to predict the pressure drop in the system, he used a separated-phase, thermal equilibrium model with slip velocities as indicated by the Martinelli-Nelson [41] correlation. Measured and predicted pressure drops were considerably less than homogeneous model calculations for pressure drops.

Chisholm [12], in 1958, developed a flow parameter relating single-phase orifice flow to two-phase orifice flow for steam-water systems. His final predictive equation, based on no mass interchange between the phases and ideal gas behavior of the vapor and (1) through (5), was

$$
\frac{\dot{\mathrm{m}}_{\mathrm{f}(\mathrm{Ch})}}{\dot{\mathrm{m}}_{\mathrm{tp}(\mathrm{Ch})}}-\frac{1}{\mathrm{C}_{\mathrm{f}(\mathrm{Ch})}}=2.1 \mathrm{Y}_{(\mathrm{Ch})}^{0.825}
$$

where

$$
\frac{\dot{m}_{f(C h)}}{\dot{m}_{\operatorname{tp}(C h)}}
$$


is the ratio of the mass ratios of flow of liquid predicted with a discharge coefficient of one to the two-phase mass flow rate. $C_{f(C h)}$ is the liquid contraction coefficient for the orifice, experimentally determined. $\mathrm{Y}_{\mathrm{Ch}}$ may also be determined by

$$
Y_{C h}=\left(\frac{x}{1-x}\right)\left(\frac{\dot{m} f(C h)}{\dot{m}_{g(C h)}}\right)
$$

where $\mathrm{m} g(\mathrm{Ch})$ is the predicted vapor flow with a coefficient of contraction of one and with the same pressure drop as $\dot{\mathrm{m}}_{\mathrm{f}(\mathrm{Ch})}$. parameter $x_{t t}$, so that

Chisholm also related his parameter $\mathrm{Y}_{\mathrm{Ch}}$ to the Martinelli

$$
Y_{C h}=x_{t t}-\frac{2}{2-m(C h)}
$$

where $\mathrm{m}_{(\mathrm{Ch})}$ is the exponent for Reynold's Number in the Blausius form of the friction factor equation,

$$
f=\frac{C}{\left(N_{R e}\right)^{m}(C h)}
$$

His equation shows good predictive $( \pm 10 \%)$ agreement with the experimental data of Benjamin and Miller ${ }^{[6]}$ and Monroe ${ }^{[45]}$.

Hesson and Peck ${ }^{[26]}$, in 1958, studied the flow of two-phase $\mathrm{CO}_{2}$ through orifices and nozzles. They found they could develop equations to predict the flow rate and choking flow, based on liquid and vapor expansion according to $\mathrm{pV}^{\mathrm{n}(\mathrm{HP})}=$ constant. The basic form of their predictive flow equation was (2) and, since for isentropic flow,

$$
u^{2}=\int_{p_{0}}^{p} v d p \text {, then } \dot{m}=A / v\left[\int_{p_{0}}^{p} v d p\right]^{1 / 2} .
$$

The exponent $n_{(H P)}$ for each phase was determined experimentally with the two-phase fluid considered homogeneous. Heat and mass interchanges between the fluids were considered negligible. They also found a choking flow to exist for saturated liquid entering the nozzle and orifice. This mass-limiting flow was not found by previous investigators in similar systems where saturated water entered orifices. Their results are shown in figure 8 a.

Murdock [48], in 1961, found that he could compute two-phase flow rates through a sharp edged orifice from an equation using fluid properties and coefficients from the ASME Fluid Meter Guide [3]. Data from many tests were reported with steam-water, air-water, 
natural gas-water, natural gas-distillate, and natural gas-salt water systems and the data agreed with the predictive equation within an accuracy of \pm 1.5 percent. The author recommended rather wide limits of flow rates and orifice dimensions for his equation, but suggested further experimental work be done for high orifice-to-pipe diameter ratios and for lower expansion-factor ratios.

Linge ${ }^{[36]}$ presented analytical and experimental work on the mass-limiting flow of $\mathrm{NH}_{3}$ and $\mathrm{CCl}_{2} \mathrm{~F}_{2}$ through throttling valves. His theory predicted mass-limiting flow using, apparently, a homogeneous, thermal equilibrium model and the velocity of sound as the choking velocity. If the total valve opening was used for the flow area, then the analytical value exceeded the experimentally measured value by a factor of approximately two. These data are reasonable in that they indicate a coefficient of discharge in the valve of about 0.5 , and also tend to agree with the conclusions of Pasqua [49]. The author mentioned that tests with water often gave higher mass-limiting flow values (relative to the $\mathrm{G}_{\mathrm{c}(\mathrm{HO})(\mathrm{TH})}$ predictions) than the refrigerating fluids he tested.

\section{2. 3 Semi-Empirical Relationships for Constant-Area Flow Systems with Heat Added or Removed}

This case is treated separately from the adiabatic case because the addition or removal of heat would probably affect the degree of metastability and the density distribution and/or slip velocity in the flowing fluid. At this time it does not appear to have been finally determined whether or not critical mass flow predictions for the adiabatic case can be used for the non-adiabatic case.

Although only a few studies have been made for this case, both Schweppe and Faust [58] in 1953, and Leppert ${ }^{[35]}$, in 1955, have reported very low mass limiting velocities relative to the homogeneous, thermal equilibrium model predictions for high heat flux, steam-water systems. Leppert's data are shown in figure $8 a$.

Schweppe and Faust ${ }^{[58]}$ reported studies of steam-water flow in short vertical tubes. They used the homogeneous, thermal equilibrium model with (5) to predict critical pressures and maximum mass flow. The authors interpreted the case where $\Delta \mathrm{p} / \ell=\mathrm{a}$ maximum, in a plot of $\Delta \mathrm{p} / \mathrm{l}$ versus $\mathrm{G}$, as being a point of maximum or critical velocity. They did not have a good measure of the outlet pressure of their experimental section but they reported fairly good agreement of their experimental data and their theoretical model predictions. They found, empirically, that the critical pressure ratio was a function of mass flow rate and tube diameter. Isbin, in a discussion of this paper, suggested that although critical flow was present in the author's work, the humping of the pressure-drop flow curve was not necessarily an indication of critical flow. 
Harvey and Faust [25], in 1953, studied steam and water flow in evaporator tubes. They predicted pressure drop by use of their revision of the Martinelli [41] correlation. They also assumed the fluid was homogeneous and in thermal equilibrium. They then developed flow equations using the conservation equations. Critical flow was predicted when $\mathrm{d} \ell / \mathrm{dp}=0$ for these flow equations.

Stein, et al. [66], in 1954, reported studies of steam and water flow in a heated annulus. Uniform and cosine distribution of heat fluxes were used. Many measured values of $G$ exceeded the predicted values of $\mathrm{G}_{\mathrm{c}(\mathrm{HO})(\mathrm{TH})}$. The authors stated some of these may not have been critical flows even though $\mathrm{G}_{\mathrm{c}(\mathrm{HO})(\mathrm{TH})}$ values were exceeded.

Rogers [53], in 1956, reported an analytical study of heat addition to hydrogen in twophase flow in horizontal tubes. He developed his predictive equations for pressure drop and critical flow, following the general method of Harvey and Faust [25].

Hoopes [28], in 1957, studied the flow of water entering and vaporizing in a $1^{\prime \prime}$ I. D. by 1. 5" O. D. heated annulus with a uniform and cosine distribution of heat flux, over a range of mass flow rates and pressures. He found that the Martinelli ${ }^{[41]}$ correlation predicted the frictional pressure drop (total pressure drop minus momentum pressure drop) within approximately \pm 30 percent. In calculating the momentum pressure drop, he found the homogeneous model overpredicts the momentum pressure drop computed, using the Martinelli correlation. He took motion pictures of the flow patterns and found the Baker ${ }^{\text {[15] }}$ plot predictions generally agreed with the motion picture study. At the exit of the tube the flow was in the dispersed region. He found very steep pressure gradients near the outlet of his section but no evidence of mass limiting flow. As indicated in Section 2.2.2.2, summarizing his orifice flow studies, his mass flow rates were up to four times that predicted by $\mathrm{G}_{\mathrm{c}}(\mathrm{HO})(\mathrm{TH})^{\circ}$ The measured pressure drops were from $1 / 3$ to $1 / 10$ of those predicted by the homogeneous, thermal equilibrium model.

Mendler [44], in 1960, in an analysis of a natural circulation water loop, used several methods to predict his two-phase, heated-test-section, exit-flange pressure drops. He used the equation of the general form

$$
\Delta p=\frac{C_{(M e)} \dot{m}^{2}}{2 p A^{2}}
$$

with various density predictions. $C_{(\mathrm{Me})}$ was taken from Kays and London [33]. He found, using the Martinelli-Nelson density, the predicted pressure drop was too low. Using Lottes' [38] two-phase friction multiplier (a modification of the Martinelli-Nelson method), the predicted pressure drop was too high. The fog flow (homogeneous) model predicted $\Delta \mathrm{p}$ values which were higher but close to the experimental values. Critical flows did not occur in these tests. However, this study does indicate that the use of a homogeneous model may be reasonably appropriate in sections where there are flow disturbances. 
3. 0 GRAPHICAL COMPARISONS OF REPORTED THEORETICAL

AND EXPERIMENTAL DATA

Most of the experimental and analytical data are shown in figures $8 \mathrm{a}$ and $8 \mathrm{~b}$. Tables 1 and 2 , which follow, are summaries of the data presented. 


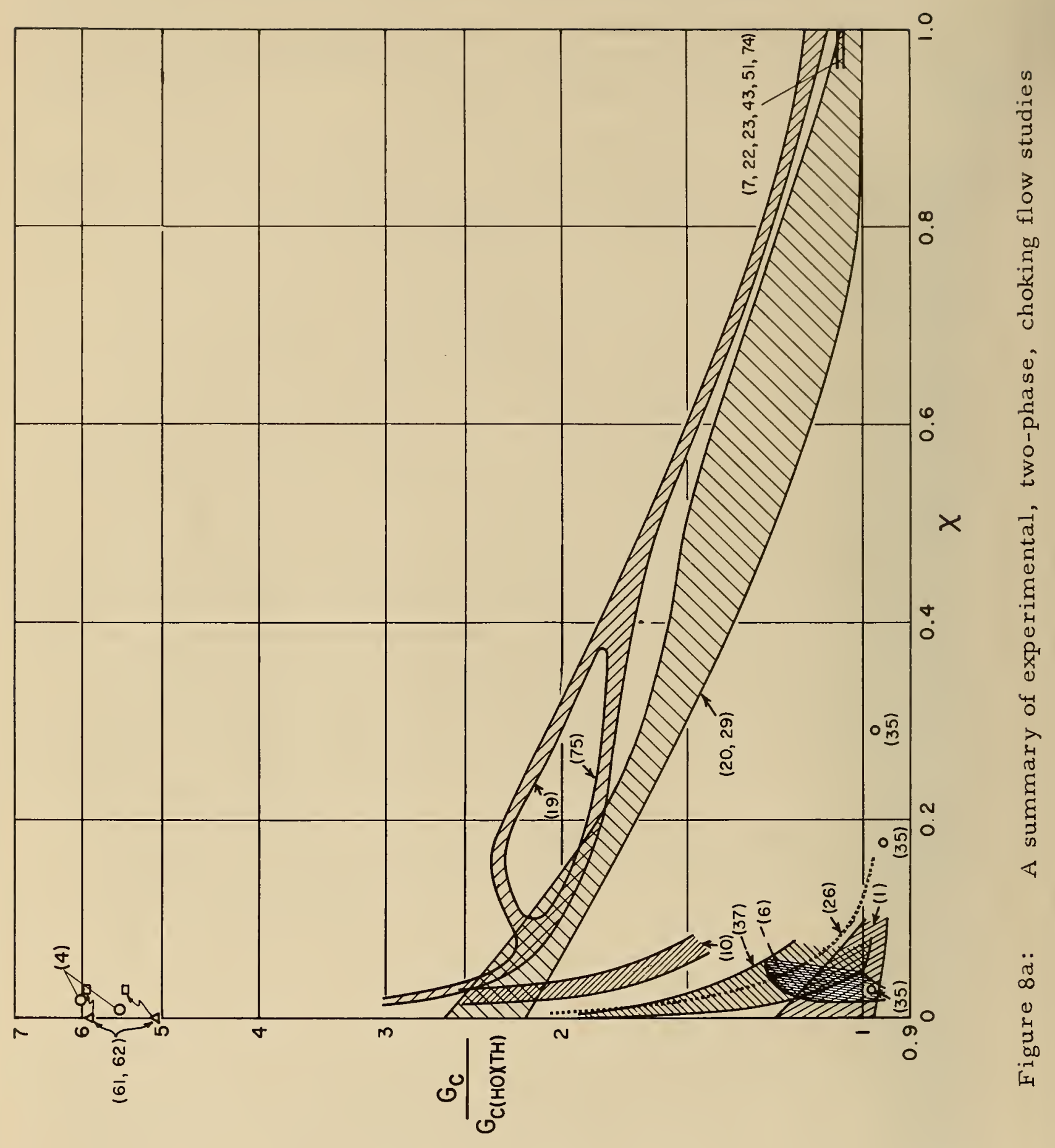




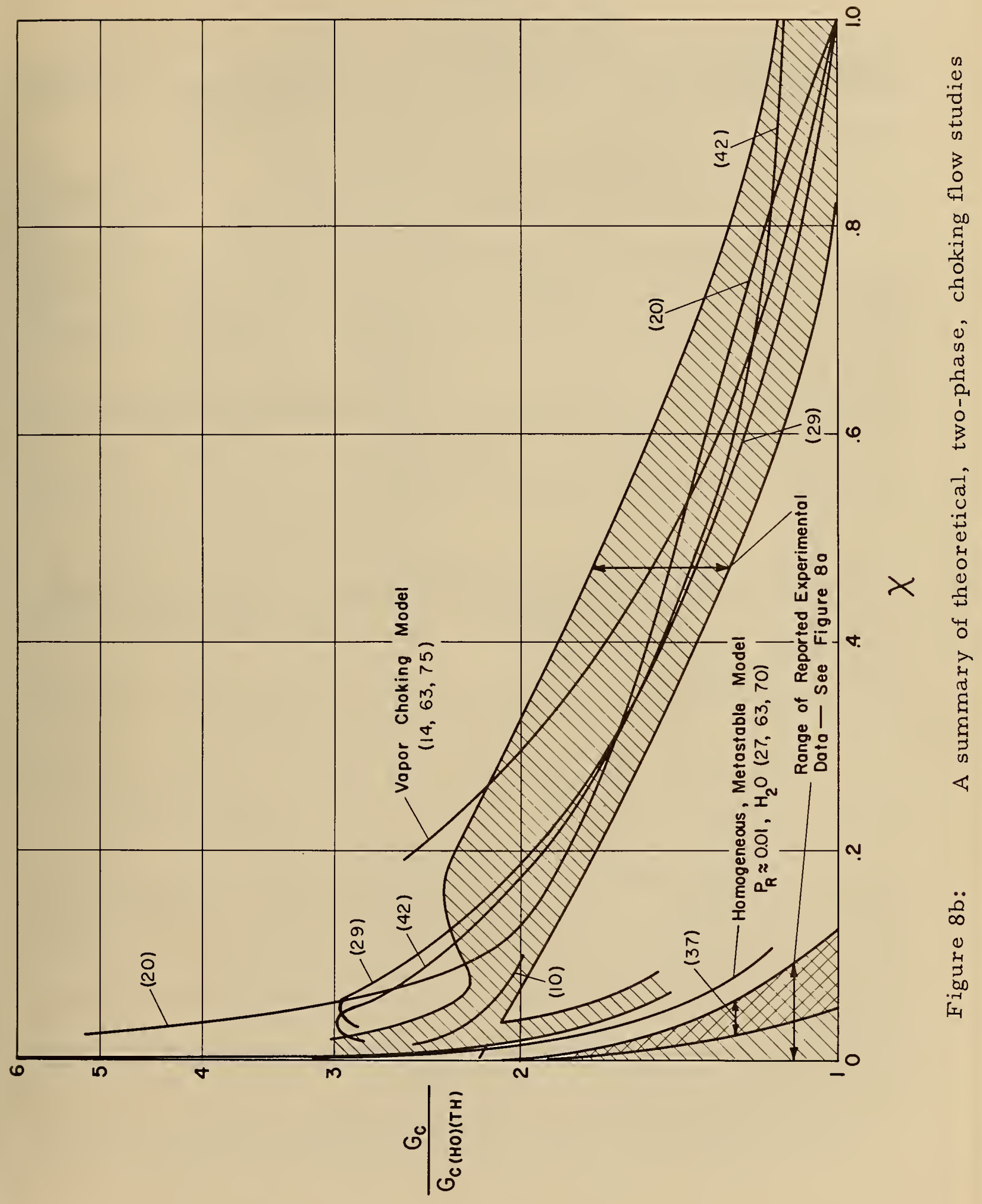


TABLE 1

Summary of Experimental Systems

\begin{tabular}{|c|c|c|c|c|c|}
\hline Name & Date & Fluid & $\begin{array}{c}\text { Two-Phase } \\
\text { Developed by: }\end{array}$ & Test Section & $\begin{array}{l}\text { Flow } \\
\text { Process }\end{array}$ \\
\hline $\begin{array}{l}\text { Agnostinelli } \\
\text { \& }[1] \\
\text { Salemann }\end{array}$ & 1957 & $\mathrm{H}_{2} \mathrm{O}$ & Mixing & $\begin{array}{l}\text { One constant-area section: } \\
\text { I. D. = l" with insert shafts } \\
\text { permitting annulus diametral } \\
\text { clearances of } .006^{\prime \prime}, .009^{\prime \prime} \text {, } \\
.012^{\prime \prime} \text {, and .017". }\end{array}$ & Adiabatic \\
\hline Bailey [4] & 1951 & $\mathrm{H}_{2} \mathrm{O}$ & Expansion & $\begin{array}{l}\text { Two short tubes: } \\
\text { I. D. }=.252^{\prime \prime}, \& .247^{\prime \prime} \\
.250^{\prime \prime} \text { orifice \& } .125^{\prime \prime} \\
\text { nozzle. }\end{array}$ & Adiabatic \\
\hline $\begin{array}{l}\text { Benjamin \& } \\
\text { Miller [6] }\end{array}$ & 1942 & $\mathrm{H}_{2} \mathrm{O}$ & $\begin{array}{l}\text { Expansion } \\
\text { flashing }\end{array}$ & $\begin{array}{l}\text { Four-inch, constant-area } \\
\text { sections. Also sharp-edged } \\
\text { orifices. }\end{array}$ & Adiabatic \\
\hline $\begin{array}{l}{[7,22,23} \\
43,51,74]\end{array}$ & $\begin{array}{l}1922- \\
1938\end{array}$ & $\mathrm{H}_{2} \mathrm{O}$ & Expansion & $\begin{array}{l}\text { Nozzle and Venturi tubes. } \\
\text { Superheated vapor at en- } \\
\text { trance. }\end{array}$ & Adiabatic \\
\hline Burnell $[10]$ & 1947 & $\mathrm{H}_{2} \mathrm{O}$ & Mixing & $\begin{array}{l}\text { Three constant area sections: } \\
\text { I. D. =.529", .904", \& } 1.50^{\prime \prime} \text {. } \\
\text { Venturi tube \& nozzle tests } \\
\text { also. }\end{array}$ & Adiabatic \\
\hline$\overline{\text { Faletti }}{ }^{[19]}$ & 1960 & $\mathrm{H}_{2} \mathrm{O}$ & Mixing & $\begin{array}{l}\text { Annular area, variable- } \\
\text { length. I. D. =.576"; } \\
\text { annulus formed by } 3 / 16^{\prime \prime} \\
\text { pressure-probe for most } \\
\text { tests. }\end{array}$ & Adiabatic \\
\hline Fauske ${ }^{[20]}$ & 1961 & $\mathrm{H}_{2} \mathrm{O}$ & Mixing & $\begin{array}{l}\text { Three constant-area sections: } \\
\text { I. D. }=.4825^{\prime \prime}, .269^{\prime \prime}, \& .125^{\prime \prime} \text {. }\end{array}$ & Adiabatic \\
\hline $\begin{array}{l}\text { Goglia \& Van } \\
\text { Wylen }[22]\end{array}$ & 1961 & $\mathrm{~N}_{2}$ & Expansion & $\begin{array}{l}\text { Venturi tube. Superheated } \\
\text { vapor entering. }\end{array}$ & Adiabatic \\
\hline $\begin{array}{l}\text { Hesson \& } \\
\text { Peck }[26]\end{array}$ & 1958 & $\mathrm{CO}_{2}$ & Expansion & $\begin{array}{l}\text { Square-edged orifice and } \\
\text { short nozzle }\left(0.062^{\prime \prime} \text { long) }\right. \\
\text { both with } 0.0357^{\prime \prime} \text { hole and } \\
d / D=0.192^{\prime \prime} \text {. }\end{array}$ & Adiabatic \\
\hline $\begin{array}{l}\text { Isbin, et } \\
\text { al. [29] }\end{array}$ & 1957 & $\mathrm{H}_{2} \mathrm{O}$ & Mixing & $\begin{array}{l}\text { Four constant area sections: } \\
\text { I. D. }=.3743^{\prime \prime}, .6249^{\prime \prime}, .8188^{\prime \prime} \text {, } \\
\& .10425^{\prime \prime} \text {. Two annuli, by } \\
\text { placing } 1 / 4^{\prime \prime} \text { pipe inside the } \\
3 / 4^{\prime \prime} \& 1^{\prime \prime} \text { sections. }\end{array}$ & Adiabatic \\
\hline $\begin{array}{l}\text { Leppert, } \\
\text { et al. [35] }\end{array}$ & 1955 & $\mathrm{H}_{2} \mathrm{O}$ & $\begin{array}{l}\text { Boiling, from } \\
\text { heat addition }\end{array}$ & $\begin{array}{l}\text { Constant area, type } 347 \text { stain- } \\
\text { less steel tube: I. D. }=.375^{\prime \prime} \text {. }\end{array}$ & $\begin{array}{l}\text { Heat Ad- } \\
\text { dition }\end{array}$ \\
\hline Linning [37] & 1953 & $\mathrm{H}_{2} \mathrm{O}$ & Expansion & $\begin{array}{l}\text { Two constant area sections: } \\
\text { I. D. }=.128 \quad \& .060^{\prime \prime} \text {. }\end{array}$ & Adiabatic \\
\hline $\begin{array}{l}\text { Silver \& } \\
\text { Mitchell }[61]\end{array}$ & 1945 & $\mathrm{H}_{2} \mathrm{O}$ & Expansion & $\begin{array}{l}\text { Throat nozzles of various } \\
\text { lengths: } \mathrm{I} . \mathrm{D} .=3 / 16^{\prime \prime} \text {. }\end{array}$ & Adiabatic \\
\hline Zaloudek $[75]$ & 1961 & $\mathrm{H}_{2} \mathrm{O}$ & Mixing & $\begin{array}{l}\text { Two constant area sections: } \\
\text { I. D. }=.520^{\prime \prime} \& .523^{\prime \prime} \text {. }\end{array}$ & Adiabatic \\
\hline
\end{tabular}


TABLE 2

Summary of Predictive Models

\begin{tabular}{|c|c|c|c|c|}
\hline Name & Date & Fluid & $\begin{array}{c}\text { Mode1 \& } \\
\text { Flow Process } \\
\end{array}$ & Equation Development \\
\hline Burnell $[10]$ & 1947 & $\mathrm{H}_{2} \mathrm{O}$ & $\begin{array}{l}\text { Homogeneous with } \\
\text { metastability. } \\
\text { Isentropic flow. }\end{array}$ & $\begin{array}{l}G_{c}=f\left(p_{1}, p_{1}, \sigma, \text { discharge }\right. \\
\text { coefficient }) .\end{array}$ \\
\hline $\begin{array}{l}\text { "Vapor Choking } \\
\text { Model" } \\
\text { Collingham [14] } \\
\text { Zaludek [75] } \\
\text { Smith [63] }\end{array}$ & $\begin{array}{l}1960 \\
1961 \\
1962\end{array}$ & $\begin{array}{l}\mathrm{H}_{2} \mathrm{O} \\
\mathrm{CCl}_{2} \mathrm{~F}_{2} \\
\mathrm{H}_{2}, \mathrm{~N}_{2} \\
\mathrm{O}_{2}\end{array}$ & $\begin{array}{l}\text { Separated-Choking } \\
\text { when } \mathrm{u}_{\mathrm{g}}=\mathrm{a}_{\mathrm{g}} ; \mathrm{u}_{\mathrm{g}} \\
\text { from Martinelli- } \\
\text { Nelson. Fanno or } \\
\text { isentropic flow. }\end{array}$ & $\begin{array}{l}\mathrm{G}_{\mathrm{c}}=\frac{\mathrm{R} \mathrm{g}^{\mathrm{a}} \mathrm{g}^{\mathrm{P}} \mathrm{g}}{\mathrm{x}} \\
\text { Trial calculation for } \mathrm{p}_{c} .\end{array}$ \\
\hline Fauske $[20]$ & 1961 & $\mathrm{H}_{2} \mathrm{O}$ & $\begin{array}{l}\text { Annular; } \\
\text { Fanno flow. }\end{array}$ & $\begin{array}{l}G_{c}=f\left(p_{c}, x_{c}, u_{g} / u_{f}\right) \\
u_{g} / u_{f}=\sqrt{P_{f} / \rho_{g}}\end{array}$ \\
\hline $\begin{array}{l}\text { Hesson \& } \\
\text { Peck }\end{array}$ & 1957 & $\mathrm{CO}_{2}$ & $\begin{array}{l}\text { Separated phases. } \\
\text { Separate phase be- } \\
\text { havior. Isentropic } \\
\text { flow. }\end{array}$ & $\begin{array}{l}\text { Each phase follows } \mathrm{pV}^{\mathrm{n}}=\text { constant } \\
\text { where } \mathrm{n} \text { is evaluated empirically, } \\
\mathrm{G}_{\mathrm{c}}=\mathrm{f}\left(\mathrm{p}_{1}, \mathrm{v}_{1}, \mathrm{x}_{1}, \mathrm{n}\right)\end{array}$ \\
\hline $\begin{array}{l}\text { "Metastable Model" } \\
\text { Holtzman [27] } \\
\text { Tangren [70] } \\
\text { Smith }[63]\end{array}$ & $\begin{array}{l}1961 \\
1949 \\
1962\end{array}$ & $\begin{array}{l}\mathrm{H}_{2} \mathrm{O} \\
\mathrm{CCl}_{2} \mathrm{~F}_{2} \\
\mathrm{CCl}_{3} \mathrm{~F} \\
\mathrm{H}_{2}, \mathrm{~N}_{2} \\
\mathrm{O}_{2}\end{array}$ & $\begin{array}{l}\text { Homogeneous. } \\
\text { Metastable. } \\
\text { Isentropic flow. }\end{array}$ & $\begin{array}{l}G_{c}=f\left(p_{c}^{*}, x, C_{p g}, C_{v f}, C_{v g}\right) \\
p_{c}=f\left(p_{o}, G, x\right)\end{array}$ \\
\hline $\begin{array}{l}\text { Isbin, } \\
\text { et al. [29] }\end{array}$ & 1957 & $\mathrm{H}_{2} \mathrm{O}$ & $\begin{array}{l}\text { Separated phase using } \\
\text { developments of Lin- } \\
\text { ning [31] and } \\
\text { Martinelli }[35]\end{array}$ & $G_{c}=f\left(R_{g}, x_{c}, p_{c}^{*}\right)$ \\
\hline Linning $^{[37]}$ & 1953 & $\mathrm{H}_{2} \mathrm{O}$ & $\begin{array}{l}\text { Separated phases. } \\
\text { Fanno flow. }\end{array}$ & $\begin{array}{l}G=f\left(p *, x, u_{g} / u_{f}, \frac{u \text { interface }}{u_{f}}\right) \\
p_{c} \text { from a graphical plot of } G .\end{array}$ \\
\hline Sajben $[57]$ & 1961 & $\mathrm{H}_{2} \mathrm{O}$ & $\begin{array}{l}\text { Homogeneous with } \\
\text { thermal equilibrium. } \\
\text { Fanno flow. }\end{array}$ & $\begin{array}{l}G_{c}=f\left(p_{s(S a)}, \frac{\left.p_{c}^{*}\right)}{f L_{t p}}\right. \\
p_{c}=f\left(p_{s(S a)}, \frac{D}{D}\right.\end{array}$ \\
\hline $\begin{array}{l}\text { Silver }{ }^{[61]} \& \\
\text { Mitche11 }\end{array}$ & 1945 & $\mathrm{H}_{2} \mathrm{O}$ & $\begin{array}{l}\text { Separated phases } \\
u_{f}=u_{g} \text {, quality } \\
\text { determined from } \\
\text { an annular-flow } \\
\text { model. }\end{array}$ & $\begin{array}{l}G=f\left(x, v_{f}, v_{g}, \dot{m}_{f} \text {, interface } p \& T,\right. \\
\text { cold water rate for same nozzle and } \\
\text { nozzle length). } \\
p_{c} \text { trom graphical plot of values of } G \text {. }\end{array}$ \\
\hline
\end{tabular}

* Includes conventional thermodynamic table properties which are a function of $p$ and their derivatives with respect to $\mathrm{p}$. 
This section is divided into two parts. The first part is a discussion of the experimental data The second part presents general evaluation of the predictive equations and correlations.

\section{1 Discussion of Reported Experimental Data}

\subsubsection{Instrumentation and Data Reduction}

In reference to figure $8 \mathrm{a}$, which reports much of the available experimental data, there are two major possibilities of error in all reported data. They are in the measurement of critical pressure and in the computation of quality.

\subsubsection{Pressure Measurements}

Most investigators report difficulties in pressure measurement of two-phase flow, because there are pressure fluctuations. In Faletti's [19] careful work, for example, he reported most of his pressure measurements as plus or minus roughly one psi with some higher, upstream pressure measurements shown as plus or minus 8 to 10 psi. Almost all investigators report that it is necessary to read "damped" pressures because of the pressure fluctuations. Also, in two-phase flow, liquid and vapor in varying proportions are often present in the lead lines to the pressure sensing device, so that the pressure correction for lead lines may be inaccurate.

The special case of measuring the critical pressure presents some additional problems. Critical flow may be determined experimentally in two ways. One experimental procedure would be to produce a curve as shown in figure 2. This is a slow procedure, as many runs are required to establish the curve shown. Also the critical pressure, which is at the point of tangency of the curve, is often difficult to determine. This was the method used to determine critical pressure by most investigators who used variable area flow cross sections $[4,26,49,61]$. Another method to determine critical pressure is to discharge the test section into a variable-pressure receiver. When receiver pressure changes do not affect pressure profiles in the test section, the critical pressure exists at the exit of the test section. This choking pressure is determined from an extrapolation of the pressure profile to the choking point. This method was used by most investigators using constant area test sections $[19,20,29,75]$. It has the advantage that the critical data can be taken in one run, and it avoids the point of tangency determination mentioned earlier. The extrapolation method has the disadvantage that the pressure cannot be measured at the choking point and the pressure gradients are very steep near the exit of a critical flow section as shown in figure 9 . Of course, the steep pressure gradients make extrapolation errors more probable. 


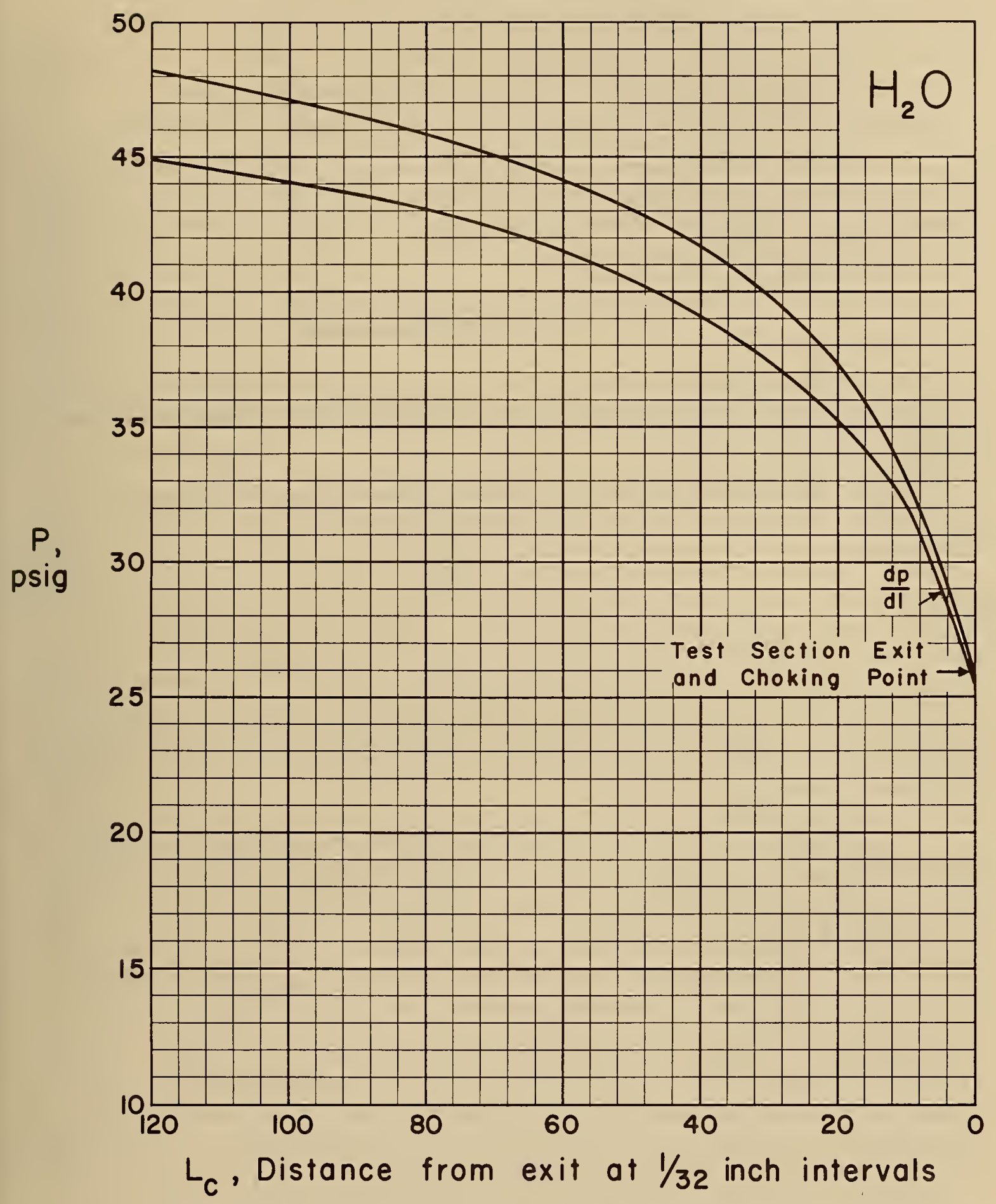

Figure 9: Typical, pressure-versus-length curves from Faletti. 
Also, with respect to the pressure measurement, Burnell ${ }^{[10]}$ and Silver ${ }^{[62]}$ both reported that the presence of a pressure tap near the exit decreases the critical mass flow rate even though one would expect the flow disturbance of a pressure tap to be very small. Earlier investigators were perhaps less careful with respect to this measurement. Linning for example, measured temperatures which can be translated into pressure measurements only if thermal equilibrium is additionally assumed. Some investigations $[19,75]$, mentioned previously reported choking pressures may be in error because of relatively long extrapolations of the pressure curve from the last measured pressure to the exit of the test section. In some examples, Faletti ${ }^{[19]}$ indicated the critical pressure may be in error by approximately 10 psi when determined by the extrapolation method.

\subsubsection{Critical Quality Determinations}

No investigation reported in this summary has directly measured the quality at the point of choking. Therefore, the reported qualities have been determined by computations making various assumptions.

The stagnation enthalpy can usually be determined fairly easily, and for thermal equilibrium,

$$
h_{o}=h_{f}+x_{c} h_{f g}
$$

and

$$
v_{c}=v_{f}+x_{c} v_{f g} .
$$

Then, if $p_{c}$ is known, $h_{f}, h_{g}, v_{f}$, and $v_{g}$ may be determined and $x_{c}$ evaluated from the above equations. Except as noted, all investigators who have reported work in figure 8 a have used this method of quality determination.

This solution involves two major sources of error: one is the assumption of a homogeneous model in computing the kinetic energy term of (3) and the other is the assumption of thermal equilibrium in the flow. The homogeneous model assumption will produce a value for the kinetic energy which will be too high if the model assumption is in error and a slip velocity actually exists between the separated or partially separated phases. Thus, the quality determination using the homogeneous model will be too low. This will affect the value used for $\mathrm{G}_{\mathrm{c}(\mathrm{HO})(\mathrm{TH})}$ in the correlating plot shown in figure $8 \mathrm{a}$, and the correction will move the point upward and to the right. Zaludek reported that with steam-water systems this quality error will reach a maximum of about 6 percent for "middle range" quality flows. If the extrapolation procedure, mentioned earlier, produces an error in the choking pressure, the more likely error will be to report a choking pressure higher than the actual pressure. Again, for the correlation of figure $8 \mathrm{a}$, the correction to the lower choking pressure (which will change both the pressure and quality used in the determination of $G_{c(H O)(T H)}$ ) will move the reported point upward and to the right. 
In variable area systems, particularly, the assumption of thermal equilibrium must place many quality calculations in error. Perhaps this is best illustrated by examining the data of Silver $[61,62]$ in figure $8 \mathrm{a}$. The higher qualities were determined by the homogeneous, thermal equilibrium model and the lower qualities determined by Silver's annular flow model.

It would appear rather simple to determine whether or not the fluid is in thermal equilibrium by a comparison of pressure and temperature measurements. Temperature measurements in two-phase, single-component flow, however, are difficult to evaluate. A liquid film on the temperature sensor may tend to provide a temperature near the sensor considerably different from the "bulk" temperature of the fluid. Many papers record metastability in variable area systems. Stuart and Yarnall [69] reported a temperature of $107^{\circ} \mathrm{F}$ above the saturation temperature in water flow through an orifice, which indicates large deviations from thermal equilibrium are possible.

\section{1. 2 Discussion of Experimental Data as Related to Systems and Fluid Properties}

It would appear that some general conclusions can be drawn with respect to the effect of flow system and fluid properties on choking by examining experimental results related to the homogeneous, thermal equilibrium model, as shown in figure $8 \mathrm{a}$, and theoretical results related to this model, shown in figure $8 \mathrm{~b}$.

One can see that most systems deviate markedly from the homogeneous, thermal equilibrium model at very low qualities. It is possible to explain this behavior if one assumes that the major factor is that metastability exists in the fluid which will produce values of $G_{c}$ quite different from those predicted from a thermal equilibrium model. At low qualities, deviations from the homogeneous model assumption may not be too significant for many flow systems, as evidenced by the flow pattern correlation of Baker [5] and several successful low quality, homogeneous model studies, for example, that of Tangren [70]. Also, it may be postulated that metastability will exist to a high degree in flow of very low quality fluids regardless of the choice of the flow pattern because, in all flow pattern possibilities, the interface area may be too small to produce the vaporization necessary for thermal equilibrium. The studies of Silver ${ }^{[62]}$ and Bailey ${ }^{[4]}$ would tend to support this premise. If thermal equilibrium is to be maintained during a pressure drop in the fluid, there must be heat transfer from the warmer liquid to the liquid-vapor interface and mass transfer at the interface sufficient to continuously reduce the liquid temperature to the equilibrium value for the fluid pressure. These heat and mass transfer processes are rate processes. The rate of the processes will be dependent on the system resistance to the processes. So, beginning with the point in the liquid furthest from an interface, the heat transfer will be a function of the fluid conductance and the length of the path to the interface. In general, lower qualities would be expected to produce longer paths. For the heat and mass transfer at, the interface, 
these rates would be primarily dependent on the molar heat of vaporization of the fluid (deduced from simple rate theory), the "true" interface vapor pressure, and the total interface area. Again, lower qualities will tend to produce smaller interface areas and, probably, higher interface vapor pressures. Thus, the degree of metastability may be concluded to be a function of the fluid properties and the quality with a greater degree of metastability predicted at lower qualities which is in agreement with reported experimental data.

In figure $8 \mathrm{a}$, as the quality is increased, the experimental data divides itself into two general groups. One group of data $[1,6,10,26,37]$ is from systems in which a good deal of mixing would be expected, such as systems with fine clearances and systems employing valves and elbows and in which all vapor was produced by pressure reduction in the fluid. The other group of data $[19,20,27,75]$ is from systems which were constant-area systems, employing smooth tubes, and, in which the entrance vapor condition was produced by mixing the vapor and the liquid.

The inherent mixing in the experimental systems of the first group would be expected to produce a more homogeneous flow pattern, as evidenced, for example, by the pressure drop study of Mendler [44], mentioned earlier. Thus, by creating a larger interface these disturbances will produce a more nearly thermal equilibrium model. This assumption is borne out by the small deviations of these data from the homogeneous, thermal equilibrium model values at quality ranges from approximately 0.005 to 0.10 in figure $8 \mathrm{a}$. This behavior is also indicated in the work of other investigators not shown in figure 8a such as Allen [2], who found the homogeneous, thermal equilibrium model reasonably accurate in determining valve capacities for liquid-vapor flow. Further indications that flow disturbances bring the flow behavior closer to the homogeneous, thermal equilibrium model predicted behavior are in the work of Silver ${ }^{[62]}$ and Burnell [10] who found that pressure taps at the throat of a converging-flow device reduced the $G_{c}$ value making that value closer to that of $G_{c(H O)(T H)}$

Also, from figure $8 \mathrm{~b}$, it is seen that the homogeneous, metastable model curve forms a general upper limit for experimental values of $G_{c}$ for these systems, indicating, again, that metastability is the major factor at very low qualities and that these systems approach thermal equilibrium behavior at higher qualities.

For the constant-area systems with smooth walls, phase separation and, therefore, a higher degree of metastability would be expected than in systems with flow disturbances. The separation would be expected as a consequence of the relatively undisturbed flow. This separation would provide a smaller interface area for the heat and mass transfer processes mentioned previously and thus make metastability more likely. Separation and metastability are indicated by Silver ${ }^{[62]}$ and Bailey ${ }^{[4]}$ with their separated-flow models. The pressurewave velocity determinations of Collingham ${ }^{[14]}$, discussed in section 2. 1. 5, also indicate metastable behavior for higher quality and partially separated phase systems. Further, the 
reasonably good agreement between $G_{c}$ values from the vapor choking model and the experimental data at higher qualities, shown in figure $8 \mathrm{~b}$, indicates metastability and separated phases play a large part in the behavior of these systems.

The effect of fluid properties is inconclusive, primarily because so few experiments have been performed with fluids other than water. The preceding reasoning would indicate that one of the liquid properties affecting the degree of metastability would be liquid-phase conductivity for the heat transfer path to the interface. At the interface, heat and mass transfer parameters such as Reynolds, Grashof, Prandtl and Schmidt Numbers would appear to be the controlling factors, along with the surface tension of the fluid, which will affect the interface vapor pressure if the interface curvative radius is small, as indicated by Burnell [10] and others. Also, the molar heat of vaporization of the fluid may affect the mass transfer rate at the interface, as deduced from simple rate theory. Fluid properties may also affect the flow pattern. The effect may be observed in the flow pattern fluid corrections of Baker [5] which employed surface tension and the phase-density ratio as the necessary correcting terms for fluids other than air-water systems on which the correlation is primarily based. One may also reach this conclusion from pressure drop studies, which are flow pattern dependent, such as the Martinelli-Nelson [41] correlating parameter which employs the properties of viscosity, and again, the phase-density ratio. The Martinelli-Nelson parameter has also been a successful correlating parameter in entrainment studies $[13,18]$, indicating the fluid property effect on the flow patterns.

From the preceding discussion of fluid property effects, one might conclude that the experimental data of water may represent the data of a fluid which will have $G_{c}$ values which will produce the highest $G_{c} / G_{c(H O)(T H)}$ ratio. This conclusion may be reached by considering the high phase density ratio and the high heat of vaporization of water relative to most fluids, which tend to produce separated, metastable flow. Perhaps the only experimental data to support this conclusion is the work of Hesson and Peck ${ }^{[26]}$ which shows lower $G_{c} / G_{c(H O)(T H)}$ values than the work of investigators who employed water in similar systems, for example, those of Silver [62] and Bailey [4]. Obviously, further experimental data work with other fluids is required before any reliable conclusions may be reached with regard to the effect of fluid properties on choking flow.

\section{2 Discussion of Predictive Equations and Correlations}

Previously discussed works indicate that two-phase, mass-limiting flow may be correlated reasonably well with respect to homogeneous model behavior or separated phase behavior. In either treatment, the general, single-phase approach is used. In all the cases, the treatment suffers from the lack of an accurate model. Models may be assumed and constants or functions determined from experimental data with respect to these models; 
however, one should be very cautious in making final conclusions from such an analysis Studies reported in this summary indicate that reasonably good predictions can be made on the basis of quite different and sometimes directly opposed models. For example, for the flow of saturated and low quality water entering short, variable-area sections, Benjamin and Miller [6] matched experimental data with a homogeneous metastable model, where the metastable effect on the flow rate was expressed as a function of surface tension. This general model was also successfully used by several other investigators. Hoopes [28], however, for the same system, was able to match experimental data with a thermal equilibrium model assuming separated phases with a slip velocity. Although the metastable assumption seems more likely to be correct at this time, no final conclusion can be reached as to whether the metastability or the slip velocity represents the primary deviation from the simple model.

The search for the "true" model has proved to be very difficult. Although quantitative conclusions cannot be made, one may make some general observations. From the most often referred to correlations, such as that of Baker [5], and from the entrainment studies, such as those of Collier [13] and Dukler, et al. [18], one would conclude that the separated model cannot be physically correct for mixtures of low and middle-range qualities. However, the time rate of entrainment may be such that entrainment in a choking flow system might be less than that predicted by the more nearly "entrainment in equilibrium" studies which allowed a larger time for the entrainment process. One may also conclude that the homogeneous model is not valid except at very low qualities, and for systems which involve "stirring", that is, where flow separations are continually disturbed. As previously discussed, the thermal equilibrium model appears to be incorrect for many systems, particularly for the low-quality, separated-phase case.

The author of this report offers the following conclusions with respect to analytical models:

1. No single model appears adequate for all qualities and all systems.

2. Semi-empirical correlations to predict mass limiting flow would appear reasonably effective but should be limited to specific ranges and specific systems. Most of these treatments are related to some form of a single phase analysis using an idealized separated phase or homogeneous model.

3. The model used for a specific system should bë in reasonable agreement with flow pattern data for that system. This would not appear to be the case in some analytical works. 
The predictive systems for this analysis, shown in figure $8 \mathrm{~b}$, which most generally fit experimental data, all involve a form of a thermal-equilibrium, separated-phase flow model or the correlating relationship with the homogeneous model.

In the separated-phase model group there are the Isbin, et al. [29], modified momentum model, Massena's [42] separated flow model, the work of Fauske [20], the vapor choking model (see section 6. 1.2), and modifications of this vapor choking model suggested by Collingham [14]. The separated-phase system that appears most generally and reliably predictive is that of Fauske ${ }^{[20]}$. Fauske's predictive system does have the disadvantages of being difficult for use by a designer because the pressure-drop analysis for the flow as it approaches the mass-limiting condition is based on a variable friction factor, the value of which would be difficult to determine. Also, his assumption of thermal equilibrium and separated phases for lower quality fluid flows is not in agreement with reported flow pattern correlations and the results of entrainment experiments. The Isbin, et al. [29], modified momentum model and the Massena [42] separated flow model appear less reliably predictive and quite complex for use by a designer.

The vapor choking model is simple and reasonably reliable at high qualities. The modifications suggested by Collingham [14] involve slip velocity data which are difficult to measure. Also, the slip velocities which he calculated are not in general agreement with slip velocity and void volume studies reported elsewhere in the literature. Johnson and Abou-Sabe ${ }^{[30]}$ and others reported that slip velocity ratios increase as the quality increases. The Collingham modifications to the vapor choking model indicate that the slip velocities increase as the quality is decreased.

The vapor choking model is recommended in this report for use for higher quality fluid flow because of its simplicity and general reliability. The more complex models raise questions which have not yet been answered, and, although some may be reasonably correct, none appears to have its validity completely proved.

The correlation of $\mathrm{G}_{\mathrm{C}} / \mathrm{G}_{\mathrm{c}}(\mathrm{HO})(\mathrm{TH})$ versus quality, shown in figures $8 \mathrm{a}$ and $8 \mathrm{~b}$ and used by Isbin, et al. ${ }^{[29]}$, Faletti [19], and Zaloudek ${ }^{[75]}$, offers a very useful way to make an empirical prediction for two-phase, mass limiting flow. The major advantage of this correlation is that it appears to have little pressure dependence. This lack of pressure dependence has been shown for the water systems and also appears to be generally the case for the data of the Hesson and Peck[26] studies of $\mathrm{CO}_{2}$ flow. This lack of pressure dependence of the correlation would indicate that the effect of pressure variations is satisfactorily accounted for in the homogeneous, thermal equilibrium model prediction which is in the denominator of the empirical correlating term. There are insufficient data at this time to indicate whether 
or not this correlating curve may be extended to fluids other than water. Even if the specific curve developed for water cannot be used for other fluids, the method is a valuable means of developing an empirical curve for a system involving any specific fluid.

\subsection{Predictive Equations and Correlations for Adiabatic, Variable-Area Systems}

Most of the comparative experimental data are either for rather low quality runs or for high quality runs. For the high quality fluid, rather minor modifications of the homogeneous, thermal equilibrium model involving the Wilson [60] line are well established. Details of these modifications may be found in the papers reported in the previous summary in this section and in many textbooks on thermodynamics and fluid mechanics. Most of the analyses of low quality systems have been either general studies which are incomplete or unproved, or studies which are largely empirical and limited to rather specific systems. For studies of flow through short sections where the flow is not disturbed, such as nozzles, the works of Silver ${ }^{[62]}$ and Bailey [4] appear to have the proper, general approach to the problem. Both studies used a separated-phase model and indicated that the amount of vaporization will be a function of the heat and mass transfer rates. They both found these rates to be far too small to produce thermal equilibrium (see figure $8 \mathrm{a}$ ). Both works also suffer from the lack of a reliable method to determine the heat and mass transfer rates. Also, Silver's assumption of $u_{g}=u_{f}$ and Bailey's proposed choking-flow criteria may be questioned. The recommendation of this report for variable-area, lower-quality flow is to use two homogeneous models to provide upper and lower limits of choking flow predictions. The homogeneous models chosen for these extremes are the completely metastable model (no vaporization) for the upper limit and the thermal equilibrium model for the lower limit. Figures $8 \mathrm{a}$ and $8 \mathrm{~b}$ show that the results of these models do bracket most of the reported experimental data.

One major justification for the choice of the homogeneous model is that many actual flow systems, where choking is likely to occur, will have flow disturbances which produce behavior similar to homogeneous model predictions. This is evidenced in many studies, for example, the work of Allen [2] with valves, of Benjamin and Miller [6] with actual plant installations, and Agnostinelli and Salemann [1] with fine clearances. This behavior is also evidenced by the reduction in flow produced by pressure taps,noted by Silver [61] and Burnell [10] and by pressure drop studies such as that of Mendler, et al. [44] Also, as mentioned previously, for very low quality flows it seems likely that a high degree of metastability will exist regardless of the flow pattern, so that the completely metastable model will reasonably well represent an upper limit for either separated or homogeneous flow models for this case. For example, figures $8 \mathrm{a}$ and $8 \mathrm{~b}$ show that the homogeneous, metastable model, choking flow values are not very different from the theoretical and experimental values of Silver [61] and Bailey ${ }^{[4]}$, who assumed and observed separated-phase flow patterns. 
It does not appear that sufficient experimental data has been reported to allow any conclusions regarding these systems. The data of Stein, et al. [66], and Leppert [35] indicate that the homogeneous, thermal equilibrium model over-predicts the data of Leppert and slightly under-predicts the data of Stein, et al. Harvey and Faust [25] and Schweppe and Faust [58] both used a thermal equilibrium, homogeneous model in their analyses with fair success. Rogers [53], in studying the flow of hydrogen, also used a homogeneous, thermal equilibrium model based on the work of Harvey and Faust.

The continual formation of bubbles at the heated surface would surely tend to make the fluid more nearly homogeneous. Use of the homogeneous, thermal equilibrium model appears to be the best design recommendation, in view of present knowledge.

\section{2. 4 Critical Flow Predictions from Upstream Flow Conditions}

For the homogeneous, thermal equilibrium model, with water, studies are reported which predict critical flow from upstream conditions using idealized Fanno flow and isentropic flow processes. Allen [2] and Bridge [9] presented two of the more recent isentropic solutions. Steltz ${ }^{[67]}$ presented an isentropic computer solution for the high quality range. For the Fanno flow process, Sajben ${ }^{[57]}$ showed an excellent treatment. The latter three results are presented in a form quite useful to designers. The homogeneous model assumption is not proper for many cases, however, either for pressure-drop or choking studies, both of which are involved.

For the $\mathrm{CO}_{2}$ system, Hesson and Peck [26] offered a solution that involved separate liquid and gas processes. The relationship between fluid properties for the flow processes was experimentally determined. This limited the relationship for general design use. The model does not appear to be entirely valid as the experimentally determined exponents vary considerably from the values one would expect from examination of similar ideal-flow, separate-phase exponents. For the separated-phase flow, one may employ the methods of Silver, Bailey, or Linning. However, all methods involve a rather lengthy computation to determine critical pressures. One may determine the pressure drops from an upstream point by means of a pressure-drop correlation, such as that of Martinelli [41] , and test for choking by use of the results of Fauske [20] or Faletti [19], or at higher qualities, the results of the vapor-choking model.

Obviously, these solutions will be idealized. However, they should present the designer with a predicted value and he may, by consultation with charts such as figure $8 \mathrm{~b}$, be able to estimate his system's deviation from the idealized prediction. 
Mass-limiting flow problems are really integral with all two-phase problems. A more satisfactory understanding of the flow pattern, and momentum, mass, and heat transfer between the phases, must be achieved before general and reliable solutions of the mass limiting, two-phase flow phenomena can be made. There are, however, many other studies which could be made to expand the limits of present knowledge and further substantiate or limit analytical solutions which have been made.

The greatest need would appear to be for data on the behavior of fluids other than water. Testing with other fluids and varying the properties of the test fluid, as Faletti [19] did with his surface tension variations to determine whether, and how far, existing equations or correlations could be extended, are urgently needed.

In much of the reported analytical and experimental work, data are reported at the critical point only. The designer needs to be able to predict critical flow from upstream conditions also. This means that the flow process to the choking point must be studied. Pressure drop, flow pattern, and degree of metastability data have not been reported at fluid velocities near choking velocities, except in [29].

There is a need for better instrumentation in the test programs. The degree of metastability (pressure-temperature measurements) and the flow pattern (velocity and density profiles) data are needed before theoretical or somewhat general empirical studies can be effective. 


\section{1 Introduction}

This section of the report presents some choking flow solutions using models representing extreme cases and is similar to information contained in [63]. The results of these solutions are intended to bracket values obtained from the actual flow cases. These solutions are planned to serve as design guides and for comparative evaluations with experimental data.

The choice of flow models was made from consideration of the state of the basic knowledge of the processes occurring in the flow and from examination of the reported work in the literature, which is the subject of the previous section of this report. As indicated in the discussion of the previous section, the results from the use of the homogeneous, thermal equilibrium model are intended to provide a lower limit for all ranges of qualities in the twophase mixtures. The homogeneous, metastable model is intended to provide upper-limit choking values for the very low quality states for all flow patterns and for the low quality systems in which the general form of the homogeneous model would be expected to occur, such as a system with flow disturbances. For higher quality flow, where separate-phase flow may be expected, the values obtained from the vapor-choking model are intended to provide the upper limit. Table 3 shows a summary of the flow models and flow processes considered in these analyses. Figure $8 \mathrm{~b}$ shows that the values obtained from the use of the proposed models generally bracket the choking-point data from the experimental systems which have been reported. As previously discussed in section 4.1.2, the homogeneous metastable model appears satisfactory as an upper-limit model for the very low quality flows $[4,61]$, regardless of the actual flow pattern. For the low quality runs, with qualities greater than 0.01 , use of the homogeneous, metastable model provides a satisfactory upper limit for systems $[1,10,26,37]$ where a tendency toward the homogeneous model would be expected.

Also, the use of the vapor-choking model provides a satisfactory upper limit for the lesser-disturbed, high-quality systems $[19,20,29,75]$.

\section{2 Mass Limiting Flow Flux in Terms of Properties at the Point of Choking}

In this section, the evaluation of $(5)$ for $G_{c}$ in terms of $p$ and $x$ is required. The computer results for the homogeneous, thermal equilibrium model are shown in figures 10,11 , and 12 .

\section{2.1 Homogeneous, Thermal Equilibrium Mode1}

Sajben ${ }^{[57]}$ has made similar evaluations for steam-water mixtures. An equation of the general form proposed by him was used. 


$$
G_{c(H O)(T H)}=\left[\left.\frac{a}{\frac{d \beta}{d p}+\left[(1-x) v_{f}+x v_{g}\right]\left(\frac{d a}{d p}-1\right)}\right|_{p_{c}} ^{1 / 2}\right.
$$

where thermodynamic terms are evaluated at constant $P_{c}$. The independent variables in this equation are $\mathrm{p}_{\mathrm{c}}$ and $\mathrm{x}_{\mathrm{c}}$, as all of the thermodynamic property* terms are functions of $\mathrm{p}_{\mathrm{c}}$. The values obtained from the computer solution are shown in figure 10.

\section{2.2 Separated-Phase, Thermal Equilibrium Model}

This model assumes the flow is choked when the velocity of the vapor phase, as predicted by the Martinelli-Nelson [41] correlation, reaches the sonic velocity for the vapor phase. Thus,

$$
\dot{m}_{g}=A_{g} u_{g} / v_{g}
$$

and

$$
A_{g}=A_{g}
$$

so that

$$
G_{g}=\dot{m}_{g} / A_{g} \text {. }
$$

Then, at mass limiting conditions,

$$
\dot{m}_{g}=x \dot{m}=R_{g} A_{g} \rho_{g}
$$

or

$$
G_{c(V C)}=\frac{\dot{m}}{A}=\frac{R g^{a} g^{\rho} g}{x}
$$

Evaluation of $(20)$ is shown in figure 12.

* Properties of the fluids reported in this section are from the following references:

$$
\begin{array}{ll}
\mathrm{H}_{2}[16,21,46,52,73] & \text { Refrig. } 12[50,71] \\
\mathrm{N}_{2}[31,66,68] & \text { Refrig. 11 }[50,71] \\
\mathrm{O}_{2}[46,59] &
\end{array}
$$


For this model, an equivalent two-phase, pressure-volume relationship for an isentropic process as proposed by Tangren ${ }^{[70]}$ may be used,

$$
p\left[1 / p-1 / p_{f}\left(1+\frac{x}{x-1}\right)\right]\left[\frac{\left(\frac{x}{1-x}\right) C_{p g}+C_{f}}{\left(\frac{x}{1-x}\right) C_{v g}+C_{f}}\right]=\text { Constant }
$$

Use of this relationship in (8) results in

$$
G_{c(\text { HO)(MET) }}^{2}=\left\lceil\frac{\left(\frac{x}{1-x}\right) C_{p g}+C_{f}}{\left(\frac{x}{1-x}\right) C_{v g}+C_{f}}\right] \frac{p}{x v g}
$$

The assumption that the liquid phase is incompressible was made in the development of (21). This assumption might introduce a considerable error in the case of hydrogen.

Therefore, for hydrogen, the following equation was developed, similar to that reported by Holtzman ${ }^{[27]}$, which considers the compressibility of the liquid phase also:

$$
G_{c(H O)(M E T)}^{2}=\frac{\left[\frac{\left(\frac{x}{1-x}\right) C_{p g}+C_{v_{f}}}{\left(\frac{x}{1-x}\right) C_{v g}+C_{v_{f}}}\right] p a_{f}^{2}}{(1-x) v_{f}^{2} p+x v_{g} a_{f}^{2}}
$$

The evaluation for this model is shown in figure 11 .

\section{3 Quality as a Function of Pressure}

For sections 6.3 and 6.4, where the flow process is considered, it will be assumed that the flow system is one in which the initial flow state is that of a saturated or a subcooled liquid. Thus, two-phase states must be limited to those which may be obtained from adiabatic flow from the saturated liquid state. For such a system, it is possible to approximately predict the quality as a function of pressure for Fanno and isentropic flow beginning with (3). Results for this section and for several subsequent sections will be presented from the point in the flow system where the fluid is a saturated liquid. 
For Fanno or isentropic flow, actual flow systems may be theoretically extended to this point if this condition does not occur in the system. For the Fanno flow, the stagnation enthalpy may be computed from (2), (3), and (5) if a state point and the mass flow flux is known,

$$
h_{0}=h+\frac{G^{2} v^{2}}{2}
$$

This stagnation enthalpy will be equal to a saturated liquid stagnation enthalpy,

$$
h_{o s}=h_{f s}+\frac{G^{2} v^{2} f s}{2} \text {. }
$$

Thus, if $G$ and $h_{o s}$ are known, and since $h_{f s}$ and $v_{f s}$ are functions of $p_{s}$, then $p_{s}$ may be established for the system. For isentropic flow, the entropy at any point in the system establishes a value of $p_{s}$. Thus, if $p$ and $x$ are known, the entropy may be computed and that entropy will be equal to the saturated liquid entropy $\left(s_{f s}\right)$ in the system. Obviously, $s_{f s}$ is a function of $p_{s}$, so that $\mathrm{p}_{\mathrm{s}}$ for the system may be determined.

\subsubsection{Fanno Flow}

Equation (3) with (6) may be written as a quadratic equation,

$$
\frac{G^{2}}{2}\left(v_{f}+x v_{f g}\right)^{2}+\frac{h_{f g}}{v_{f g}}\left(v_{f}+x v_{f g}\right)-\left[h_{o}-\left(h_{f}-\frac{h_{f g}}{v_{f g}} v_{f}\right)\right]=0
$$

Since all of the thermodynamic property terms at saturation are a function of $p$, the variables in (25) are $G, x, h_{0}$, and $p$. At the liquid saturation point, from (2) and (3),

$$
h_{0}=h_{f}+\frac{G^{2} v_{f}^{2}}{2}
$$

so that $h_{0}$ is a function of $p_{s}$ and $G$. Then, for a fixed value of $G$ and $p_{s}$, $x$ may be determined as a function of the pressure at any point in the flow system. Evaluation is shown as figure 13.

\section{3.2 Isentropic Flow}

From (43) one has:

$$
\frac{d x}{d p}=\frac{-(1-x) \frac{d s_{f}}{d p}-x \frac{d s}{d p}}{s_{f g}}
$$


Then, for an approximate solution,

$$
\left(x_{2}-x_{1}\right)=\frac{-(\bar{x}-1)\left(\frac{\overline{d s_{f}}}{d p}\right)-\bar{x}\left(\frac{\overline{d s}}{d p}\right)\left(p_{2}-p_{1}\right)}{\overline{s_{f g}}}
$$

where $x_{2}$ is an assumed quality at pressure $p_{2}$ and $\bar{x}=\frac{x_{1}+x_{2}}{2}$. Then $\overline{s_{f g}}$ and the derivatives of entropy will be evaluated at the arithmetic average pressure. The solution may begin at any point in the flow system. As in the previous case, the point in the flow system where the fluid is a saturated liquid was used as a parameter. Results are shown as figure 14.

\section{4 Critical Pressure Predictions for Idealized Flow Processes}

All homogeneous model solutions involve equating the velocity in (1) to the sonic velocity in (4). The separated-phase model solutions require trial pressure drop determinations until the vapor velocity, as predicted by Martinelli and Nelson [41], equals the critical velocity predicted by (4).

\subsubsection{Homogeneous, Thermal Equilibrium Model; Fanno Flow Process}

From (1) and (2) one may write

$$
\frac{d v}{v}+\frac{d p}{G^{2} v}+\frac{1}{2} \quad(f / D) d \ell=0
$$

Then, integrating from the point in the system where the fluid is a saturated liquid to the critical point gives

$$
\ln \frac{v_{c}}{v_{f s}}+\frac{l}{G_{c}^{2}} \int_{p_{s}}^{p_{c}} \frac{d p}{v}+\frac{f L_{t p}}{2 D}=0 .
$$

Equation (25) provides a relationship between $\mathrm{v}$ and $\mathrm{p}$ to permit the integration of the second term in (28). Although $p$ does not appear in that expression, all of the thermodynamic property terms are a function of $p$. Substitution of this relationship into (28) gives 


$$
\begin{aligned}
\frac{f L}{D}= & \frac{1}{G_{c}^{2}} \int_{p_{c}}^{p} \frac{a+\sqrt{a^{2}+2 G_{c}^{2}\left(h_{o}-\beta\right)}}{h_{o}-\beta} d p \\
& +2 \ln \left\{v_{f s}\left[\frac{a+\sqrt{a^{2}+2 G_{c}^{2}\left(h_{o}-\beta\right)}}{2\left(h_{o}-\beta\right)}\right] p_{c}\right\} .
\end{aligned}
$$

In (29), $G_{c}$ and $p_{c}$ must have values to satisfy the relationship of mass-limiting flow as expressed in (5).

It is now necessary to express $G_{c}$ in terms of $p_{s}, p_{c}$, and thermodynamic properties which are a function of $\mathrm{p}_{s}$ and $\mathrm{p}_{c}$. The quadratic equation (25) may be solved for $v$ and that expression differentiated with respect to $\mathrm{p}$. That expression with (3) and (5) will result in an expression identical with that of Sajben ${ }^{[57]}$ which gives $G_{c}$ in terms of the desired variables:

$$
G_{c}^{2}=\frac{B_{2}}{B_{1}}-\left[\left(\frac{B_{2}}{B_{1}}\right)^{2}-\frac{a^{2}}{B_{1}}\left(2 \frac{d a}{d p}-1\right)\right]_{p_{c}}^{1 / 2}
$$

Thus, for critical flow the values of $p_{s}, p_{c}$ and $G_{c}$ must be satisfied in (29) and (30). Computed results are shown in figure 15.

For a given system, if $f, L_{t p}, D$, and $p_{s}$ are known, then a relationship between $p_{c}$ and $p_{s}$ may be determined. This evaluation also establishes a value for $G_{c}$.

\section{4. 2 Homogeneous, Thermal Equilibrium Model; Isentropic Flow Process}

For this process, (1) and (4) become

$$
-\int_{p_{o s}}^{p} c\left(v_{f}+x v_{f g}\right) d p=\frac{a^{2}}{2} .
$$


Then, from (2), (5) and (9)

$$
-\int_{p_{o s}}^{p_{c}}\left(v_{f}+x v_{f g}\right) d p=\left[\frac{a\left(v_{f}+x_{f g}\right)^{2}}{\frac{d \beta}{d p}+\left(v_{f}+x v_{f g}\right)\left(\frac{d o}{d p}-1\right)}\left(\frac{1}{2}\right)\right]_{p_{c}} .
$$

In order to evaluate the integral on the left of (32), $x$ must be determined as a function of $p$. Values for $x$ as a function of $p$ are available from section 6.3. 2 for specific $p_{s}$ values (or specific entropy values). Equation (32) requires, also, that the initial pressure be a stagnation value. Thus, the integration may be performed from initial points of saturated-liquid stagnation-pressure values. Figure 16 shows the computed values.

\section{4. 3 Homugeneous, Metastable (Equivalent of Two-Component) Model; Isentropic Flow Process}

In considering metastability, two models are possible. For one model, one may assume the mass transfer is negligible only very near the choking condition when the pressure drop is very rapid and thermal equilibrium is maintained in the flow to that point. For an approximation of this condition, the choking condition, or evaluation of (4), may be made considering metastable conditions and the flow process to choking assumed to follow equilibrium conditions. For another model which is completely metastable, one may assume mass transfer is negligible both at choking and in the flow process.

Equations (1), (7), and (11) will produce

$$
-\int_{p_{o s}}^{p_{c}}\left(v_{f}+x v_{f g}\right) d p=\left[\frac{\left(\frac{x}{1-x}\right) c_{p g}+C_{f}}{\left(\frac{x}{1-x}\right) c_{v g}+C_{f}}\right] \frac{p\left(v_{f}+x v_{f g}\right)^{2}}{2 x v_{g}},
$$

and for the case of liquid compressibility for hydrogen

$$
-\int_{p_{o s}}^{p_{c}}\left(v_{f}+x v_{f g}\right) d p=\frac{\left[\frac{\left(\frac{x}{1-x}\right) c_{p g}+c_{v_{f}}}{\left(\frac{x}{1-x}\right) c_{p g}+c_{v_{f}}}\right]}{2\left[(1-x) v_{f}^{2} p+x v_{g} a_{f}^{2}\right]} p a_{f}^{2}\left(v_{f}+x v_{f g}\right)^{2} .
$$


The right side of (33) represents a form of (4) which is not a function of the flow process. The left side of the equation may be evaluated in two ways, depending on whether or not metastability is assumed for the flow process. First, if the ratio of (dp/d $\ell$ ) is very large (as, for example, in a short nozzle) then the time for the vaporization process necessary to produce thermal equilibrium will be very short and, for one extreme case, vaporization may be considered negligible. For that condition, the integral on the left of (21) may be evaluated with $x$ equal to a constant.

For the other extreme case, where thermal equilibrium may be approached in the flow process where the pressure gradient is not steep, as shown in figure 9 , but not in a small pressure wave process represented by the right side of (33), the left side of (33) will have the same value as the left side of (32). Figures 17 and 18 show the computed values.

\section{4. 4 Separated-Phase, Thermal Equilibrium Model; Fanno or Isentropic Flow Process}

Critical pressure for the Fanno flow process may be determined by the usual trial pressure-drop solution used with the Martinelli-Nelson [41] correlation, proceeding until the vapor velocity reaches sonic velocity. This solution will probably be predictive only at higher quality flows where the vapor flow is controlling. Briefly, the Martinelli-Nelson pressure drop computation involves the following steps. First, the correlating term $x_{t t}$ must be determined from

$$
x_{t t}=\left(\sqrt{\frac{(\Delta p / \Delta L)_{g}}{(\Delta p / \Delta L)_{f}}}\right)_{\text {Friction }}
$$

This term, for a small pressure increment, may be expressed in terms of fluid properties as

$$
x_{t t}=\left(\frac{\bar{v}_{\ell}}{\bar{v}_{g}}\right)^{0.571}\left(\frac{\bar{\mu}_{\ell}}{\overline{\bar{\mu}}_{g}}\right)^{0.143}\left(\frac{1}{\bar{x}}-1\right),
$$

where the mean value terms on the right are evaluated as in (27). Figure 19 shows $x_{t t}$ as a function of $p$ and $x$. Then, from the Martinelli-Nelson correlation,

$$
\left(\frac{(\Delta \mathrm{p} / \Delta \mathrm{L})_{t p}}{(\Delta \mathrm{p} / \Delta \mathrm{L})_{\mathrm{f}}}\right)_{\text {Friction }}
$$


may be determined. In the next step, the pressure drop for the liquid phase only, $(\Delta p / \Delta L)_{f}$, flowing in the same flow section is determined by conventional means. Then, the two-phase friction pressure drop may be evaluated from

$$
\left(\frac{\Delta p}{\Delta L}\right)_{t p(\text { Friction })}=\left(\frac{(\Delta p / \Delta L)_{t p}}{(\Delta p / \Delta L)_{f}}\right)_{\text {Friction }}\left(\frac{\Delta p}{\Delta L}\right)_{f} .
$$

The value of the vapor and liquid flow area ratios $R_{g}$ and $R_{f}$ may be determined from the correlation, since $x_{t t}$ is known. Next, the acceleration pressure drop may be computed from

$\Delta p_{t p \text { (Acceleration) }}=G^{2}\left\{\left[\frac{x^{2} v g}{R_{g}}+\frac{(1-x)^{2} v_{f}}{R_{f}}\right]_{1}-\left[\frac{x^{2} v_{g}}{R_{g}}+\frac{(1-x)^{2} v_{f}}{R_{f}}\right]_{2}\right\}$.

Finally, the total pressure drop, $\Delta \mathrm{p}_{\mathrm{tp} \text { (Friction) }}+\Delta \mathrm{p}_{\mathrm{tp} \text { (Acceleration) }}$ may be computed and the final pressure determined. For the check on the previously assumed value of $x_{2}$, (3) may be solved to see if the assumed $x_{2}$ is in agreement with the computed $p_{2}$. Figures 13 and 14 have been constructed for a rapid determination of $\chi_{t t}$ as a function of $p$ and $x$. This chart will also be useful in pressure drop and heat and mass transfer studies involving these fluids.

For the isentropic flow case, the procedure is the same except the friction pressure drop may be omitted and (1) becomes

$$
\Delta p=\frac{1}{\bar{v}_{f}}\left(\frac{u_{1}^{2}-u_{2}^{2}}{2}\right)_{f}=\frac{1}{\bar{v}_{g}}\left(\frac{u_{1}^{2}-u_{2}^{2}}{2}\right)_{g}
$$

thus equating the pressure drop for each phase. Approximate phase velocities $\left(u_{f}\right.$, $\left.u_{g}\right)$ may be determined from values $R_{g}$ and $R_{f}$ obtained from $x_{t t}$ and the Martinelli-Nelson correlation and (5). Then, the check can be made for the mean value assumptions.

In both the isentropic and Fanno flow cases, the pressure drop computations are continued until sonic velocity is reached in the vapor phase.

\section{4. 5 Separated-Phase, Metastable (Equivalent of Two-Component) Model; Isentropic Flow Process}

This solution is intended for use where the acceleration pressure drop is very great and the quality change (because of the limited time for vaporization) is regligible. Equation (37) 
may be used with $\bar{v}_{f}$ and $\bar{v}_{f g}$ evaluated for an assumed pressure drop and with $\mathrm{x}$ assumed constant. Pressure drops for each phase should be equated as before and the trial solutions continued.

\section{5 The Use of Idealized Solutions in Design Problems}

This section is written for those interested in using the idealized solutions for design problems, but not interested in the details of the mathematical experssions developed in the previous parts of this section. Table 3 is a summary of all the idealized solutions.

The process section of the table lists "at choking" for the first four divisions. These treatments are for determinations of choking conditions at the choking point, in contrast to the divisions following, which predict choking or quality from upstream conditions.

Figures $8 \mathrm{a}$ and $8 \mathrm{~b}$ may be used to determine the model that best describes the specific flow system to be studied. These figures show comparisons of the results obtained from use of the models of the idealized solutions and experimental results reported.

The recommended procedure in using these idealized solutions for design studies is to select models which will produce results that will provide upper and lower limit values for choking mass flow $\left(G_{c}\right)$.

The results from the use of the homogeneous, thermal equilibrium model (shown as $\left.G_{c} / G_{c(H O)(T H)}=1\right)$ serve as a lower limit for $G_{c}$ values for the entire range of qualities $(x)$. Figure $8 \mathrm{~b}$ shows that the homogeneous, metastable model will serve as a satisfactory upper limit for all systems for very low qualities, up to about $x=0.01$. This metastable model also will serve as an upper limit up to about $\mathrm{x}=0.10$ for systems where mixing would be expected. At higher qualities, the vapor choking model serves as an upper limit for $G_{c}$ values for qualities from $x=0.20$ to $x=1.00$. For non-mixing systems from $x=0.01$ to $x=0.10$ and for all systems from $x=0.10$ to $x=0.20$, none of the idealized solutions present a satisfactory upper limit. The recommendation of this report is to use the upper limit of the experimental data as a correlating parameter for this range. That is, the upper limit may be

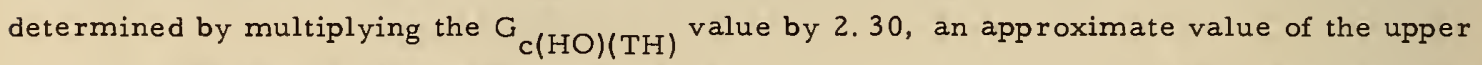
limit of the experimentally determined value of $G_{c} / G_{c}(H O)(T H)$. Of course, the experimental data may be used for all ranges of quality for an upper limit value of $G_{c}$, but the idealized solutions are recommended except for this narrow range as they should better reflect fluid property effects. Most of the data reported in figures $8 \mathrm{a}$ and $8 \mathrm{~b}$ are for water at relatively low pressures.

Then, for the "at chiking" case, table 3 indicates figures 10, 11 and 12 will provide the upper and lower limit values of $G_{c}$ for the models chosen. 
For the divisions below the first six headings in the process column of Table 3 , the designer must choose a flow process as well as a model. Obviously, although the previous discussion assumes $\mathrm{P}_{c}$ and $\mathrm{x}_{c}$ are known and $\mathrm{G}_{c}$ is to be determined, any of the three terms may be evaluated from the figures if the other two are known or can be estimated. Figures 13 and 14 have been prepared to provide a means of estimating $\mathrm{x}$ at any pressure in the flow system if $\mathrm{p}_{\mathrm{S}}$ is known.

In most engineering cases, the flow will only approach isentropic or Fanno conditions, and for the Fanno case there are no precise data for the friction factor. However, if design guides are required, figures 15 through 18 should provide reasonably close estimates. As for the previous cases, a selection of models to provide upper and lower limit values is recommended. For the last case considered in the bottom column of table 3 , no figures are provided for a solution of choking flow conditions; however, a method is outlined in sections 6. 4. 4 and 6.4.5 of the text. Figure 19 has been prepared to provide for a rapid determination of the Martinelli [41] correlating term. This term is also used in pressure drop, heat transfer, and entrainment studies. Some example problems follow.

Example 1:

It is desired to determine the choking-flow rate for a mixture of liquid and vapor hydrogen flowing through a short nozzle. The fluid enters the nozzle with a quality of 0.01 and at a pressure of 1.84 atmospheres. Discharge pressure for the flowing mixture is one atmosphere. Note: If the discharge is into a larger receiver, the receiver pressure may be lower than one atmosphere. In this case, the computations will indicate a mass flow rate for which the critical pressure is one atmosphere and further pressure reductions to the receiver pressure will be accomplished downstream from the choking point.

Solution:

Since the quality at choking will be low, homogeneous model solutions will be used. $G_{C}$ values will be determined for three cases:

(1) Thermal equilibrium in the flow, thermal equilibrium at choking,

(2) Thermal equilibrium in the flow, metastable choking, and

(3) Metastable flow, metastable choking.

Case (1)

The first step is to determine a $p_{s}$ value for this system. This may be accomplished by making an imaginary extension of the isentropic flow upstream to a point where the fluid is a saturated liquid. This will be a trial solution. Assuming $p_{s}=2$ atm., from figure $14 a$, $\frac{p_{s}-p}{p_{s}}=0.08$ for $x=0.01$. Thus, the as sumed value of $p_{s}$ is correct as it satisfies the entrance conditions of $\mathrm{p}=1.84 \mathrm{~atm}$. and $\mathrm{x}=0.01$. 
Then for Case (1), figure 16a, for isentropic flow, homogeneous, thermal equilibrium model, shows that

$$
G_{c}=112 \frac{\text { grams }}{\mathrm{cm}^{2}-\mathrm{sec}}
$$

For Case (2) from figure 17a, same as $16 a$ except metastable at the point of choking,

$$
G_{c}=158 \frac{\text { grams }}{\mathrm{cm}^{2}-\mathrm{sec}} \text {. }
$$

These cases may also be solved by other figures, simply by following the flow process to the point of choking. Figure $14 a$ shows that $x=0.063$ at $p=1$ atm.; thus, $p_{c}=1$ atm. and $x_{c}=$ 0.063 .

Then, from figure 10a,

$$
G_{c(H O)(T H)}=110 \frac{\text { grams }}{\mathrm{cm}^{2}-\mathrm{sec}}
$$

for Case (1).

The choking quality and pressure will be the same for Case (2); so from figure 11 a,

$$
G_{c}=156 \frac{\text { grams }}{\mathrm{cm}^{2}-\mathrm{sec}} \text {. }
$$

For Case (3), one must determine $G_{c}$ from the at-choking curves. Here $p_{c}=1$ atm. and $x_{c}=0.01 . \quad F r o m$ figure $11 \mathrm{a}$,

$$
G_{c}=370 \frac{\text { grams }}{\mathrm{cm}^{2}-\mathrm{sec}} \text {. }
$$

Figure 18 a could not be used in this problem, except by a trial solution. Case (3) data, however, may be checked by the use of this figure. The stagnation pressure may be approximately computed from

$$
\begin{aligned}
p_{0} & \approx p_{c}+\frac{G_{c}^{2} v_{c}}{2} \\
p_{0} & \approx 1+\frac{358^{2} \times 21.46}{2 \times 1.0133 \times 10^{6}} \\
& \approx 2.33 \mathrm{~atm} .
\end{aligned}
$$


Therefore,

$$
\begin{aligned}
\mathrm{p}_{c} / \mathrm{p}_{0} & =\frac{1}{2.33} \\
& =0.43 .
\end{aligned}
$$

Then, from figure $18 \mathrm{a}$ at $\mathrm{x}=0.01$, the above ratio,

$$
G_{c} \approx 370 \frac{\operatorname{grams}}{\mathrm{cm}^{2}-\sec }
$$

is in agreement with the previously determined value.

Example 2:

Hydrogen is flowing adiabatically through a tube such that saturated liquid conditions are reached when $\mathrm{P}_{\mathrm{s}}={ }^{\prime} 2$ atm.

a) If the tube length is $125 \mathrm{~cm}$., the two-phase friction factor is estimated at 0.01 , and the tube diameter is $2.5 \mathrm{~cm}$. What is the maximum discharge pressure at which choking will occur?

b) What is the maximum discharge rate?

Solution:

$$
\text { a) } \begin{aligned}
\frac{f L_{t p}}{D} & =\frac{0.01 \times 125}{2.5} \\
& =0.5
\end{aligned}
$$

From figure $15 a$, for Fanno flow

$$
\begin{aligned}
& p_{c} / p_{s}=0.74, \\
& p_{c}=1.48 \mathrm{~atm} .
\end{aligned}
$$

b) Then

$$
G_{c}=168 \frac{\text { grams }}{\mathrm{cm}^{2}-\mathrm{sec}}
$$

It should be recognized that these values are obtained from homogeneous, thermal equilibrium models for a low quality at discharge ( $x=0.02$ from figure 14a). Assuming metastability at choking with $\mathrm{x}=0.02$ from figure $11 \mathrm{a}, \mathrm{G}_{\mathrm{c}(\mathrm{MET})} \approx 350 \frac{\mathrm{grams}}{\mathrm{cm}^{2}-\mathrm{sec}}$. This would generally represent the upper limit for $G_{c}$. 
Example 3:

Hydrogen with a quality of 0.8 is discharging through an orifice-like opening. The pressure of the hydrogen at discharge is one atmosphere. What is the maximum mass flow rate?

Solution:

For high quality, the results from the separated-phase model will be determined. For a short flow section we will assume metastable flow. Therefore, the quality at discharge will be 0.8 also. From figure 10 a,

$$
G_{c(H O)(T H)}=47 \frac{\text { grams }}{\mathrm{cm}^{2}-\mathrm{sec}} \text {. }
$$

Then from figure 12 ,

$$
\begin{aligned}
G_{c(V C)} & =1.14 G_{c(H O)} \\
& =53.5 \frac{\text { grams }}{\mathrm{cm}^{2}-\mathrm{sec}} .
\end{aligned}
$$

Since this flow case would probably involve a vena contracta, the actual flow area in $G_{c}$ should be determined by multiplying the exit (or minimum) flow area by an appropriate coefficient of discharge.

\section{Summary}

In summary, section 6 has presented equations and their numerical solutions for choking for flow of liquid-vapor mixtures of hydrogen, nitrogen, oxygen, and refrigerants 11 and 12. In order to derive the equations, several assumptions have been made regarding the flow patterns and liquid-vapor equilibrium. The flow models were "selected" so that the analytical results would bracket the actual flow cases; however, further experimental data will be required to finally verify these results.

The design charts are prepared in units which appear to be more commonly used for the specific fluids. 


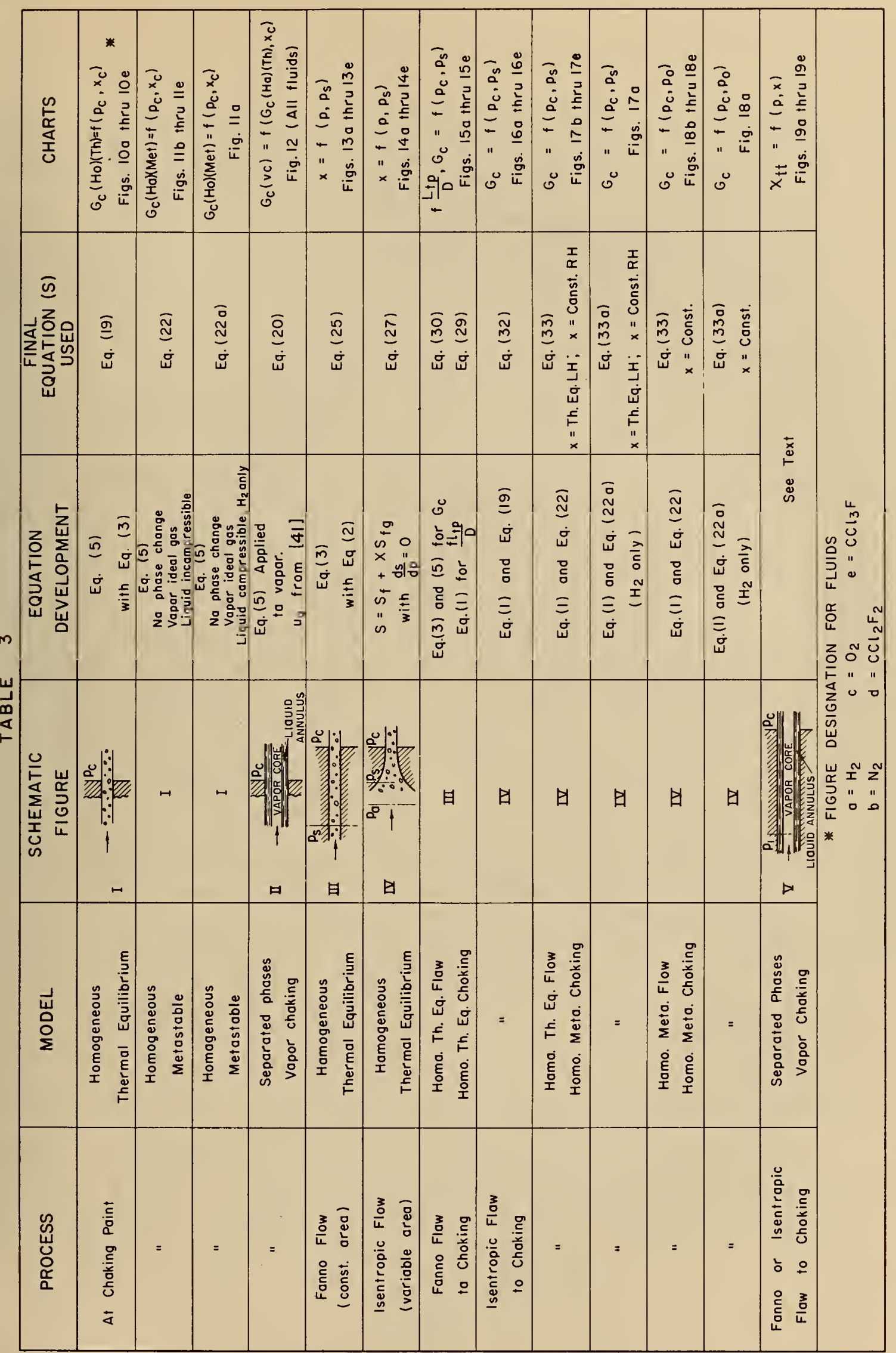




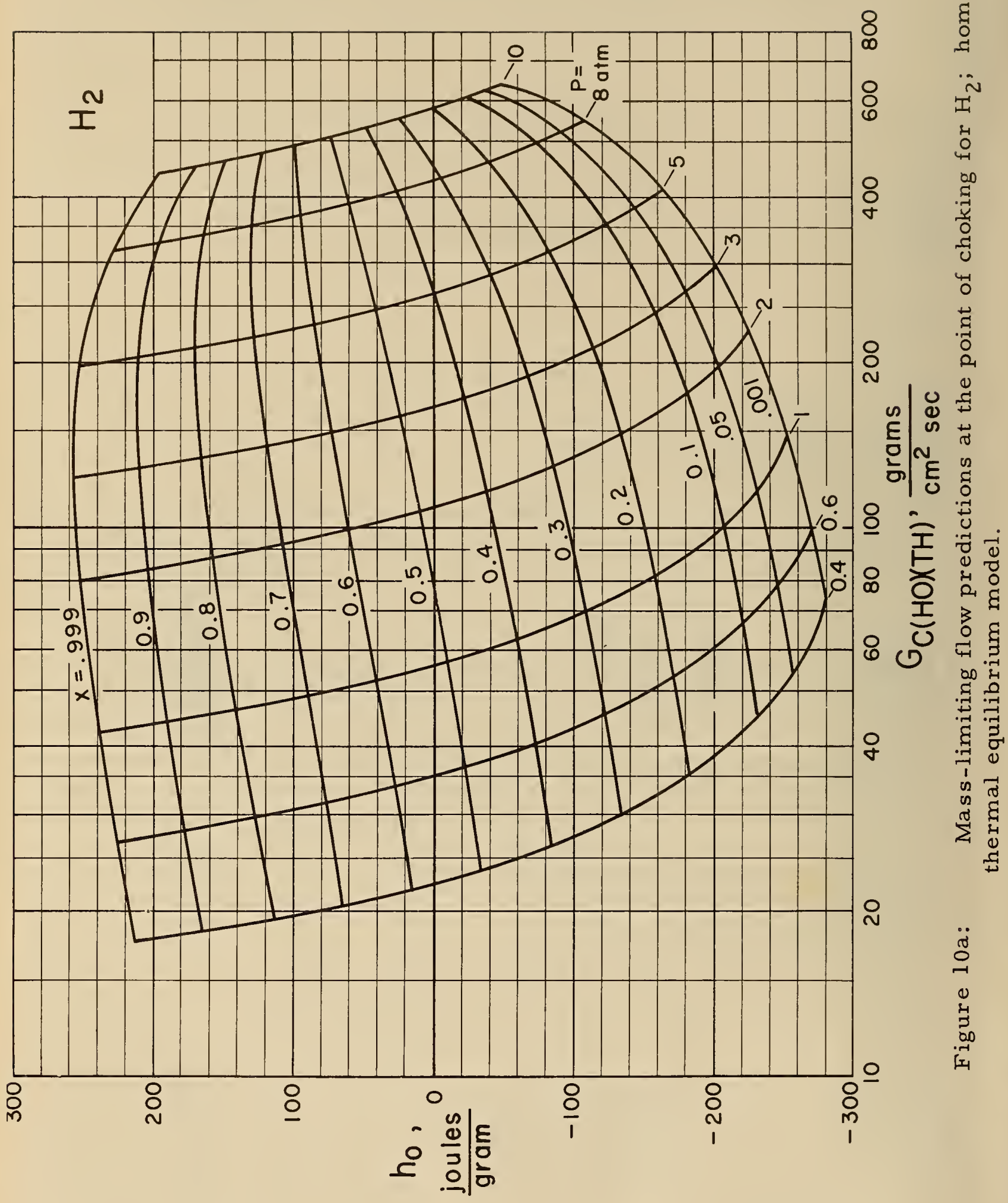




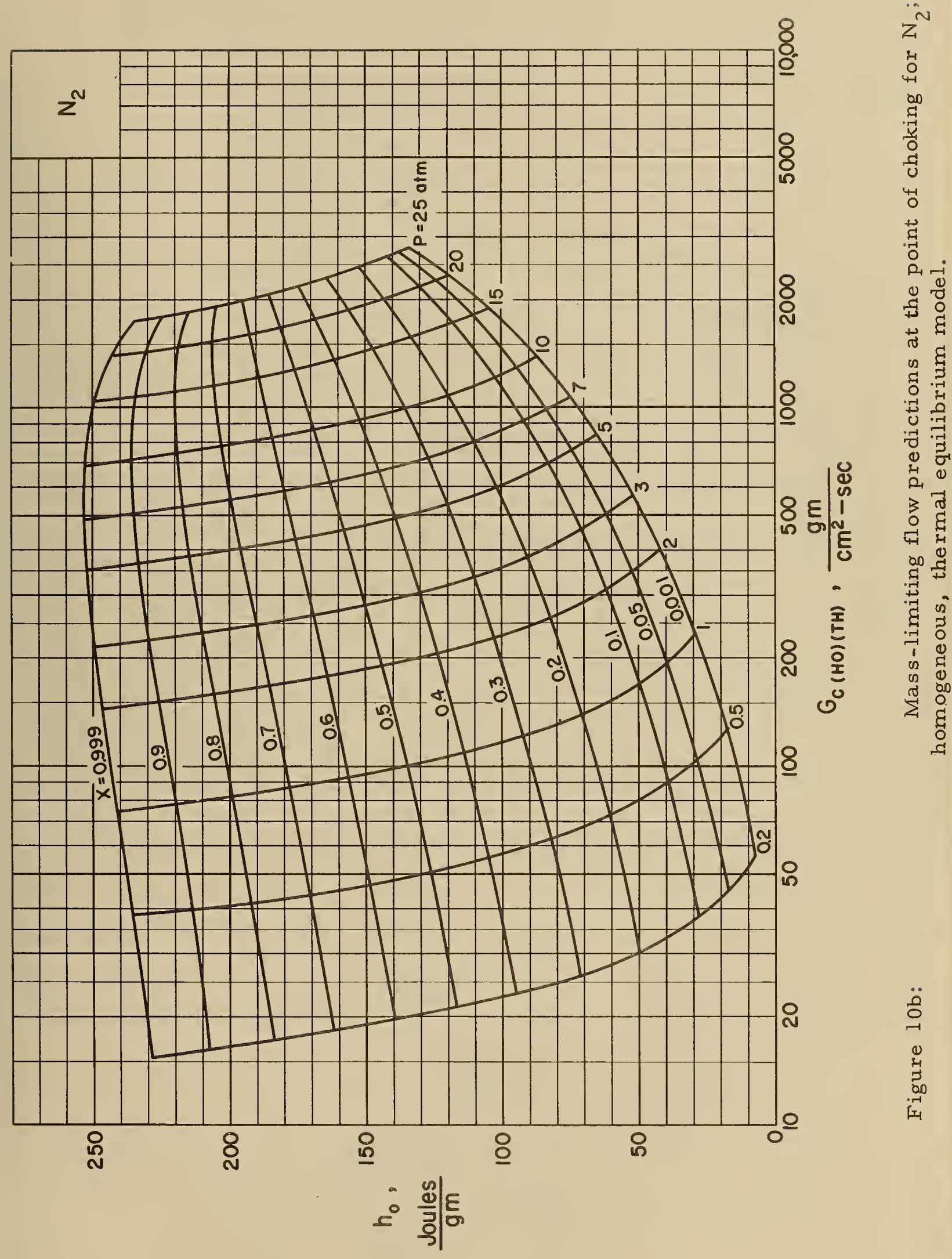




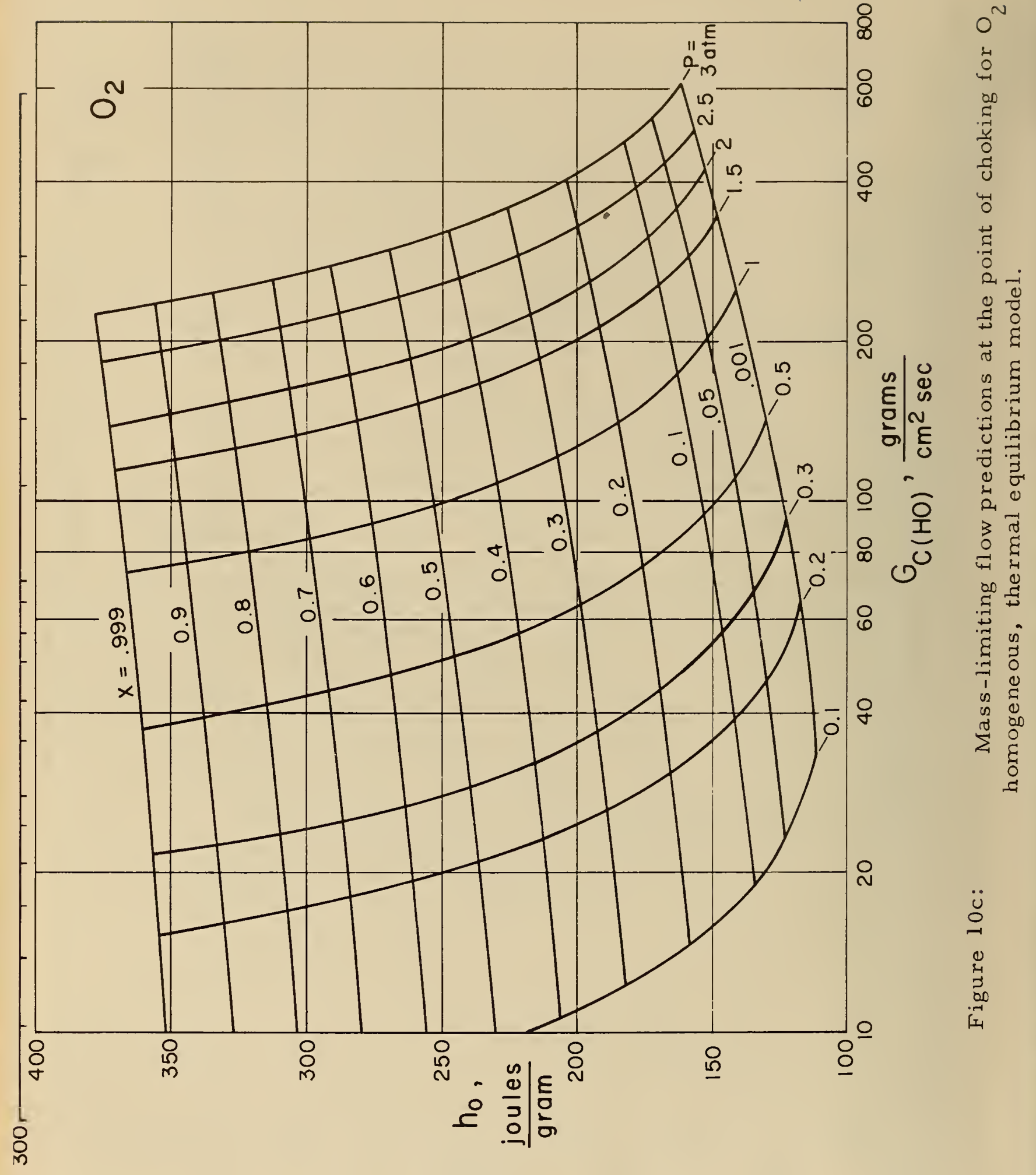




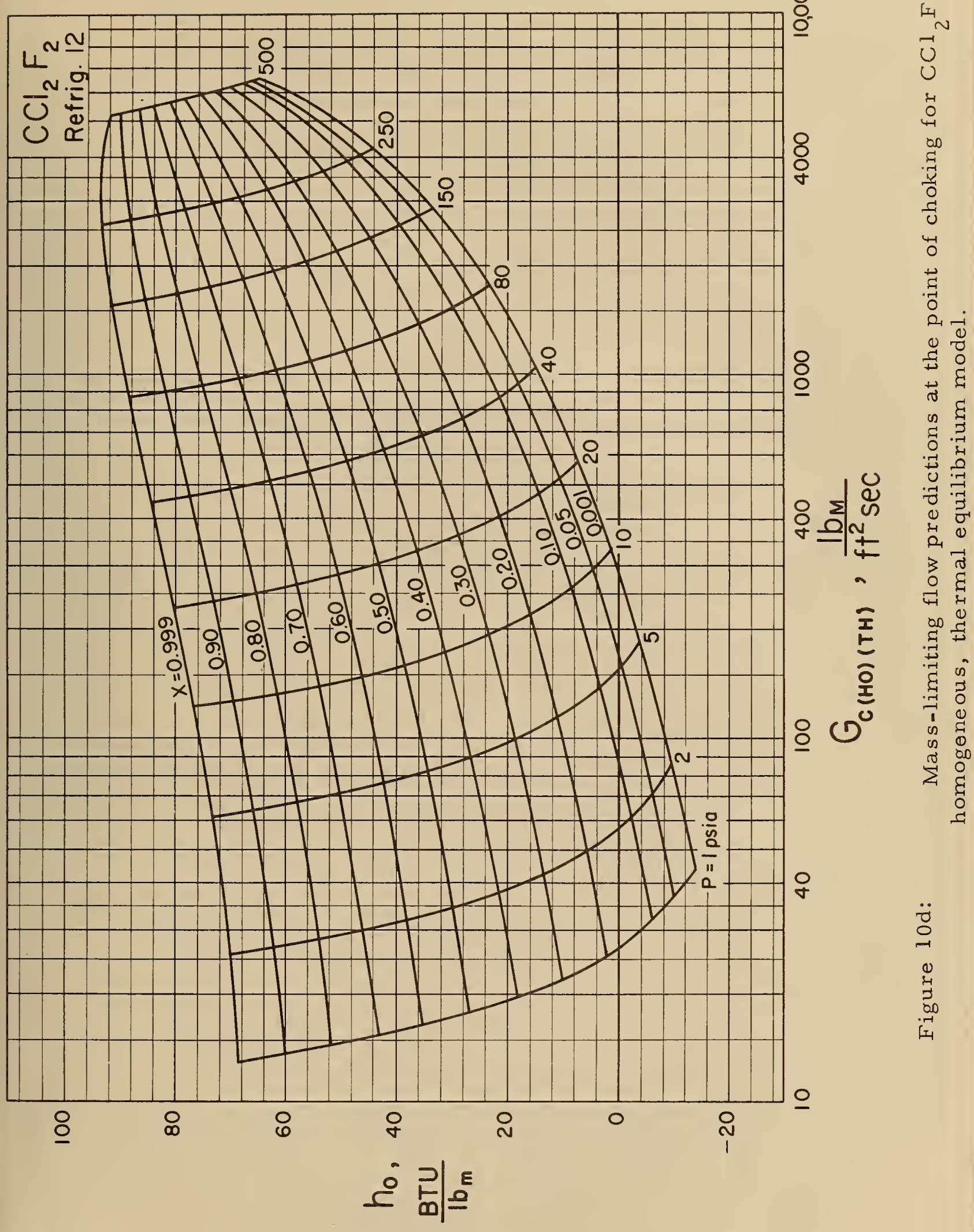




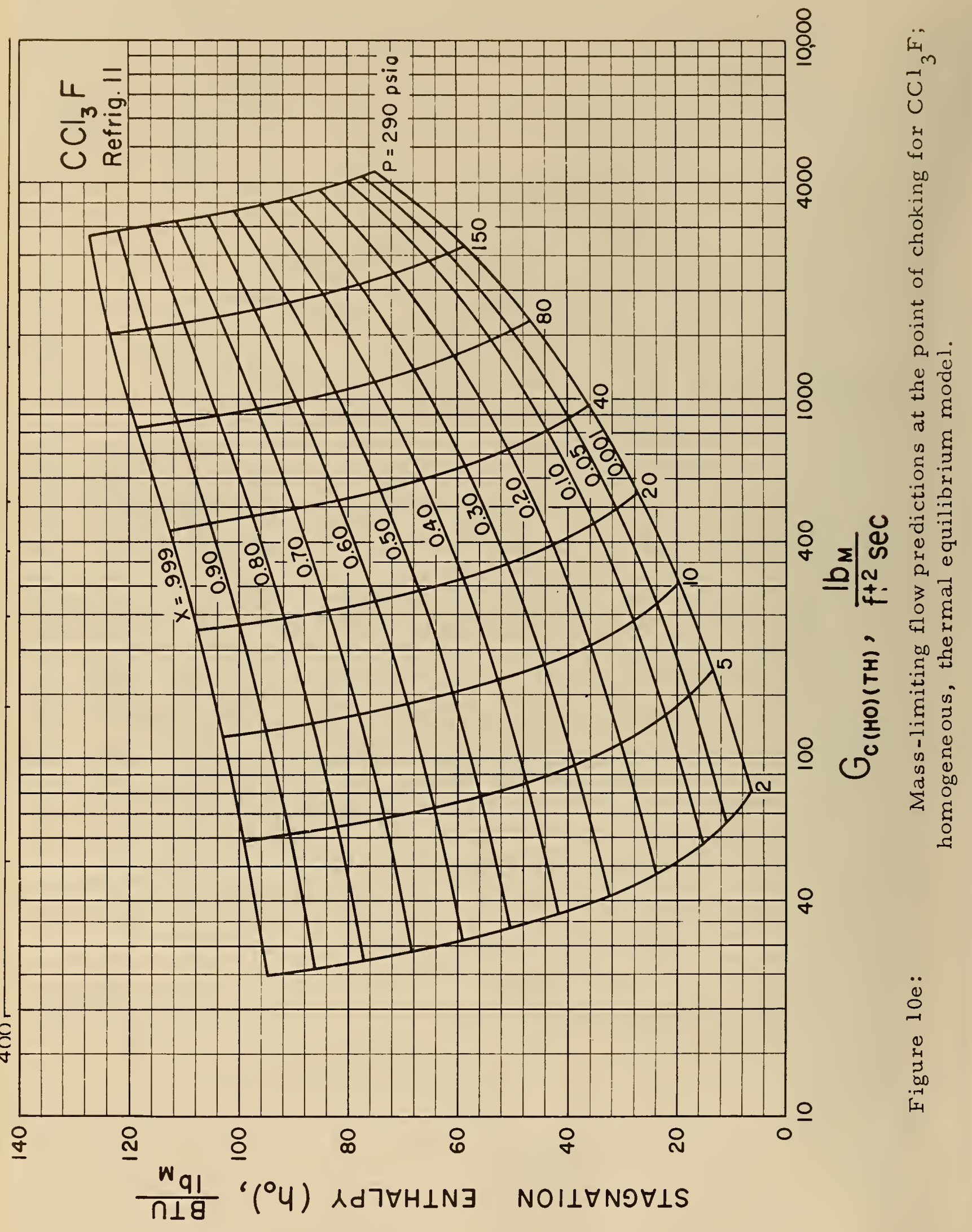




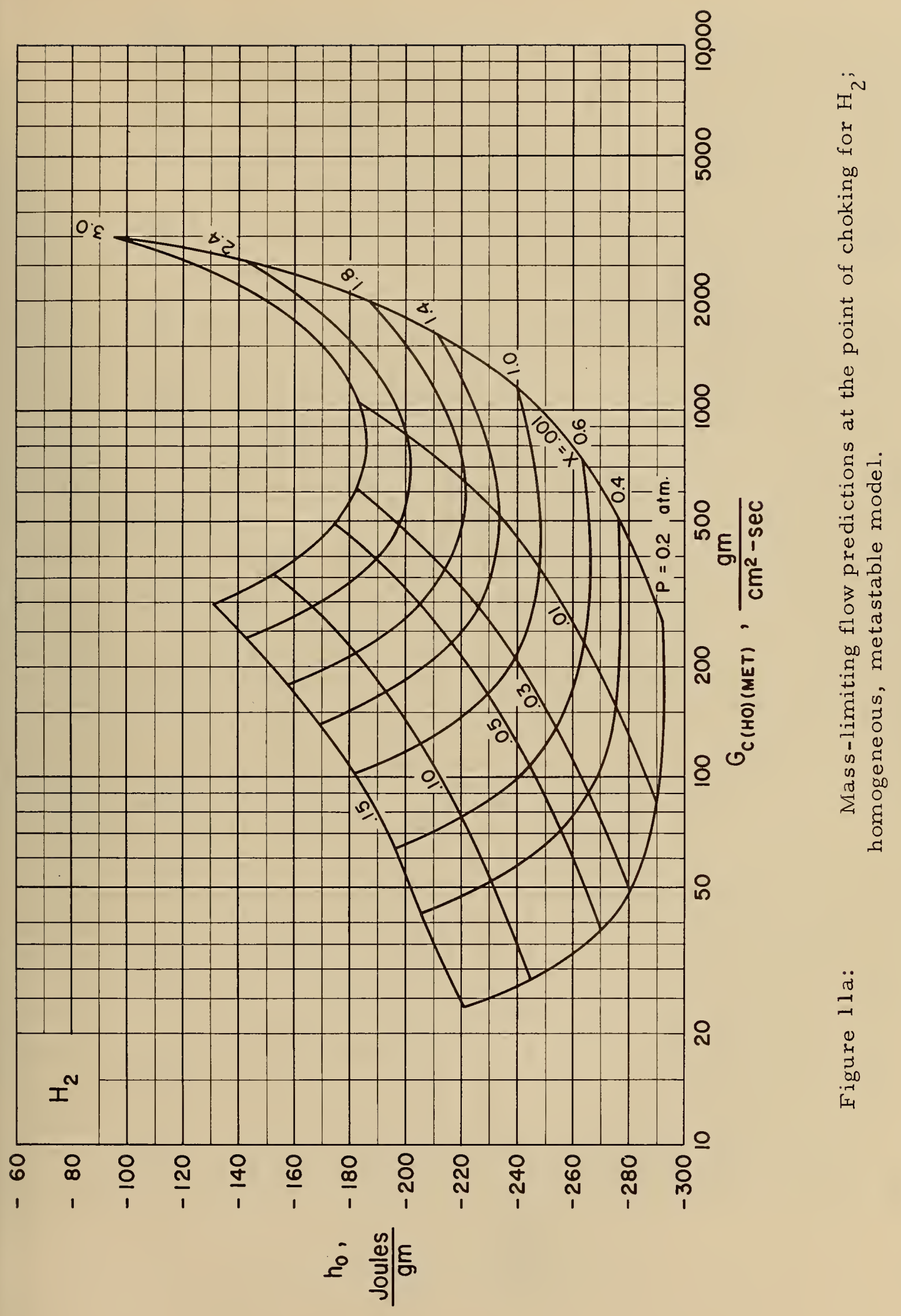




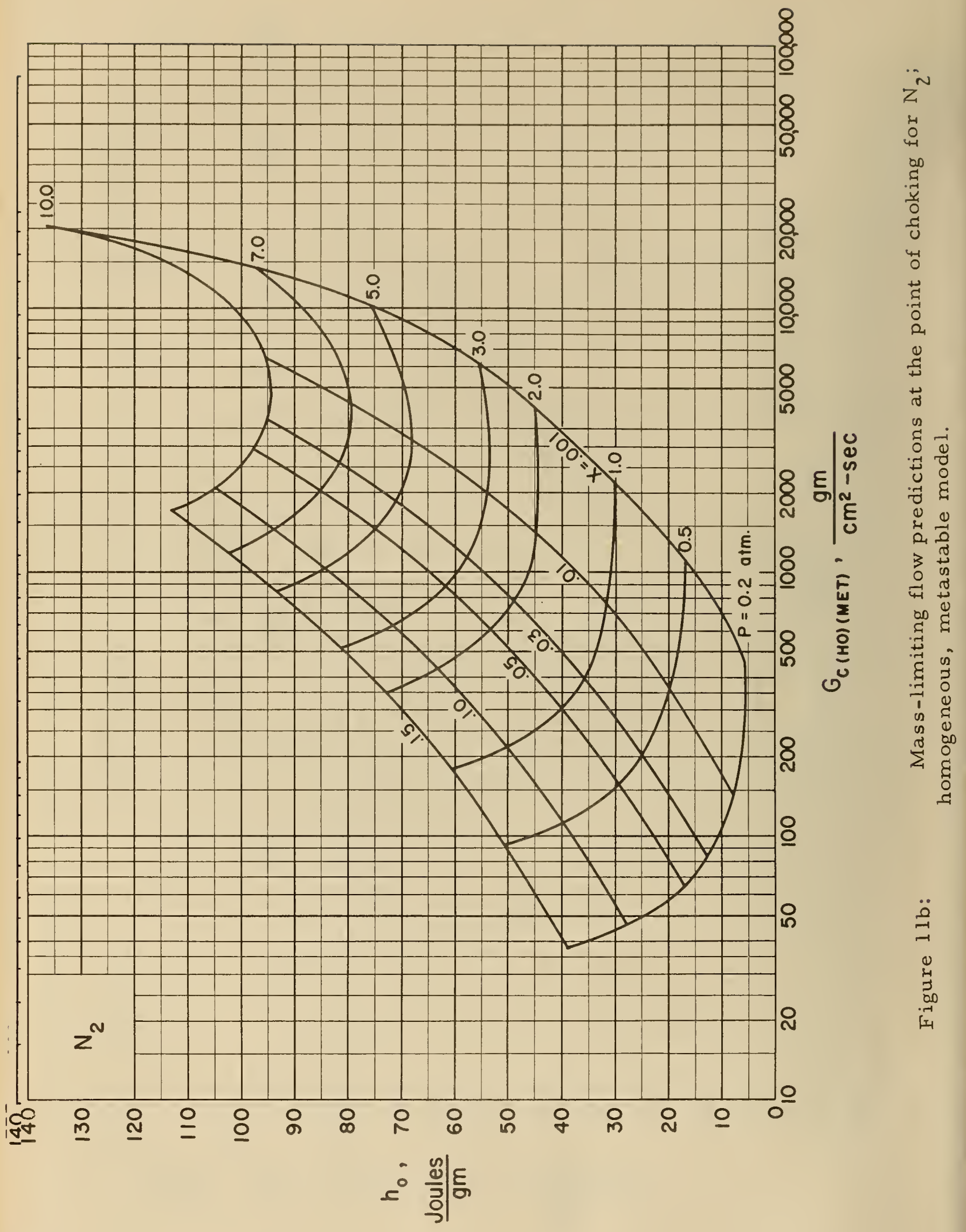




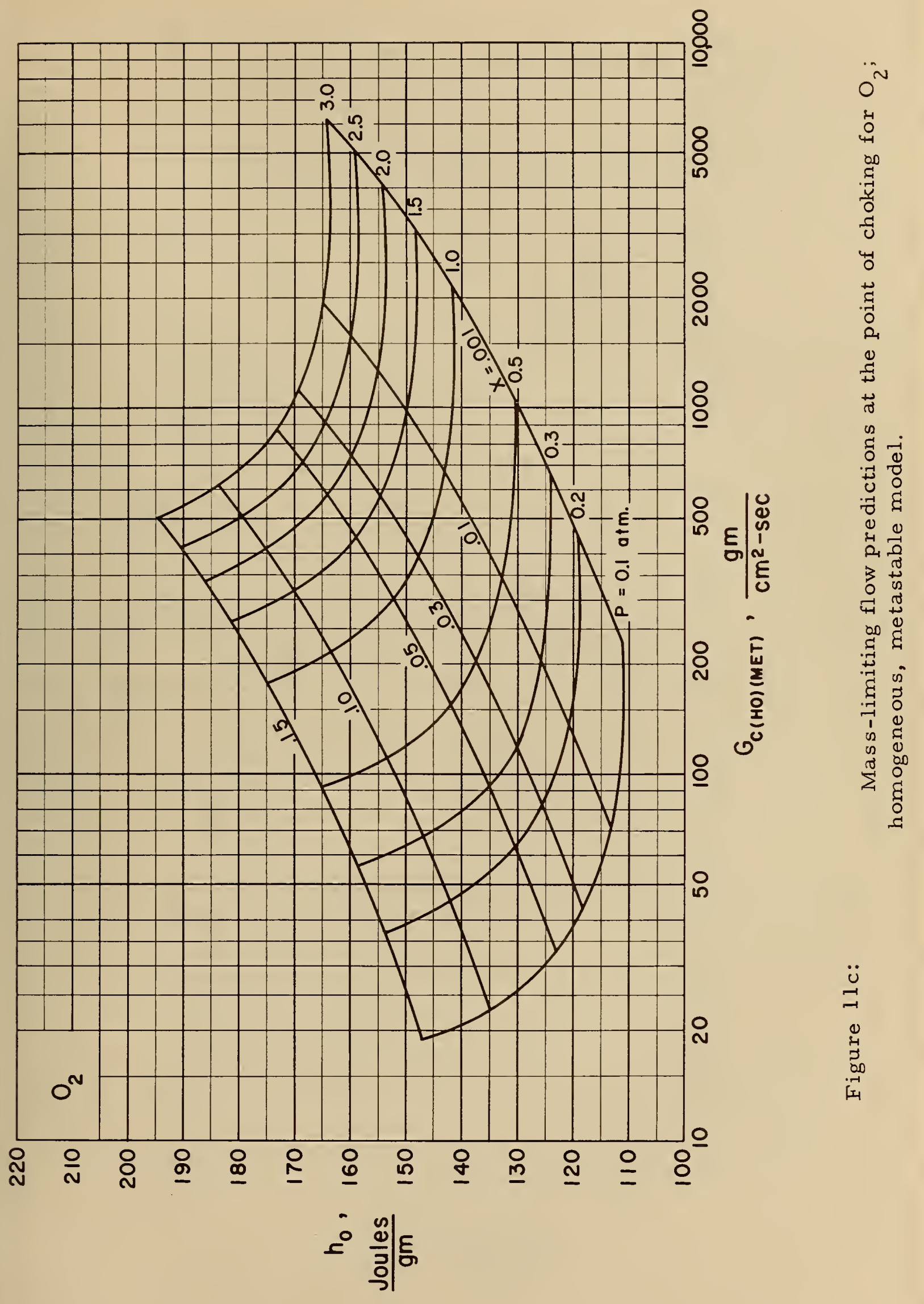




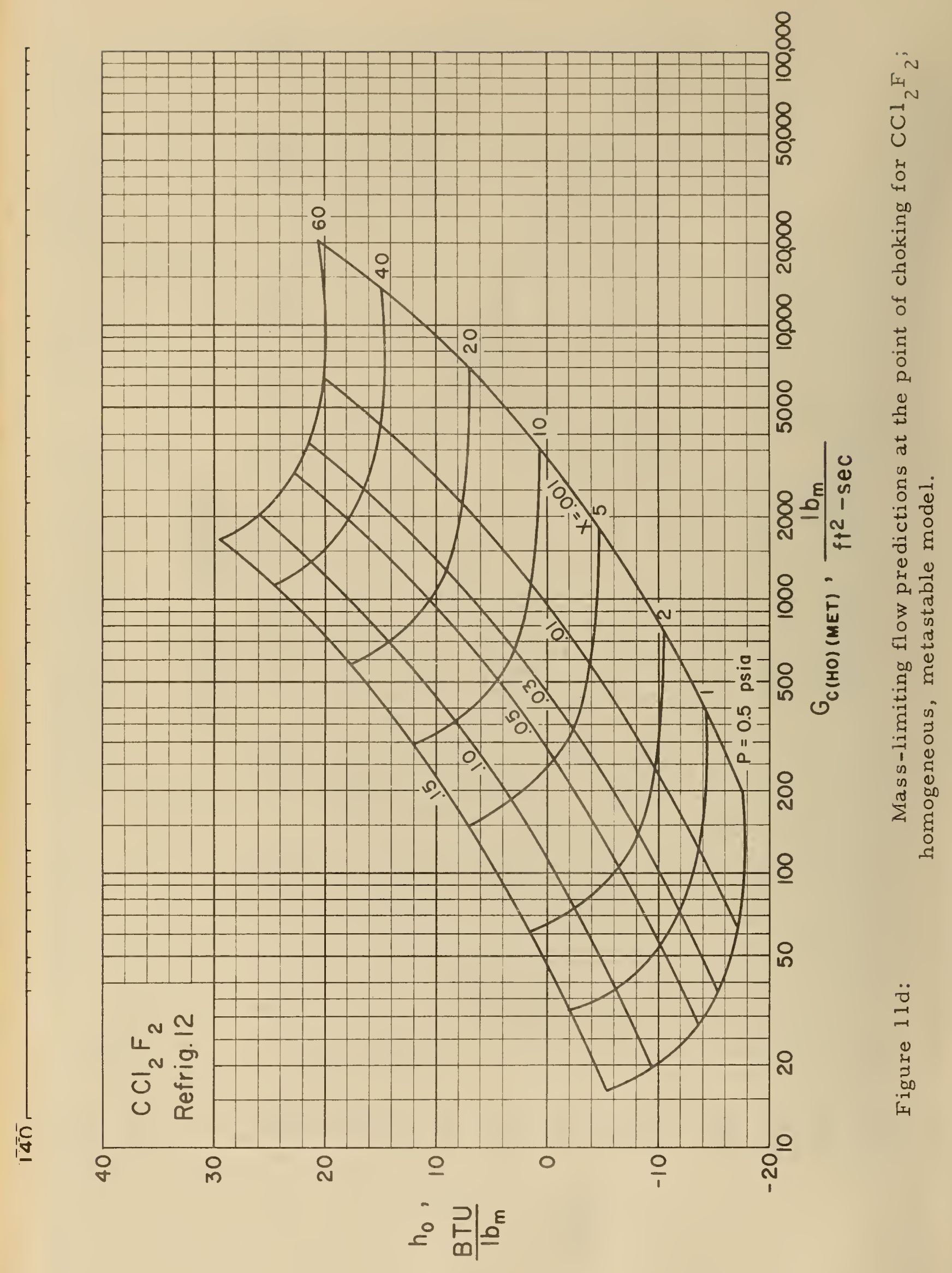




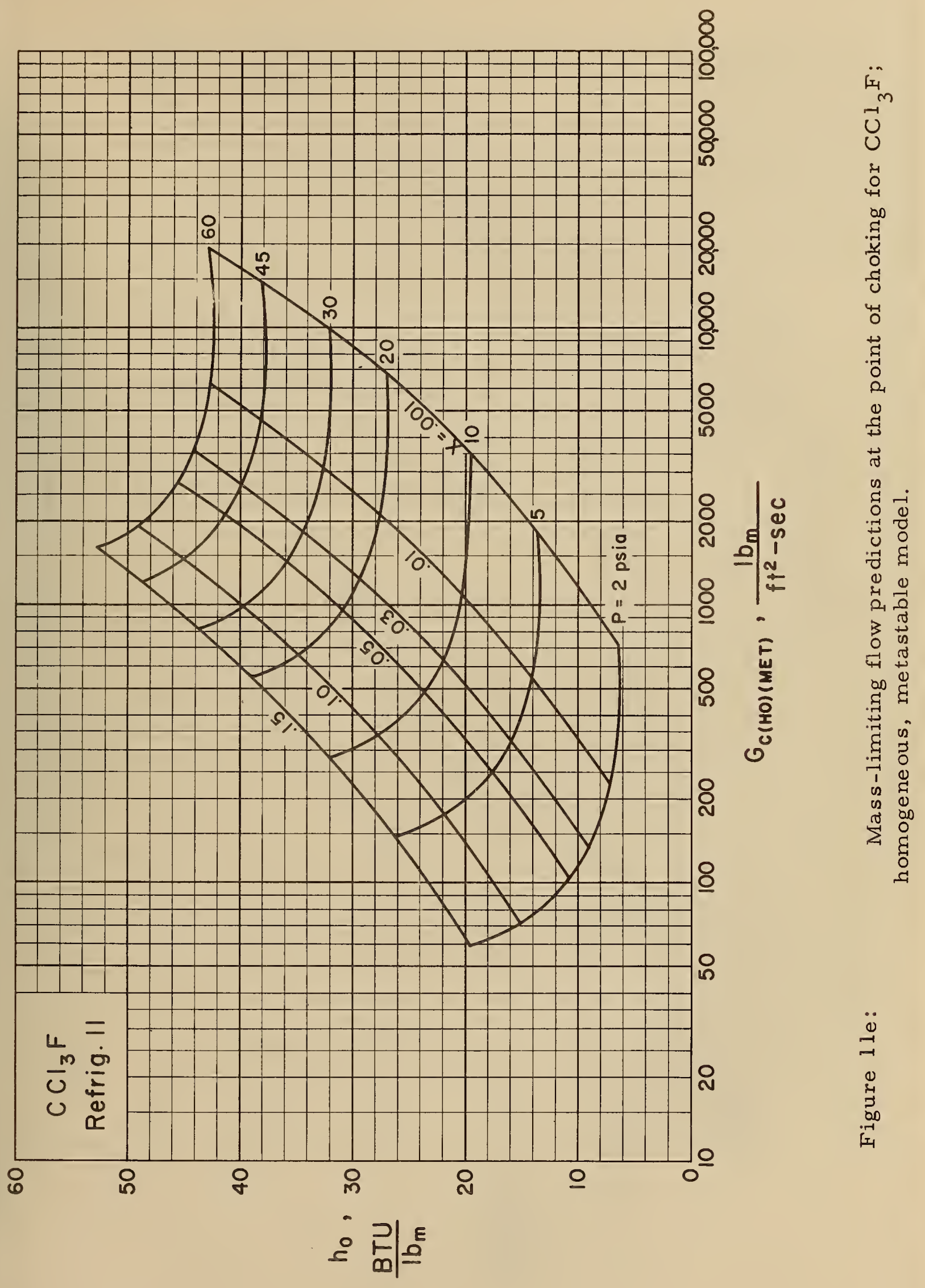




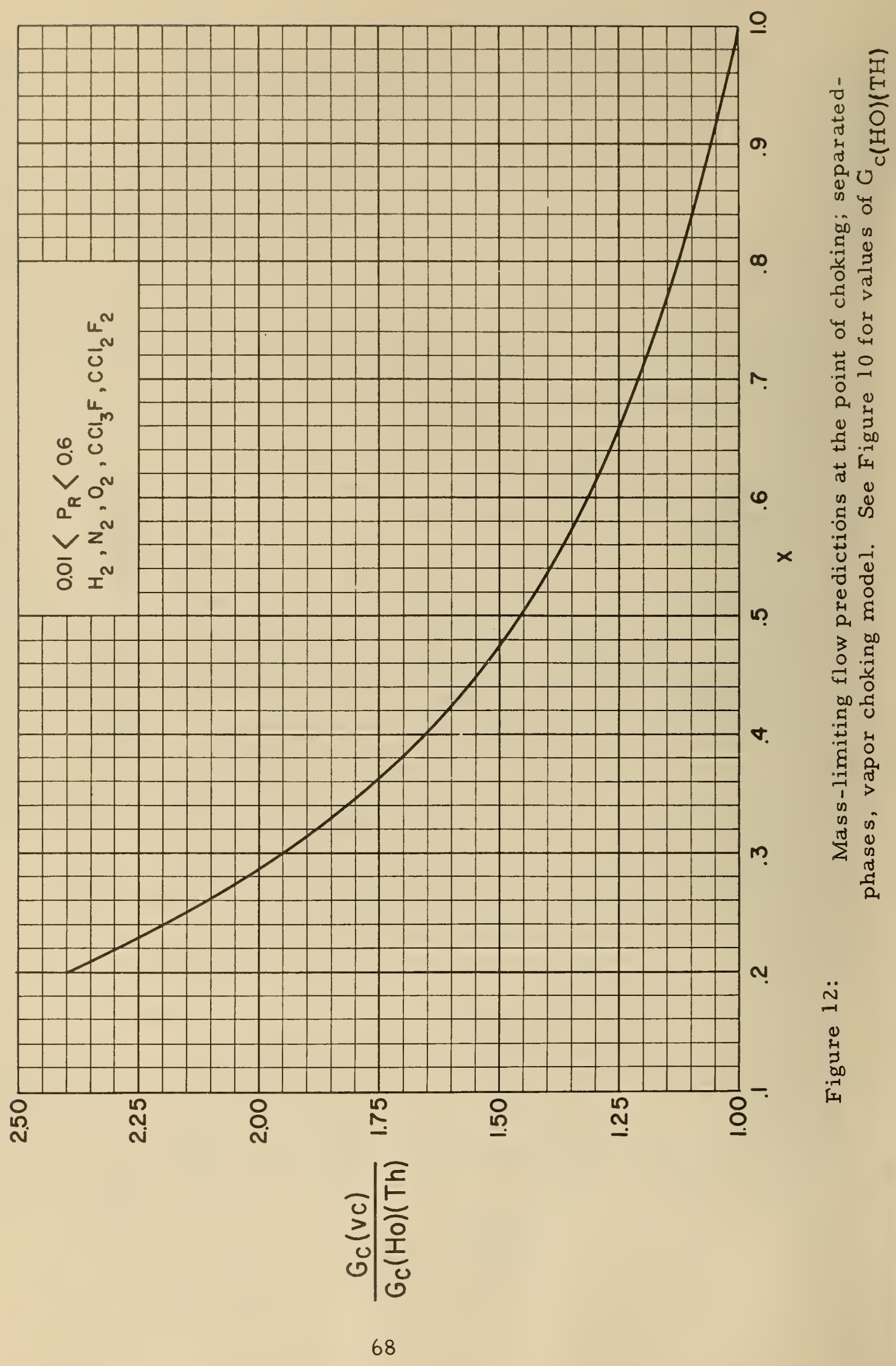




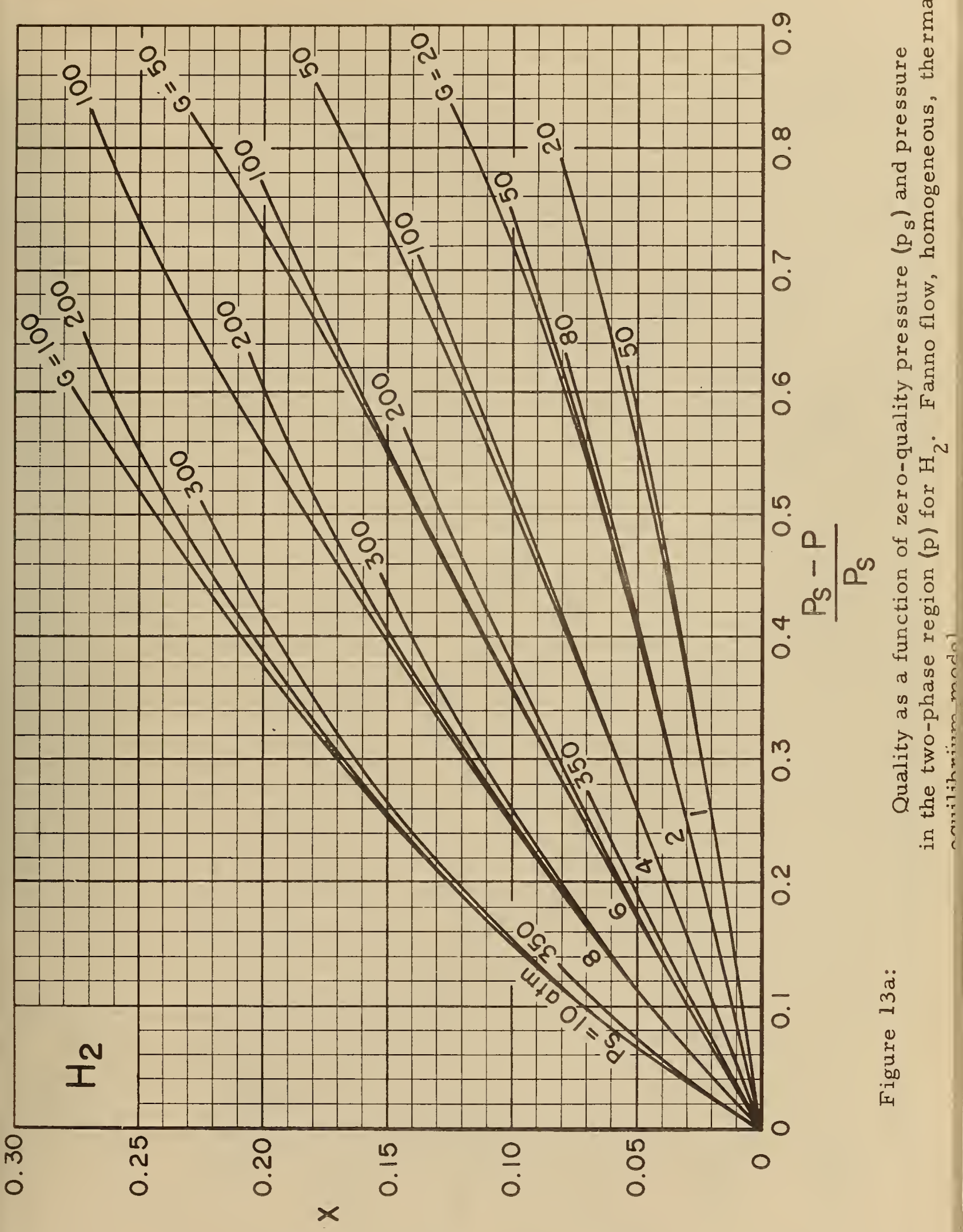




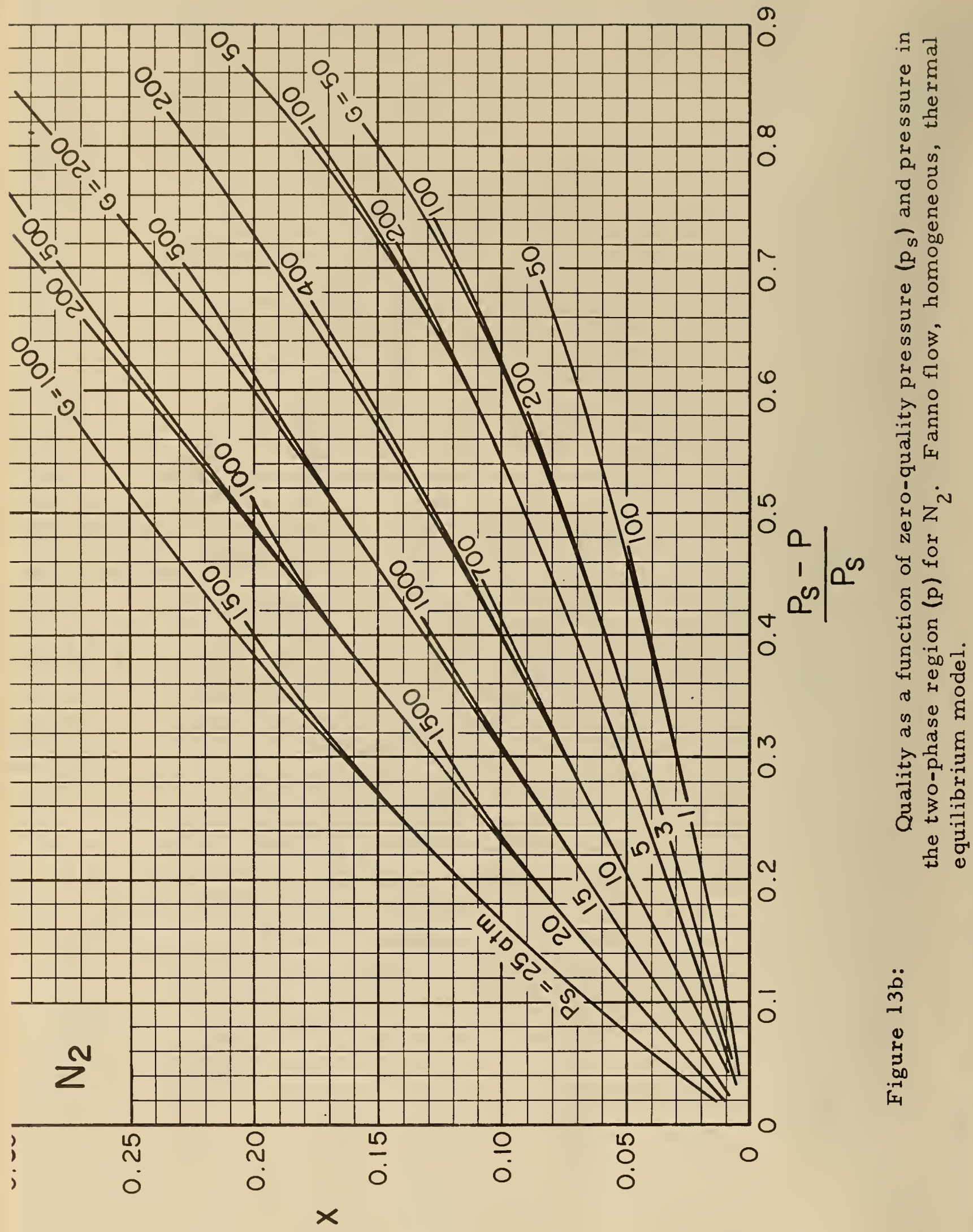




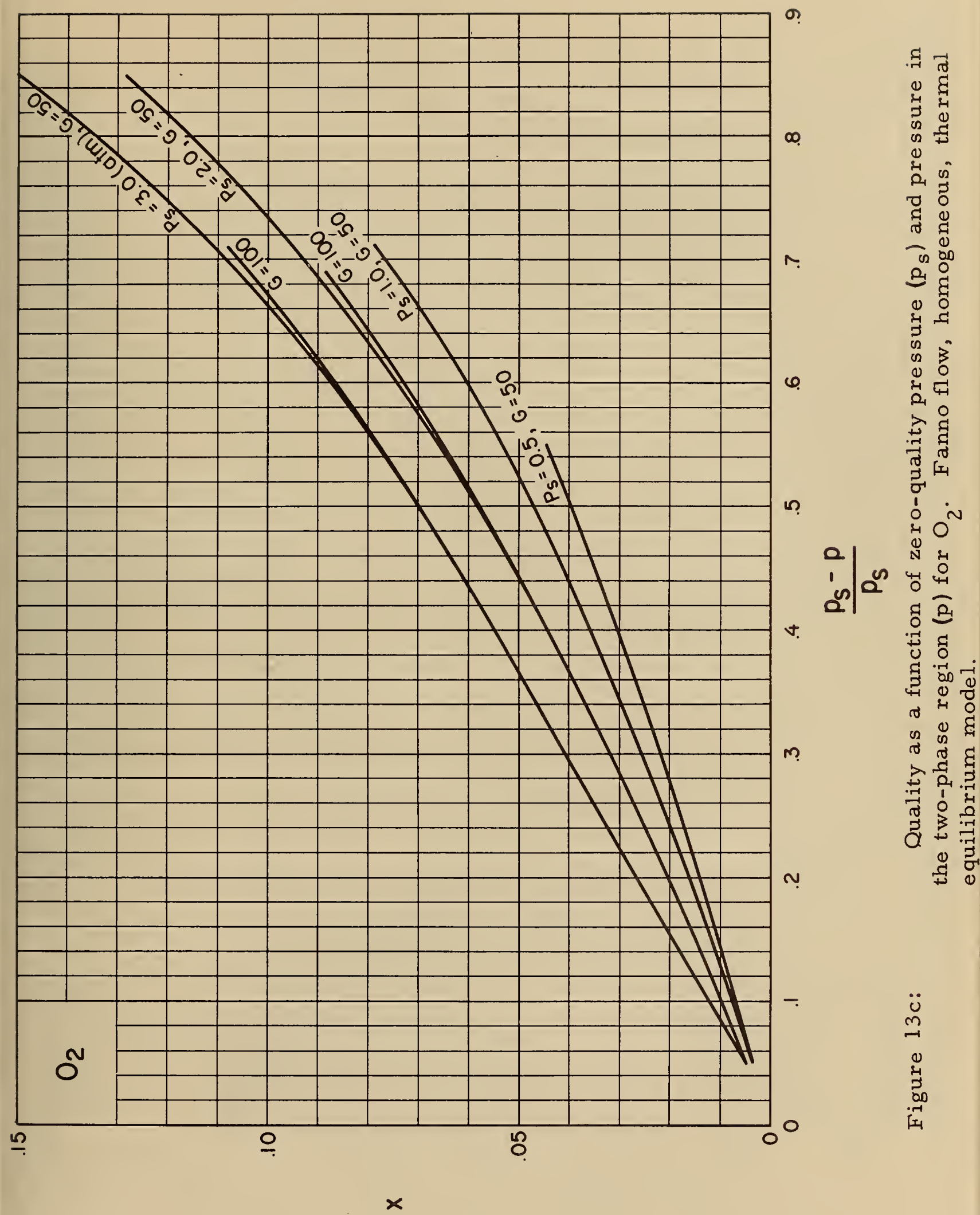




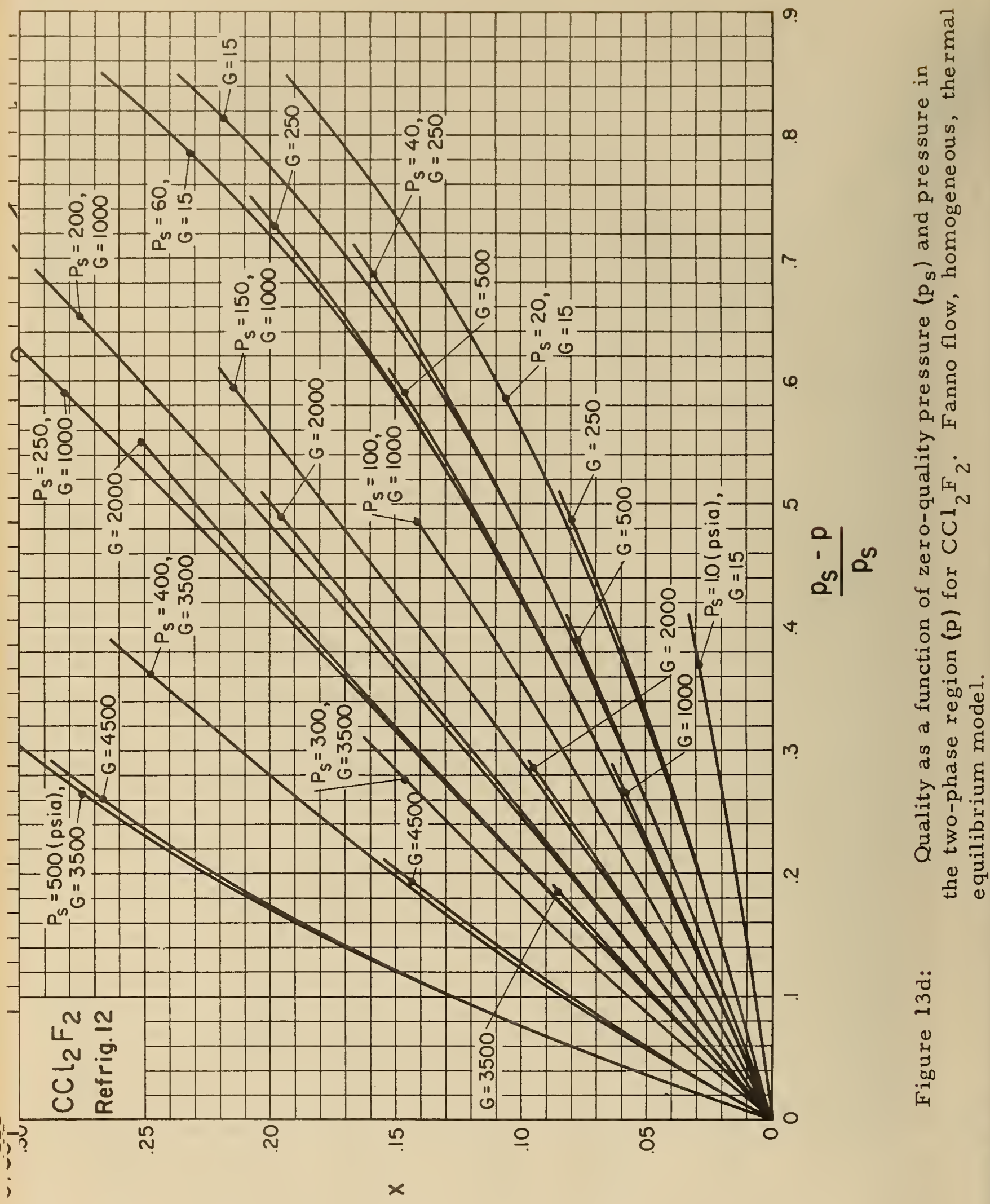




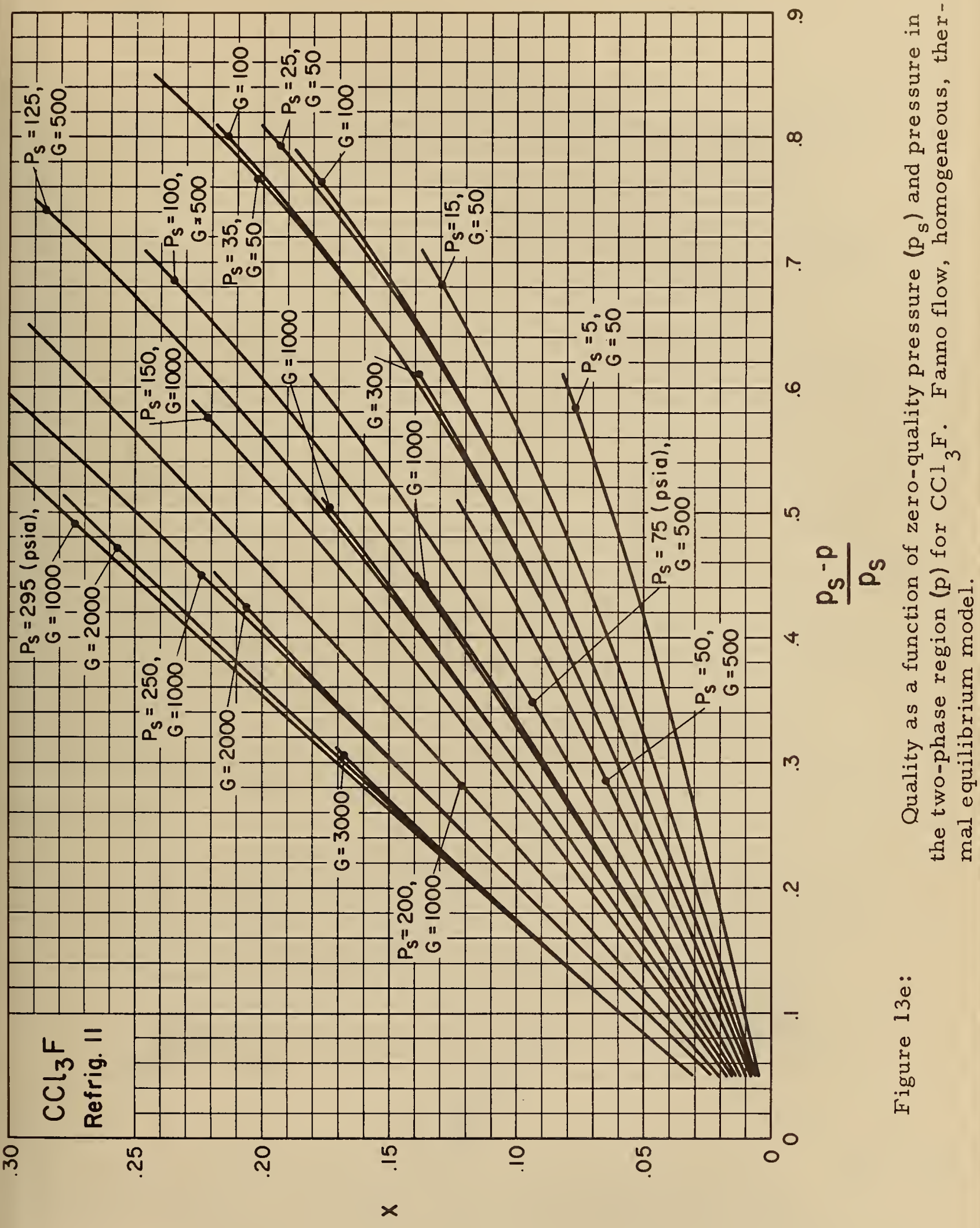




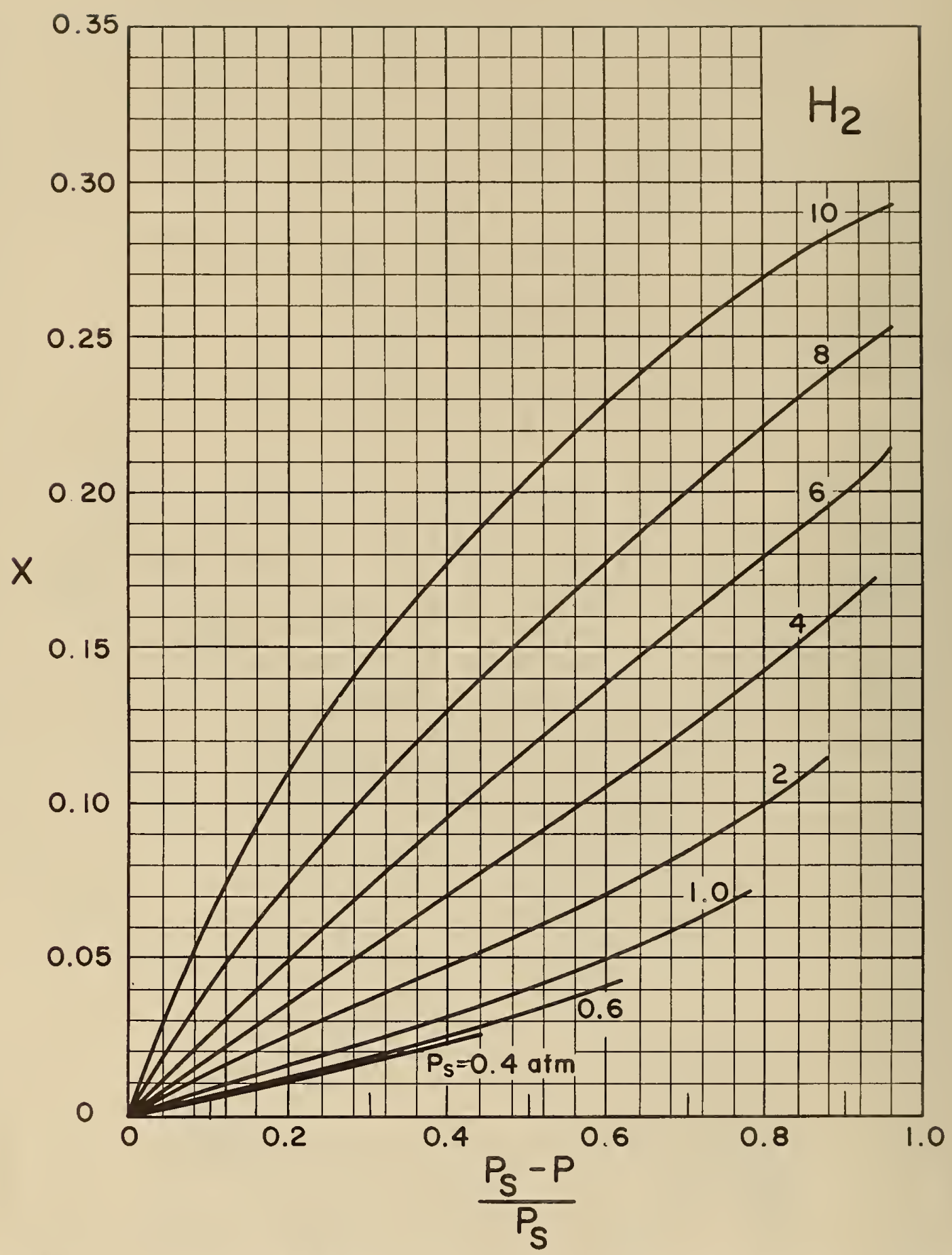

Figure 14a: Quality as a function of zero-quality pressure $\left(p_{s}\right)$ and pressure in the two-phase region ( $\mathrm{p}$ ) for $\mathrm{H}_{2}$. Isentropic flow, homogeneous, thermal equilibrium model.. 


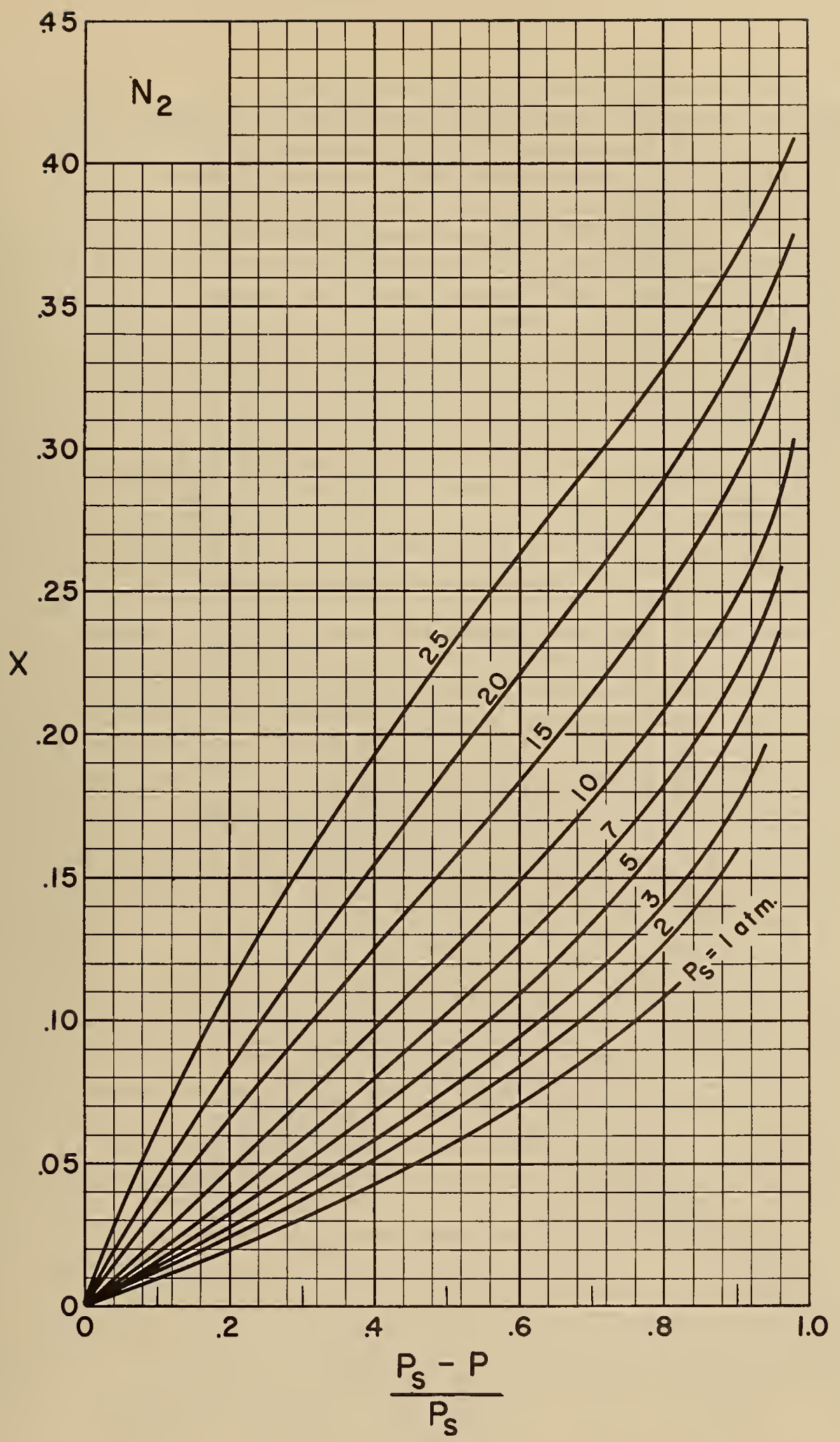

Figure 14b: Quality as a function of zero-quality pressure $\left(\mathrm{p}_{\mathrm{s}}\right.$ ) and pressure in the two-phase region (p) for $\mathrm{N}_{2}$. Isentropic flow, homogeneous, thermal equilibrium model. 


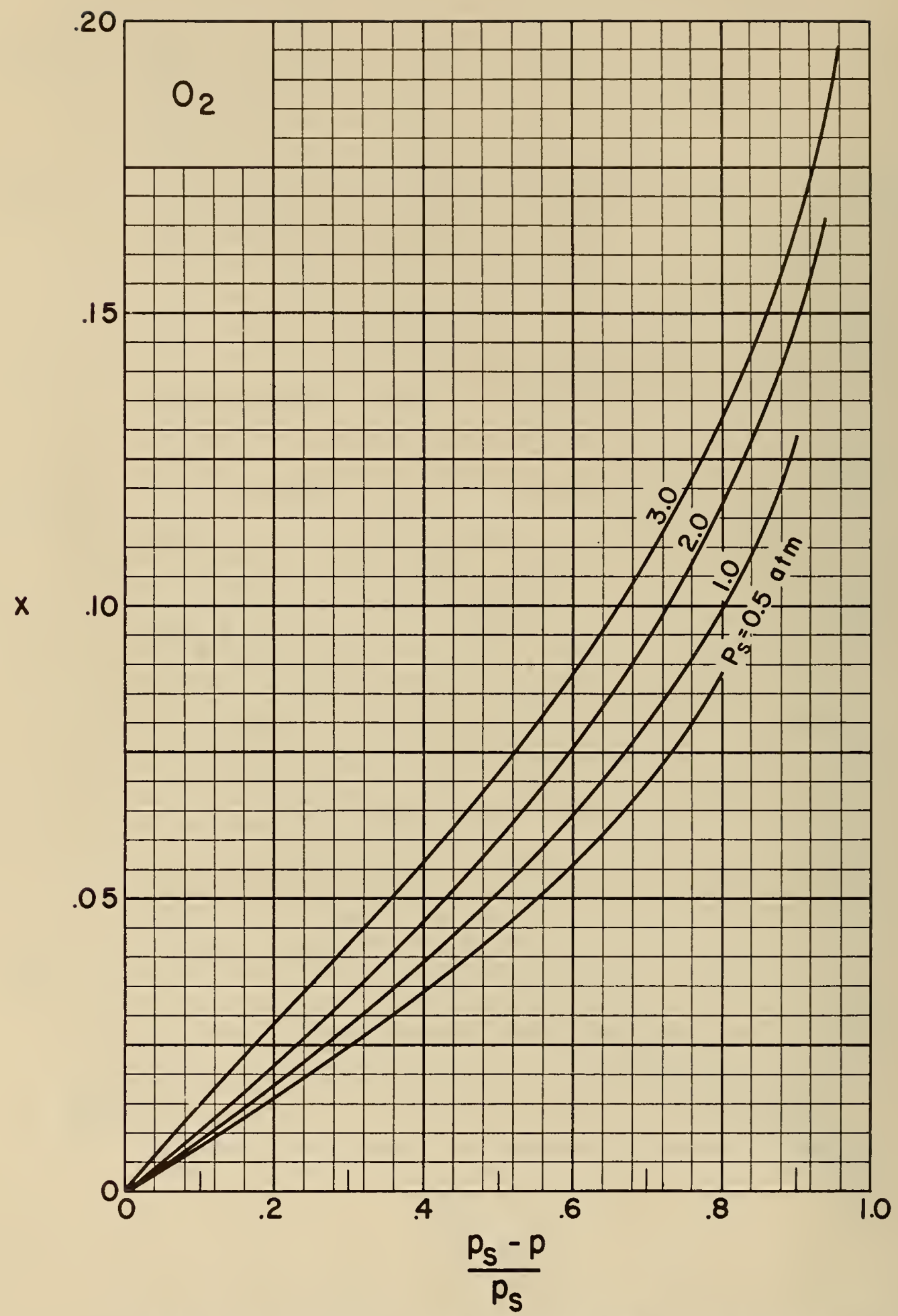

Figure 14c: Quality as a function of zero quality pressure $\left(\mathrm{p}_{\mathrm{s}}\right)$ and pressure in the two-phase region $(p)$ for $\mathrm{O}_{2}$. Isentropic flow, homogeneous, thermal equilibrium model. 


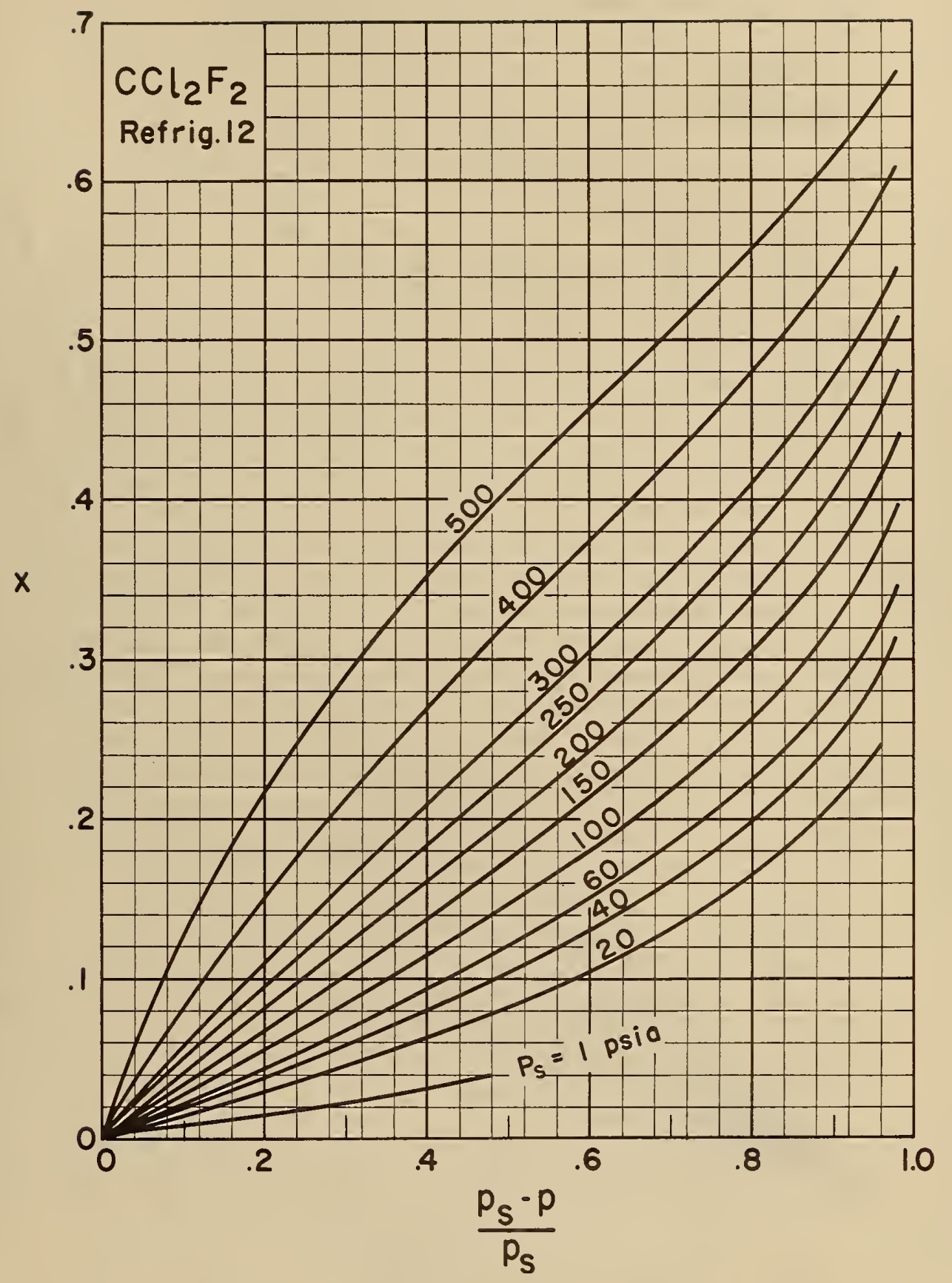

Figure 14d: Quality as a function of zero-quality pressure $\left(p_{s}\right)$ and pressure in the two-phase region ( $p$ ) for $\mathrm{CCl}_{2} F_{2}$. Isentropic flow, homogeneous, the rmal equilibrium model. 


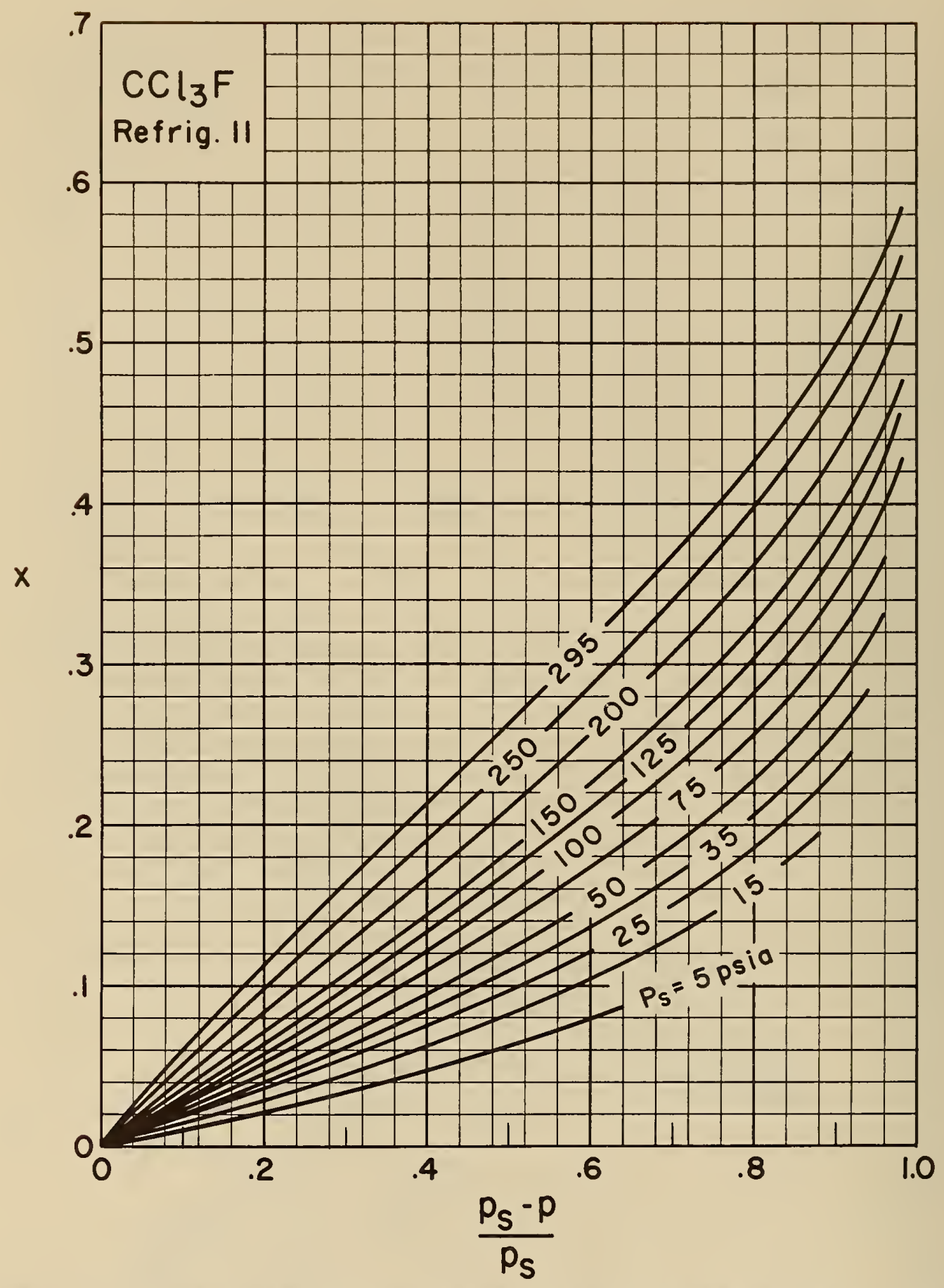

Figure 14e:

Quality as a function of zero-quality pressure $\left(p_{s}\right)$ and pressure in the two-phase region (p) for $\mathrm{CCl}_{3} \mathrm{~F}$. Isentropic flow, homogeneous, thermal equilibrium model. 


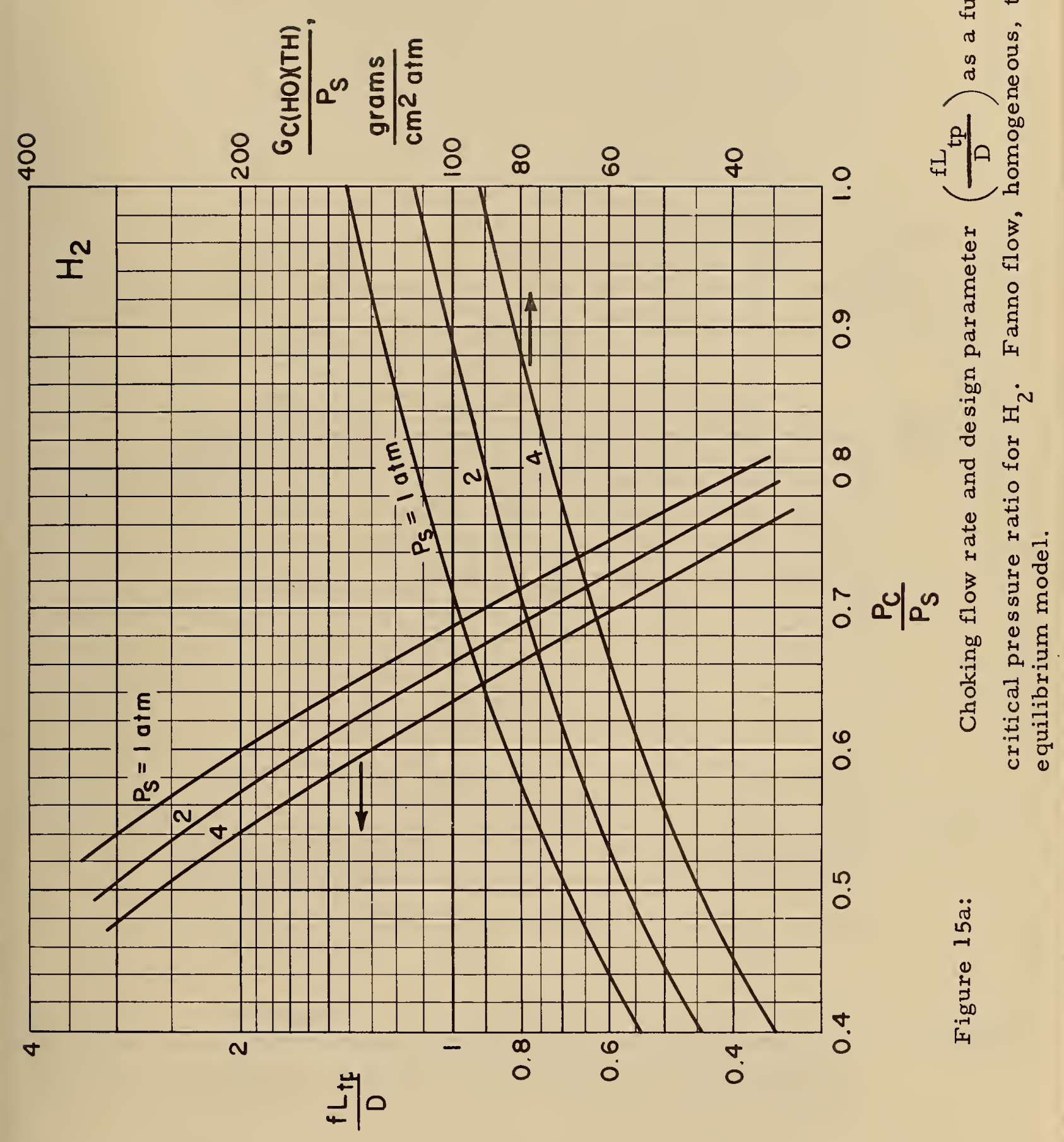




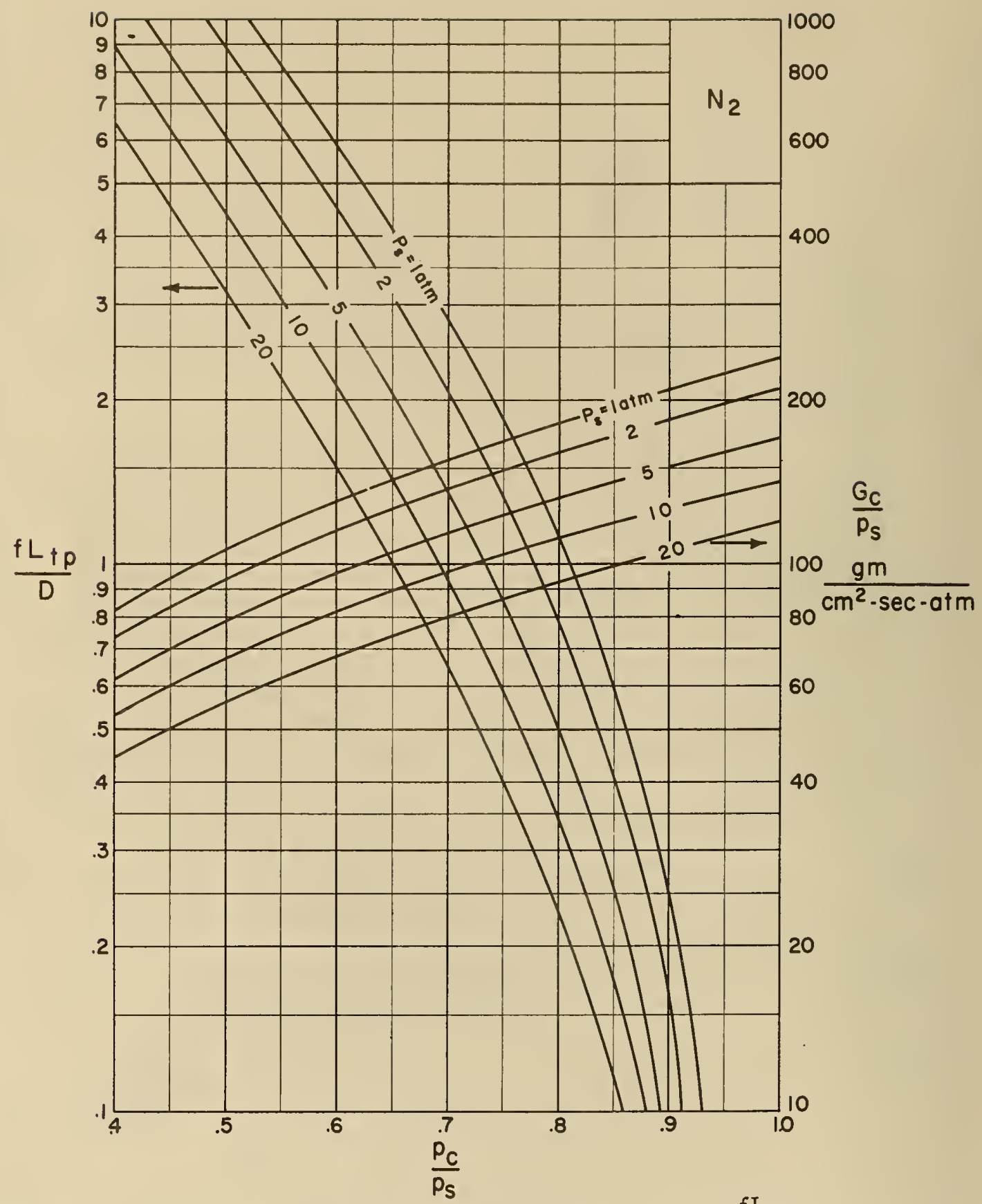

Figure 15b: Choking flow rate and design parameter $\left(\frac{f L}{D}\right)$ as a function of a critical pressure ratio for $\mathrm{N}_{2}$. Fanno flow, homogeneous, thermal equilibrium model. 


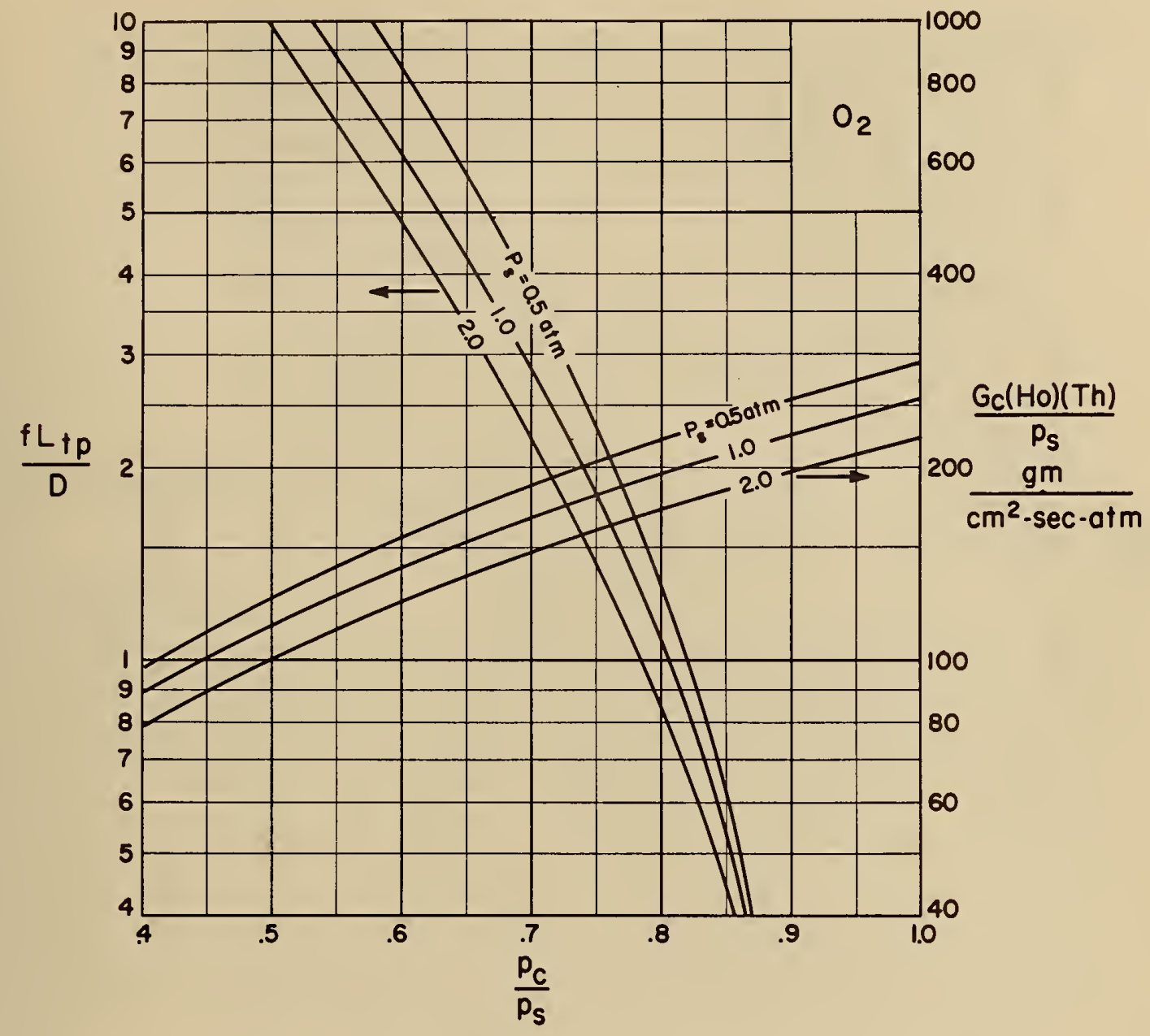

Figure 15c: Choking flow rate and design parameter $\left(\frac{f L t p}{D}\right)$ as a function of a critical pressure ratio for $\mathrm{O}_{2}$. Fanno flow, homogeneous, thermal equilibrium model. 


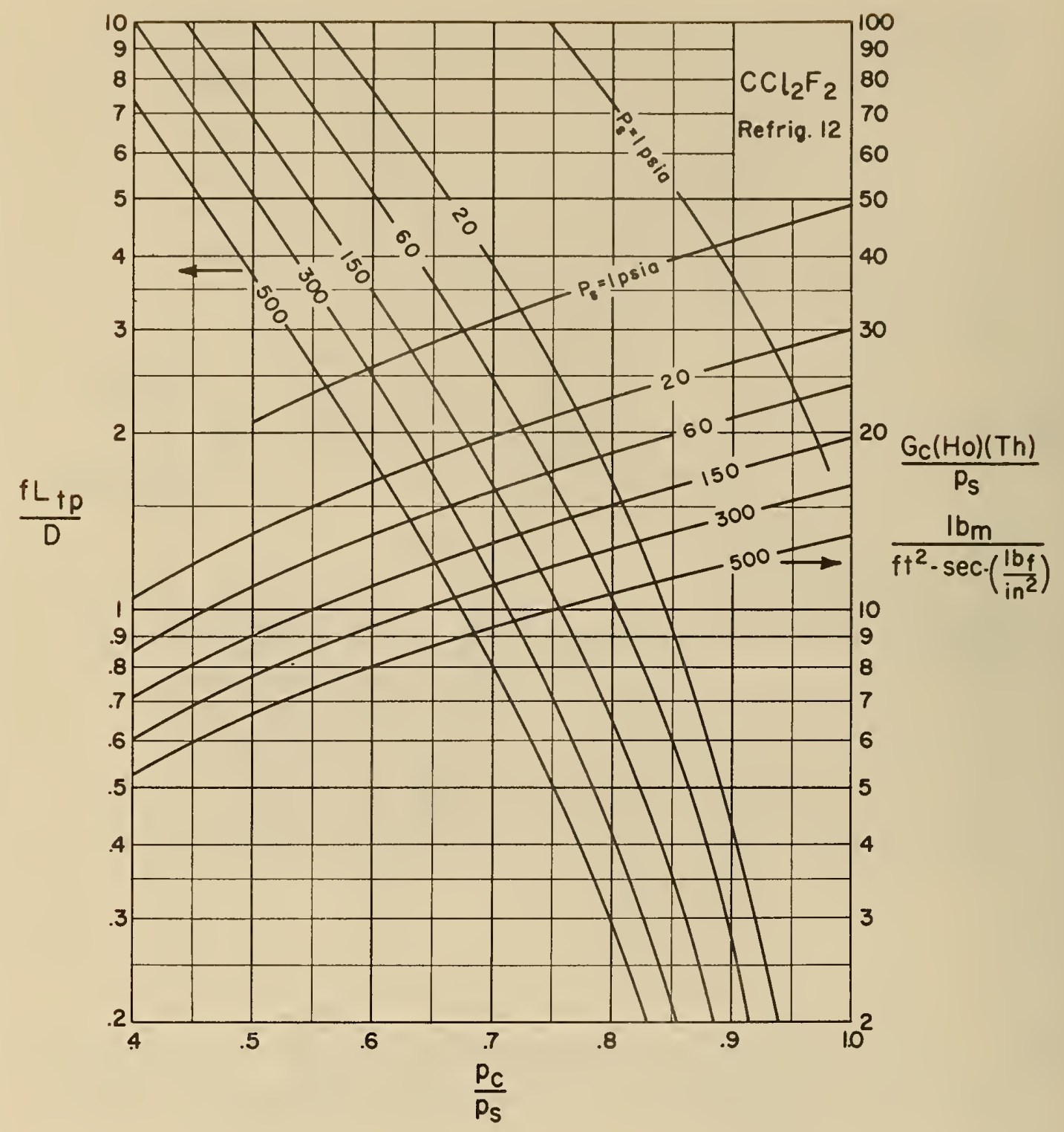

Figure 15d: Choking rate and design parameter $\left(\frac{\mathrm{fL}}{\mathrm{tp}}\right)$ as a function of a critical pressure ratio for $\mathrm{CCl}_{2} \mathrm{~F}_{2}$. Fanno flow, homogeneous, thermal equilibrium model. 


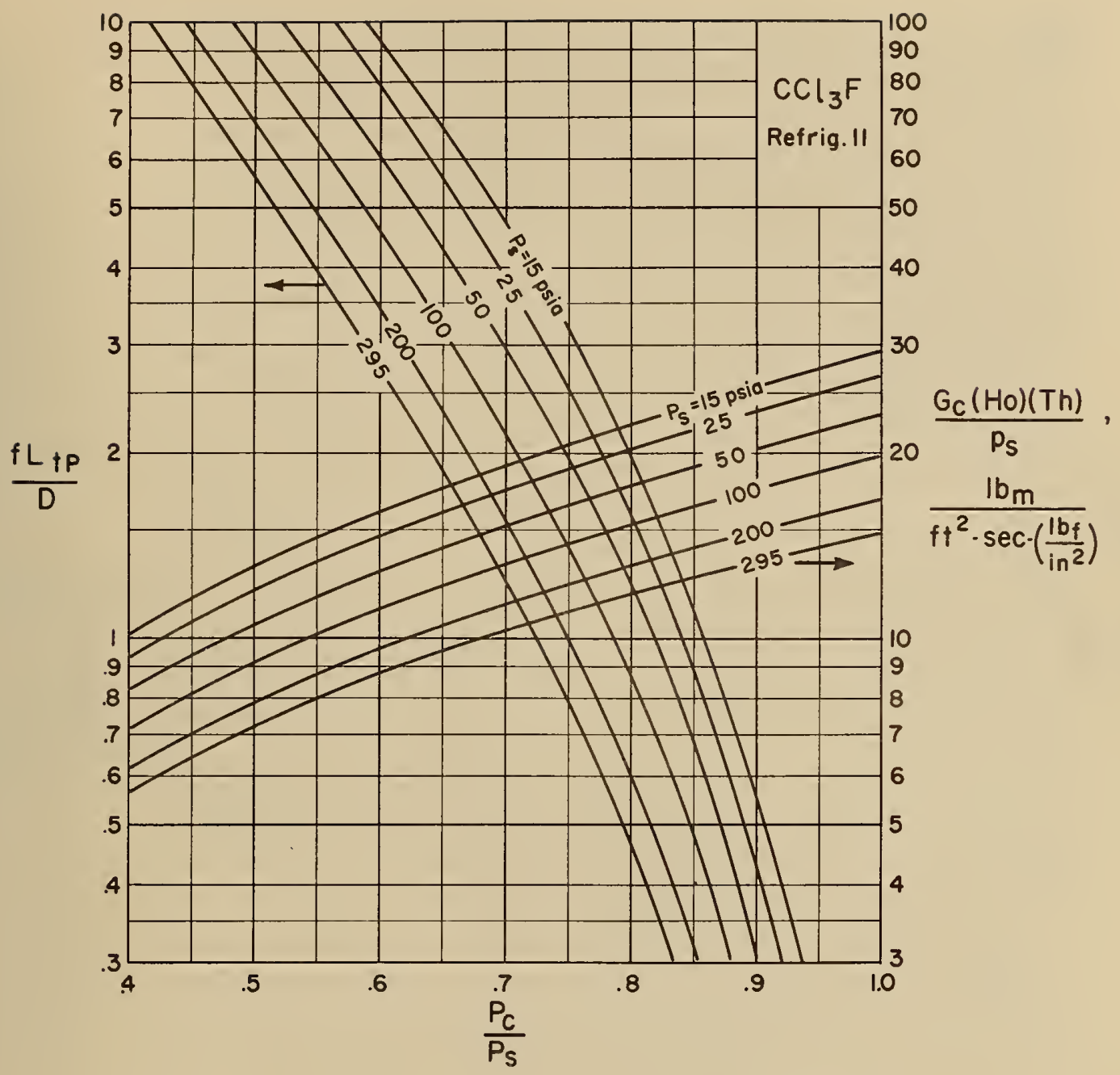

Figure 15e: Choking rate and design parameter $\left(\frac{f L_{t p}}{D}\right)$ as a function of a critical pressure ratio for $\mathrm{CCl}_{3} \mathrm{~F}$. Fanno flow, homogeneous, the rmal equilibrium model. 


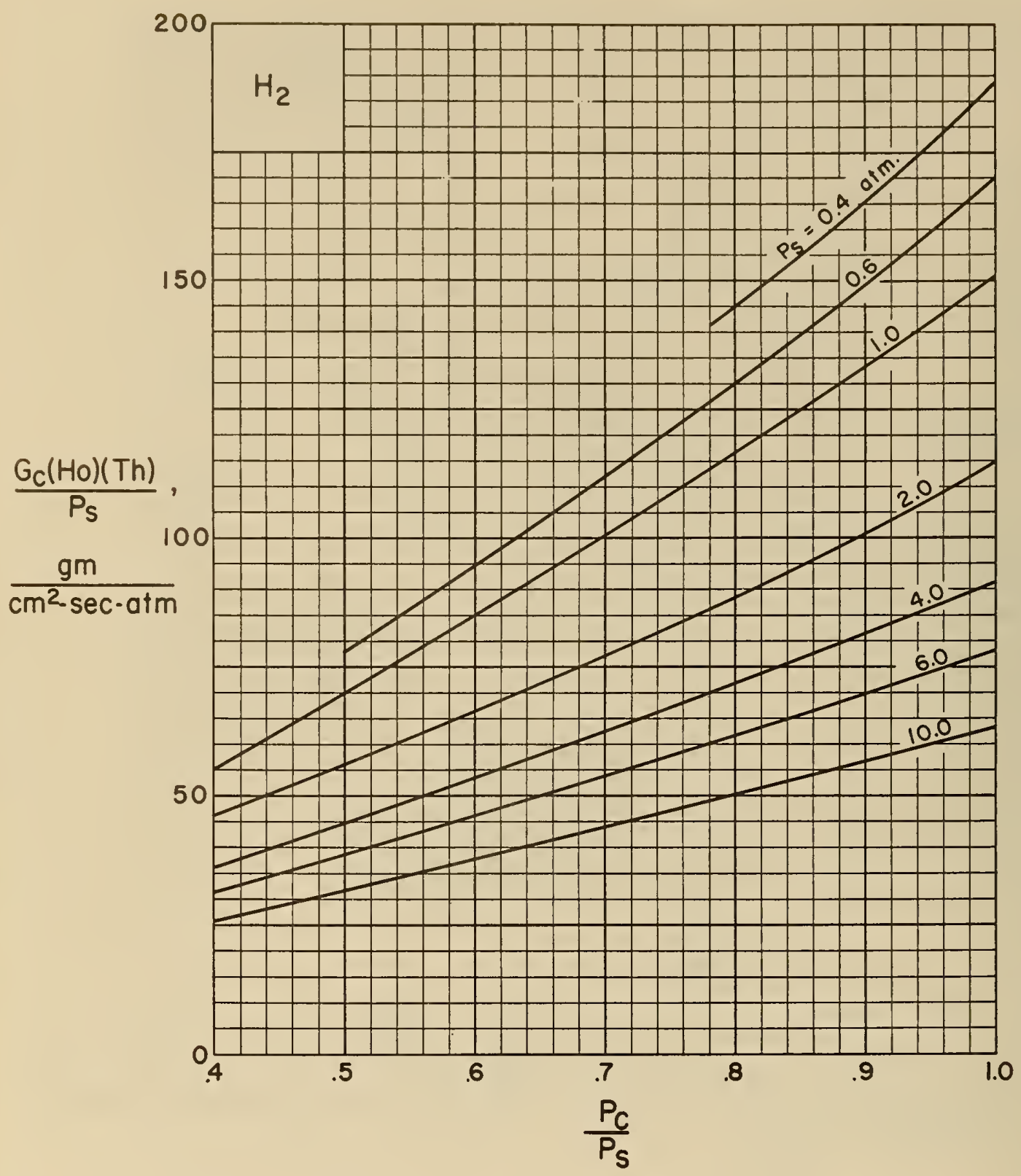

Figure 16a: Choking flow rate as a function of a critical-pressure ratio for $\mathrm{H}_{2}$. Isentropic flow, homogeneous, thermal equilibrium model. 


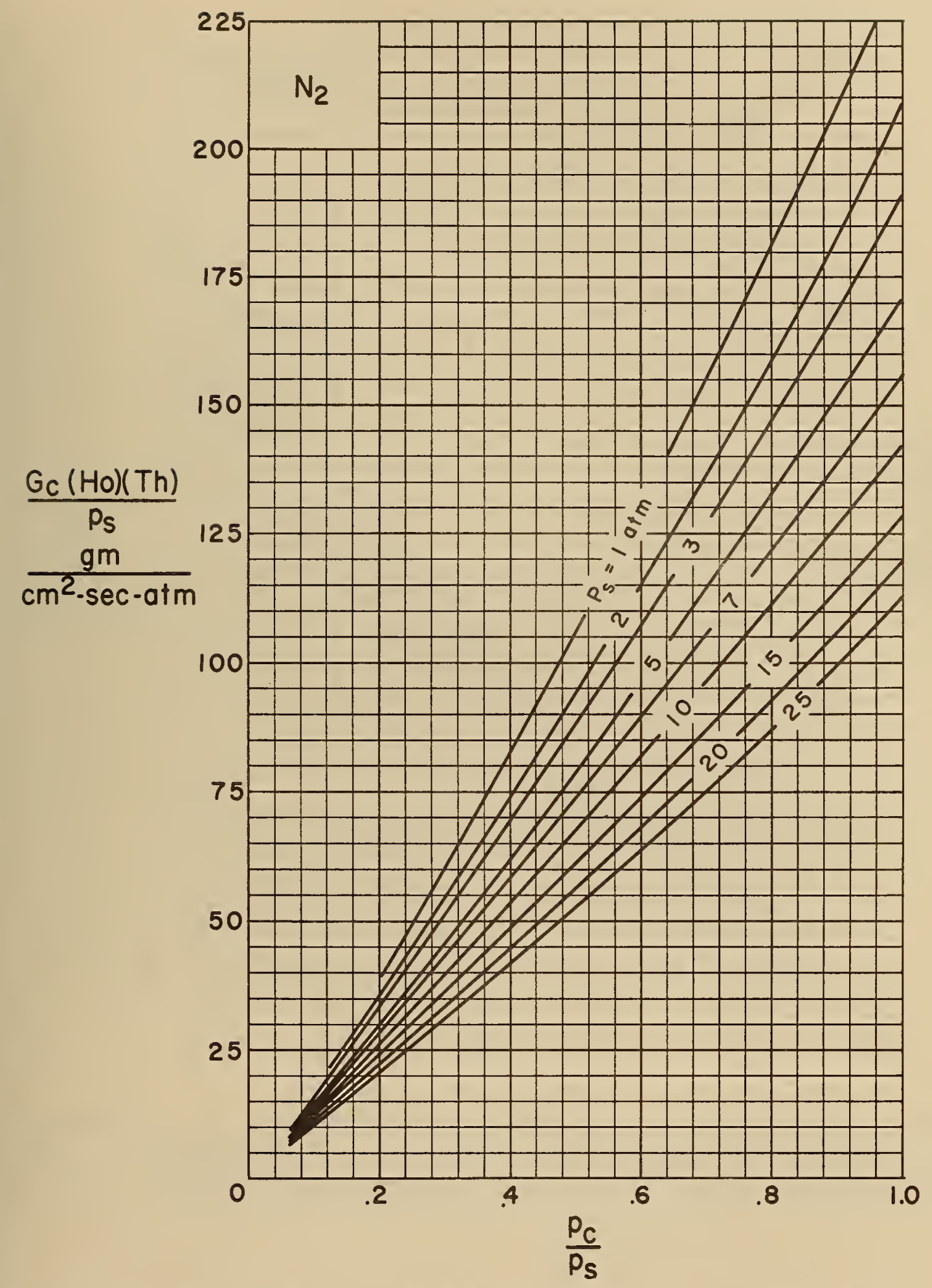

Figure 16b: Choking flow rate as a function of a critical pressure ratio for $\mathrm{N}_{2}$. Isentropic flow, homogeneous, thermal equilibrium model. 


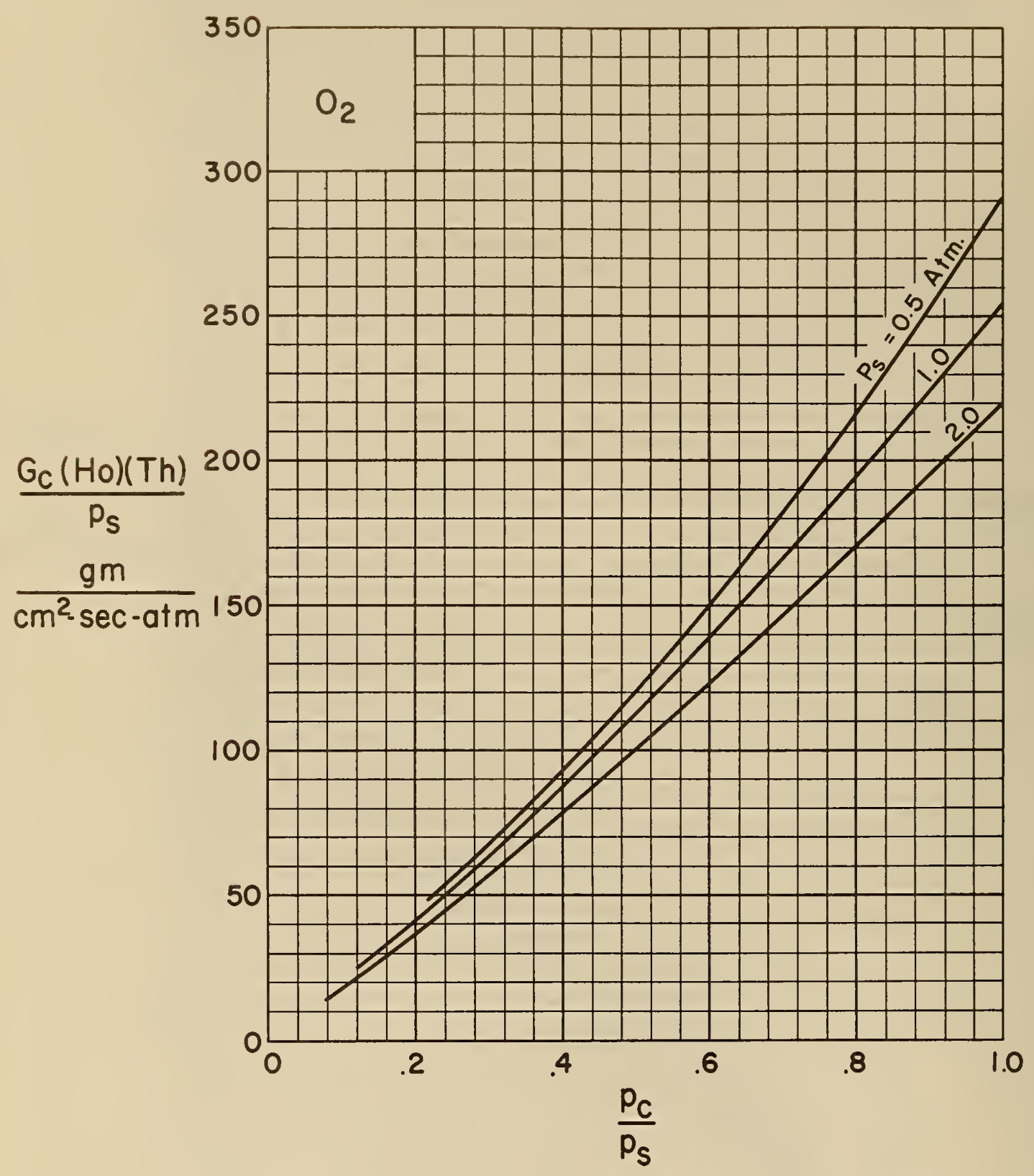

Figure 16c: Choking flow rate as a function of a critical-pressure ratio for $\mathrm{O}_{2}$. Isentropic flow, homogeneous, thermal equilibrium model. 


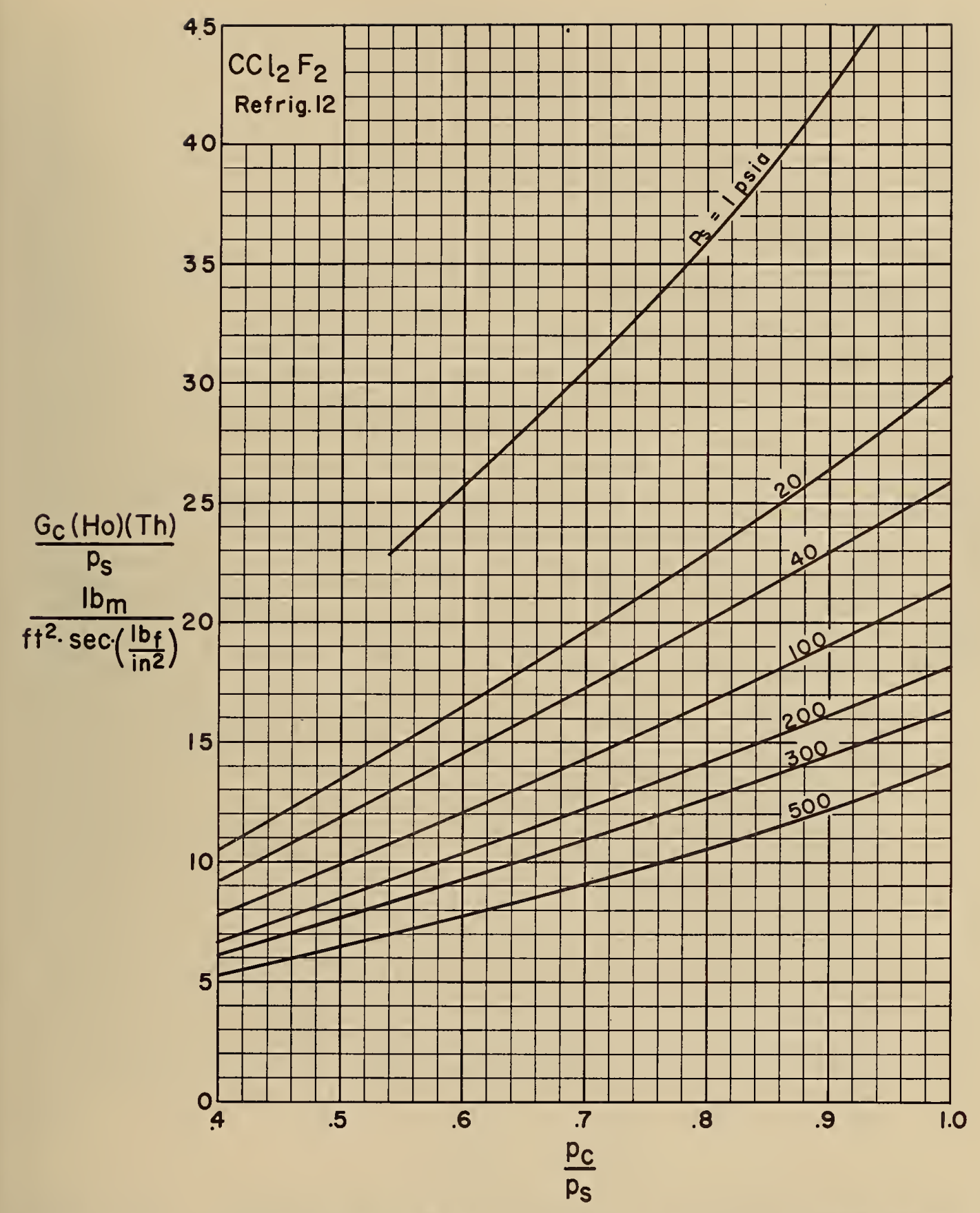

Figure 16d: Choking flow rate as a function of a critical-pressure ratio for $\mathrm{CCl}_{2} \mathrm{~F}_{2}$. Isentropic flow, homogeneous, thermal equilibrium model. 


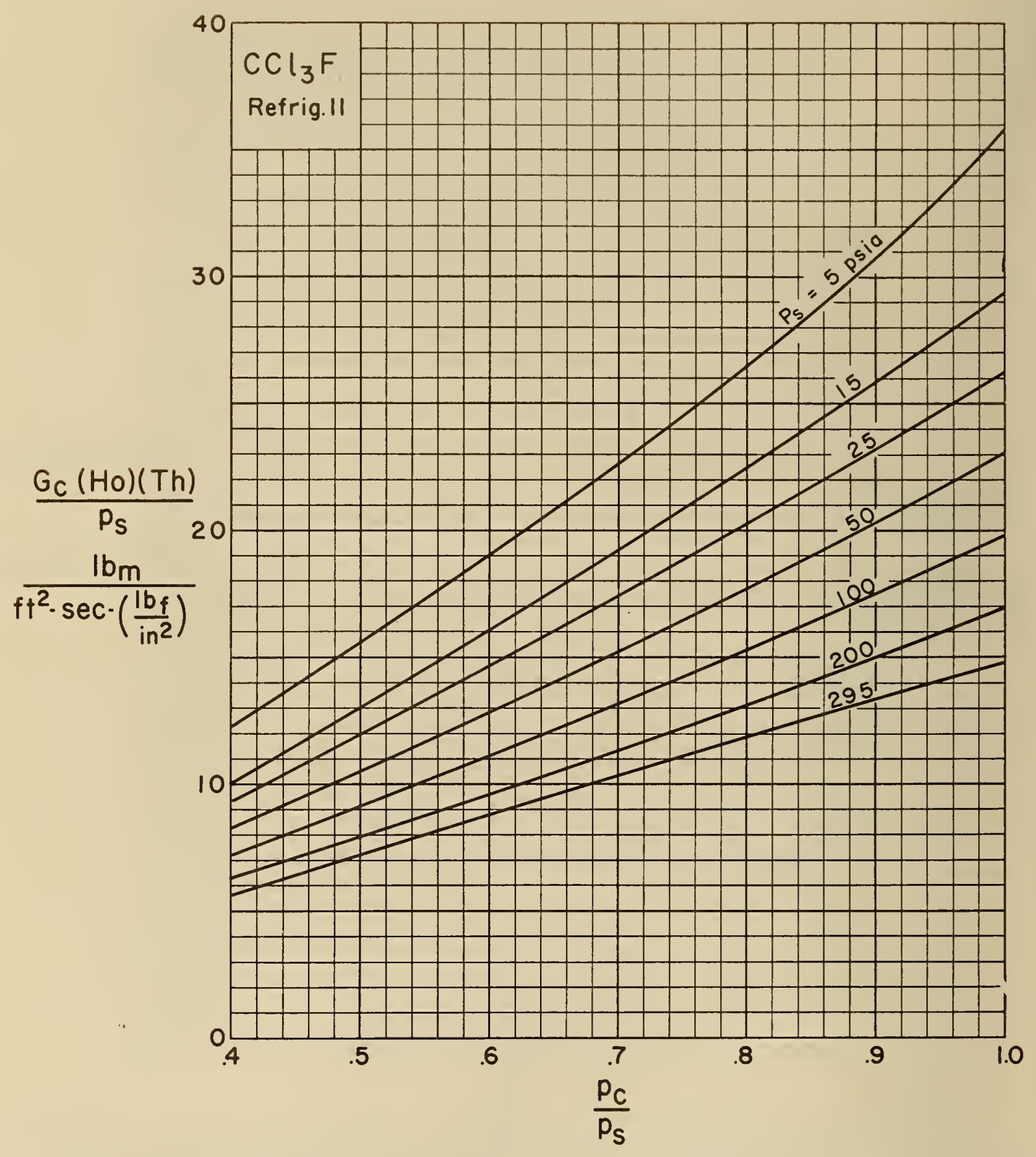

Figure 16e: Choking flow rate as a function of a critical-pressure ratio for $\mathrm{CCl}_{3} \mathrm{~F}$. Isentropic flow, homogeneous, thermal equilibrium model. 


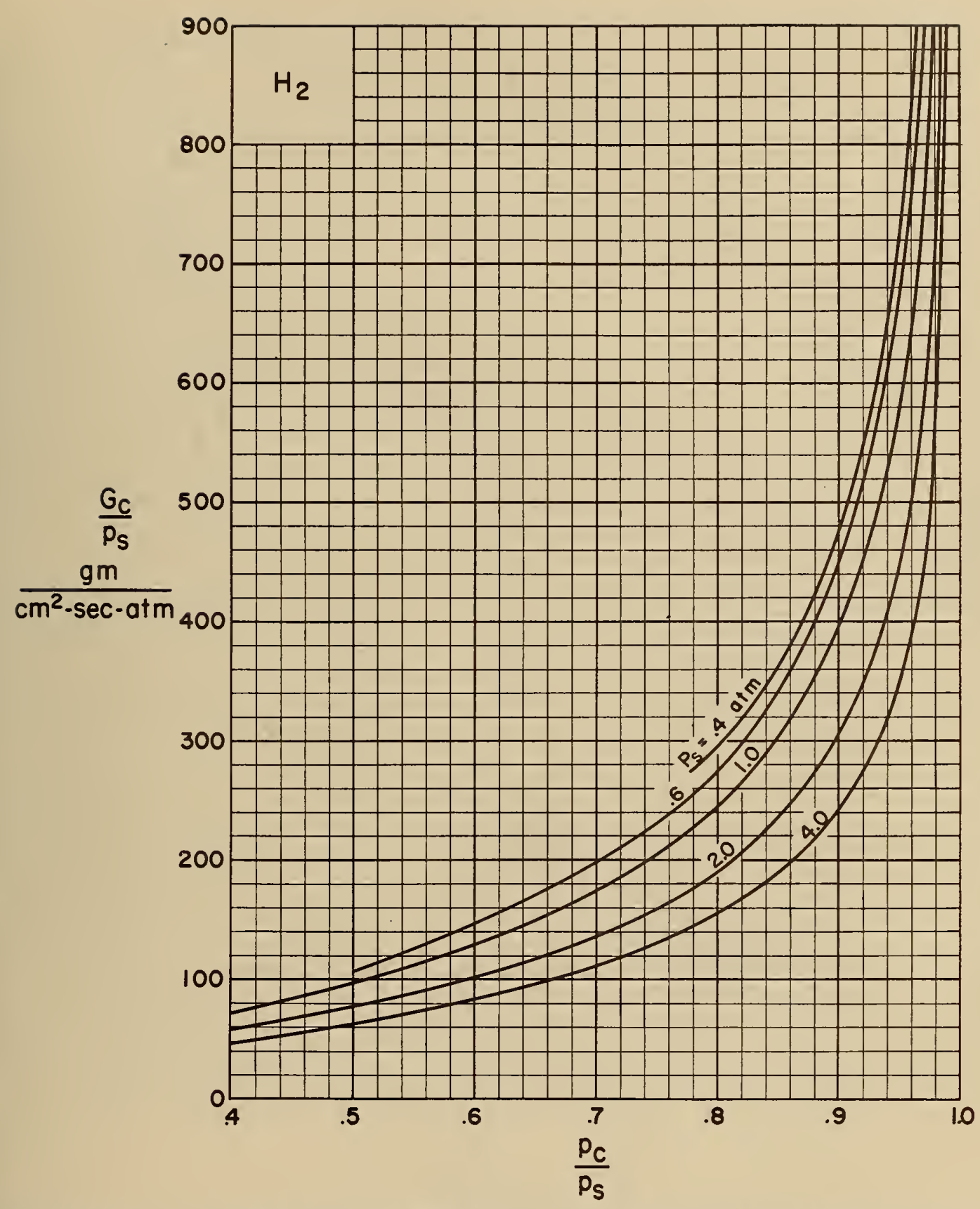

Figure 17a: Choking flow rate as a function of a critical pressure ratio for $\mathrm{H}_{2}$. Isentropic flow, homogeneous, thermal equilibrium model to the point of choking, homogeneous, metastable model at the choking point. 


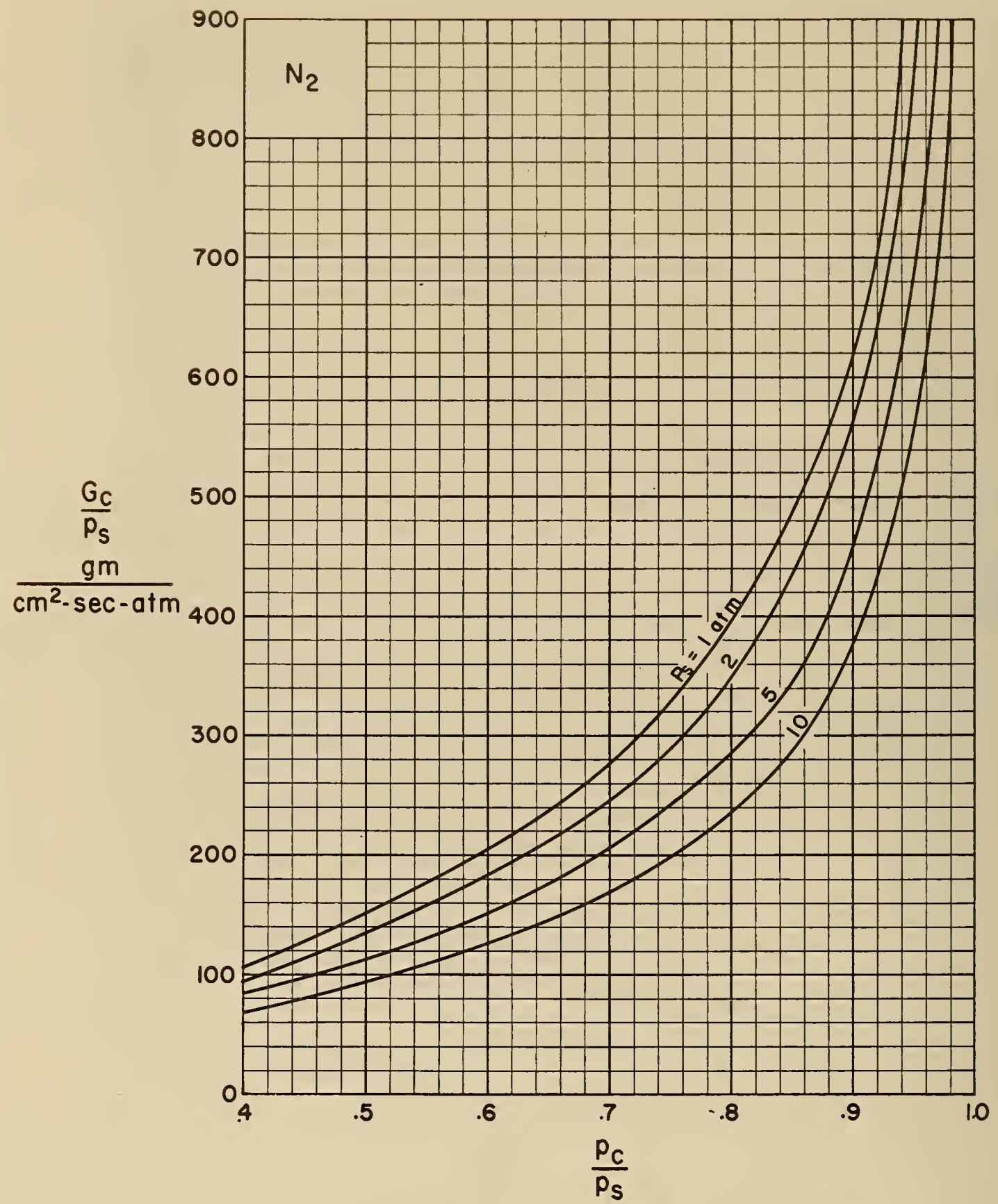

Figure 17b: Choking flow rate as a function of a critical pressure ratio for $\mathrm{N}_{2}$. E Isentropic flow, homogeneous, thermal equilibrium model to the point of choking, homogeneous, metastable model at the choking point. 


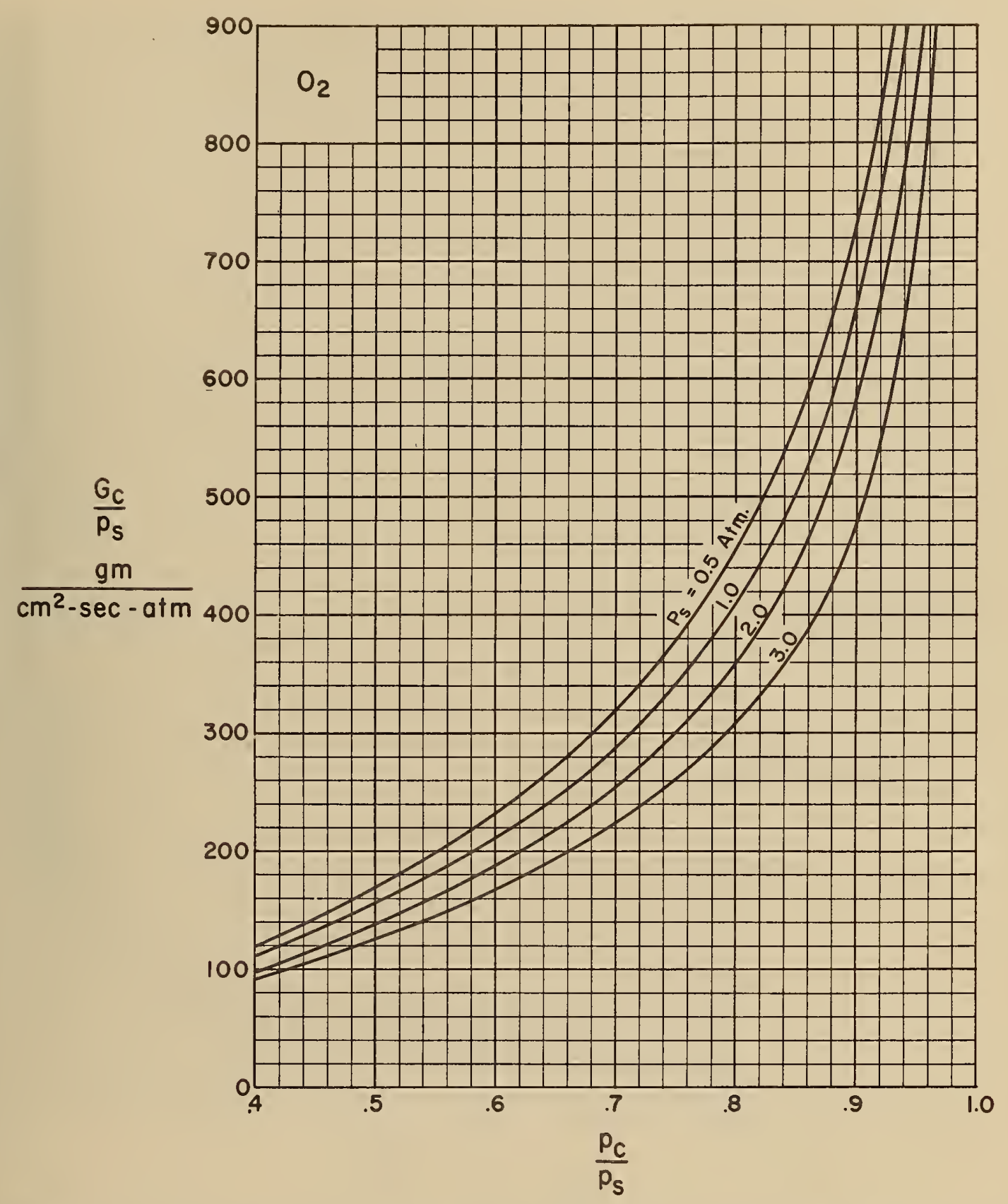

Figure 17c: Choking flow rate as a function of a critical pressure ratio for $\mathrm{O}_{2}$. Isentropic flow, homogeneous, thermal equilibrium model to the point of choking, homogeneous, metastable model at the choking point. 


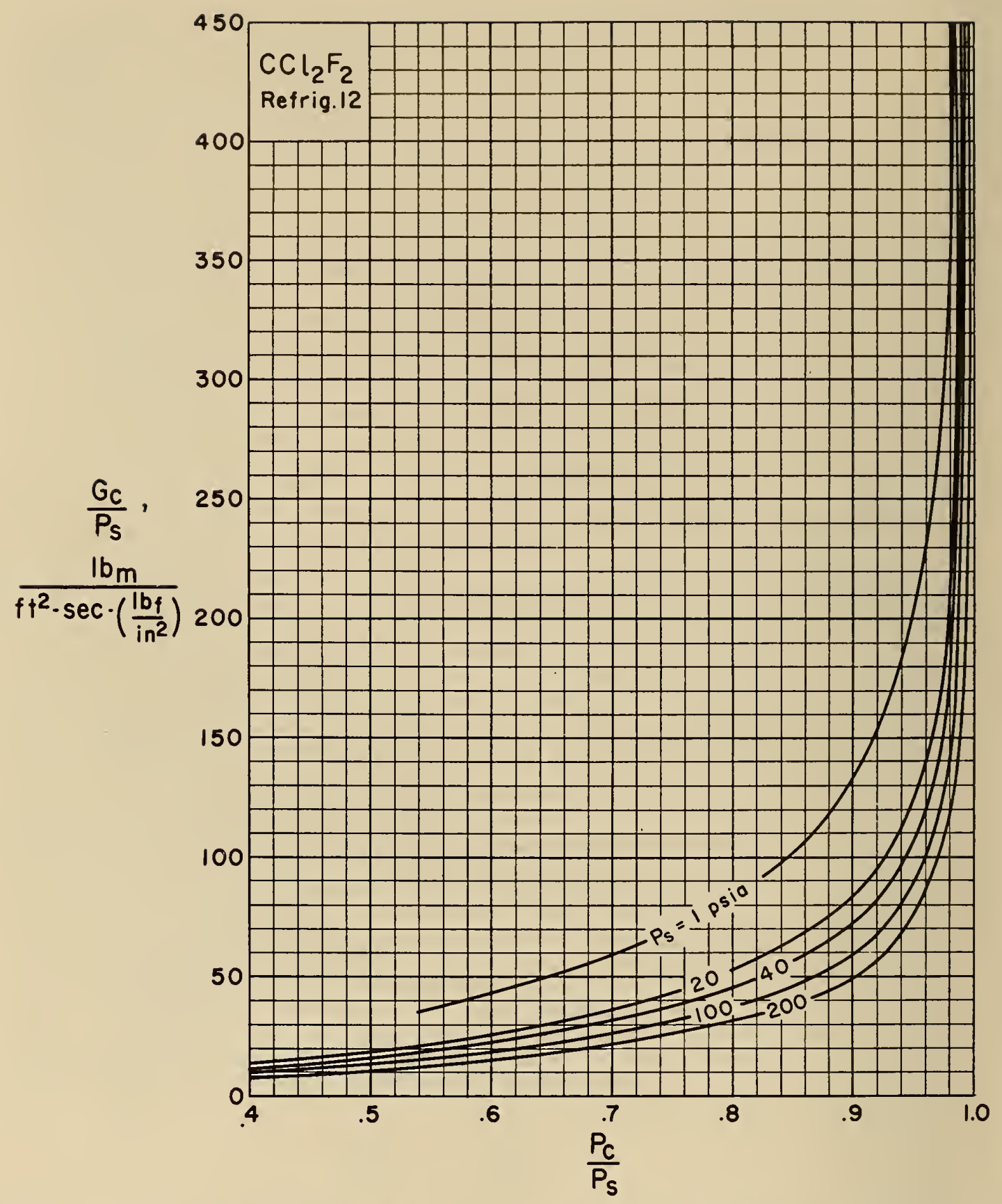

Figure 17d: Choking flow rate as a function of a critical pressure ratio for $\mathrm{CCl}_{2} \mathrm{~F}_{2}$. Isentropic flow, homogeneous, thermal equilibrium model to the point of choking, homogeneous, metastable model at the choking point. 


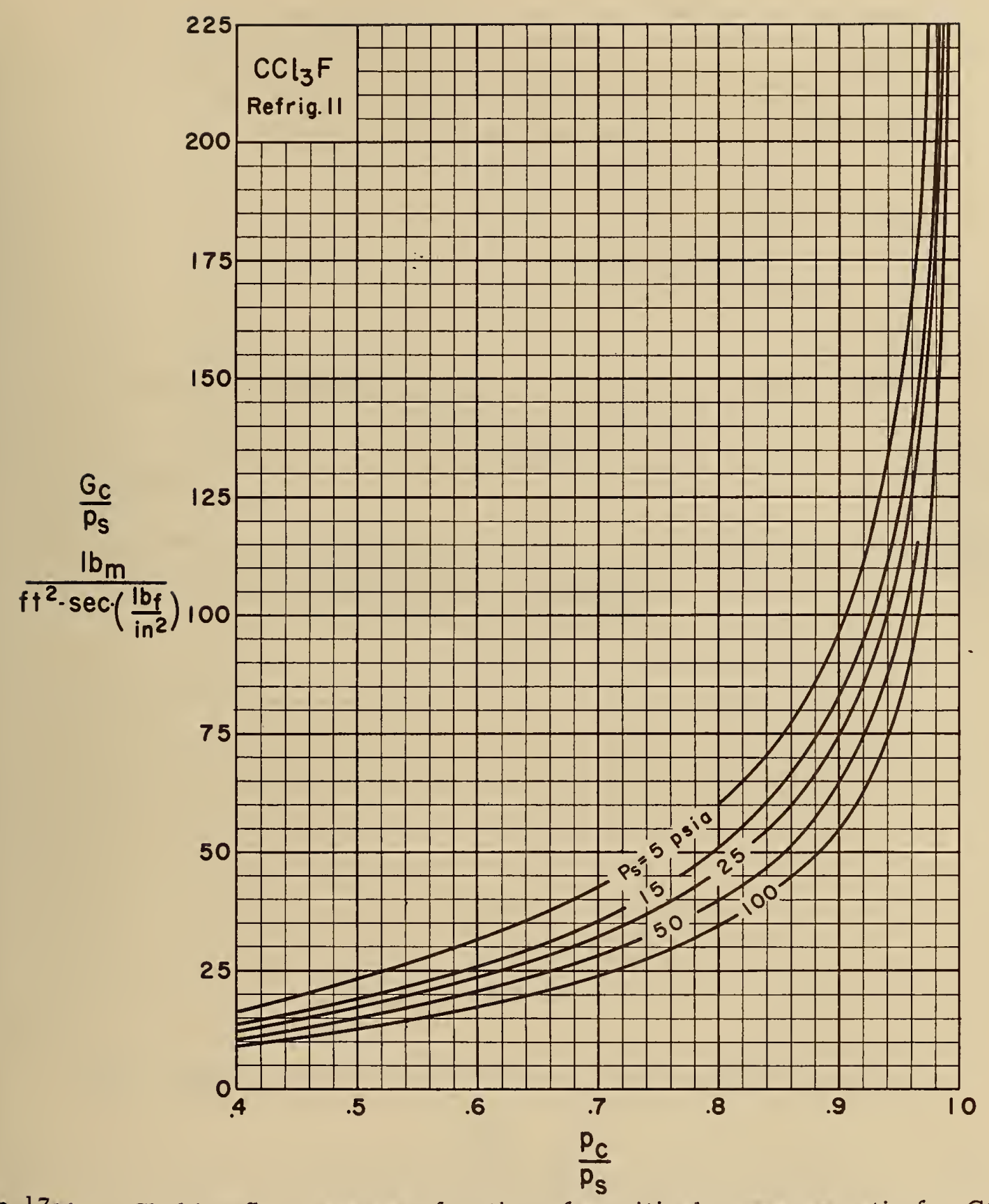

Figure 17e: Choking flow rate as a function of a critical pressure ratio for $\mathrm{CCl}_{3} \mathrm{~F}$. Isentropic flow, homogeneous, thermal equilibrium model to the point of choking, homogeneous, metastable model at the choking point. 


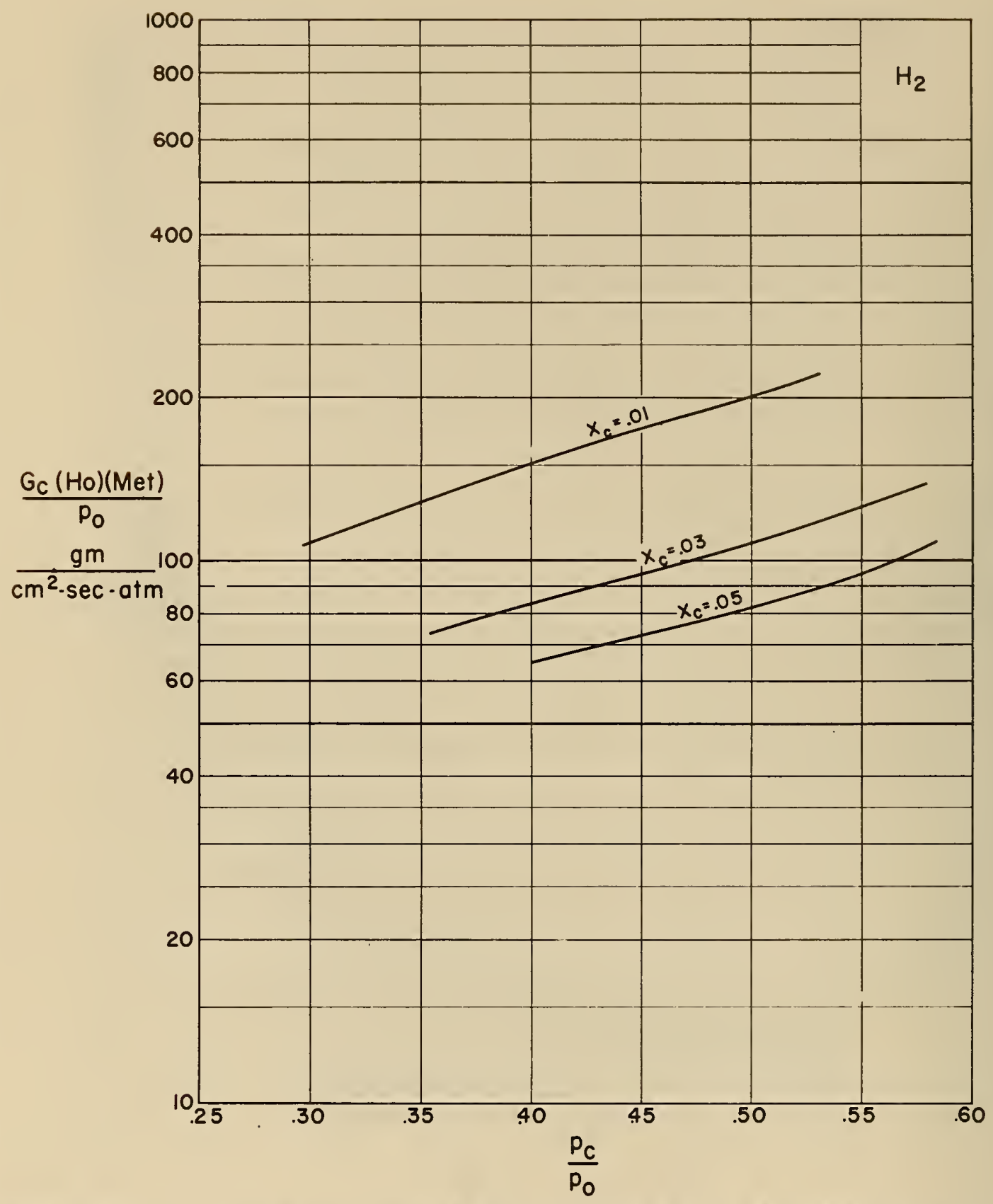

Figure 18a: Choking flow rate as a function of a critical pressure ratio for $\mathrm{H}_{2}$. Isentropic flow, homogeneous, metastable model for the flow process and at the point of choking. 


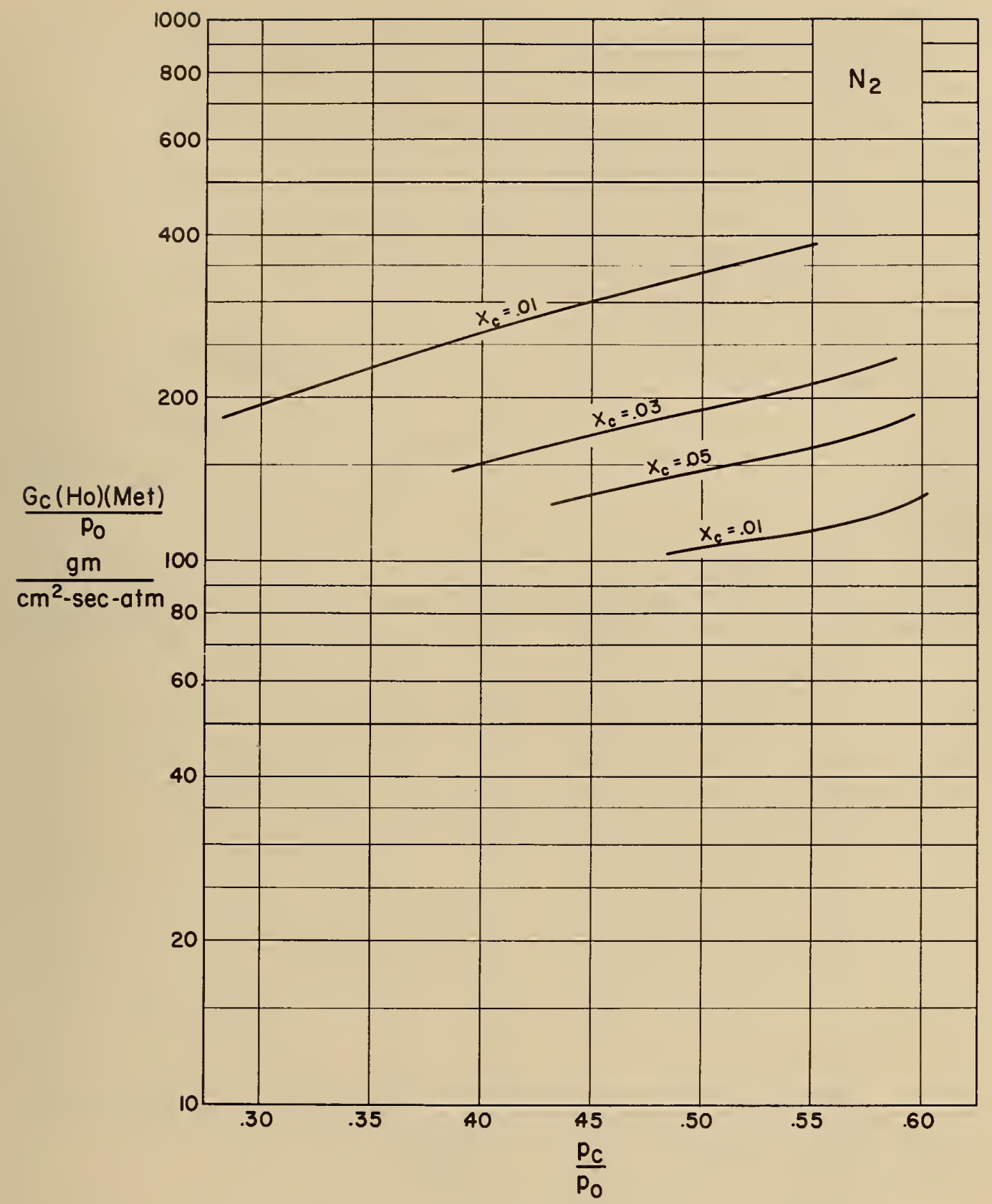

Figure 18b: Choking flow rate as a function of a critical pressure ratio for $\mathrm{N}_{2}$. Isentropic flow, homogeneous, metastable model for the flow process and at the point of choking. 


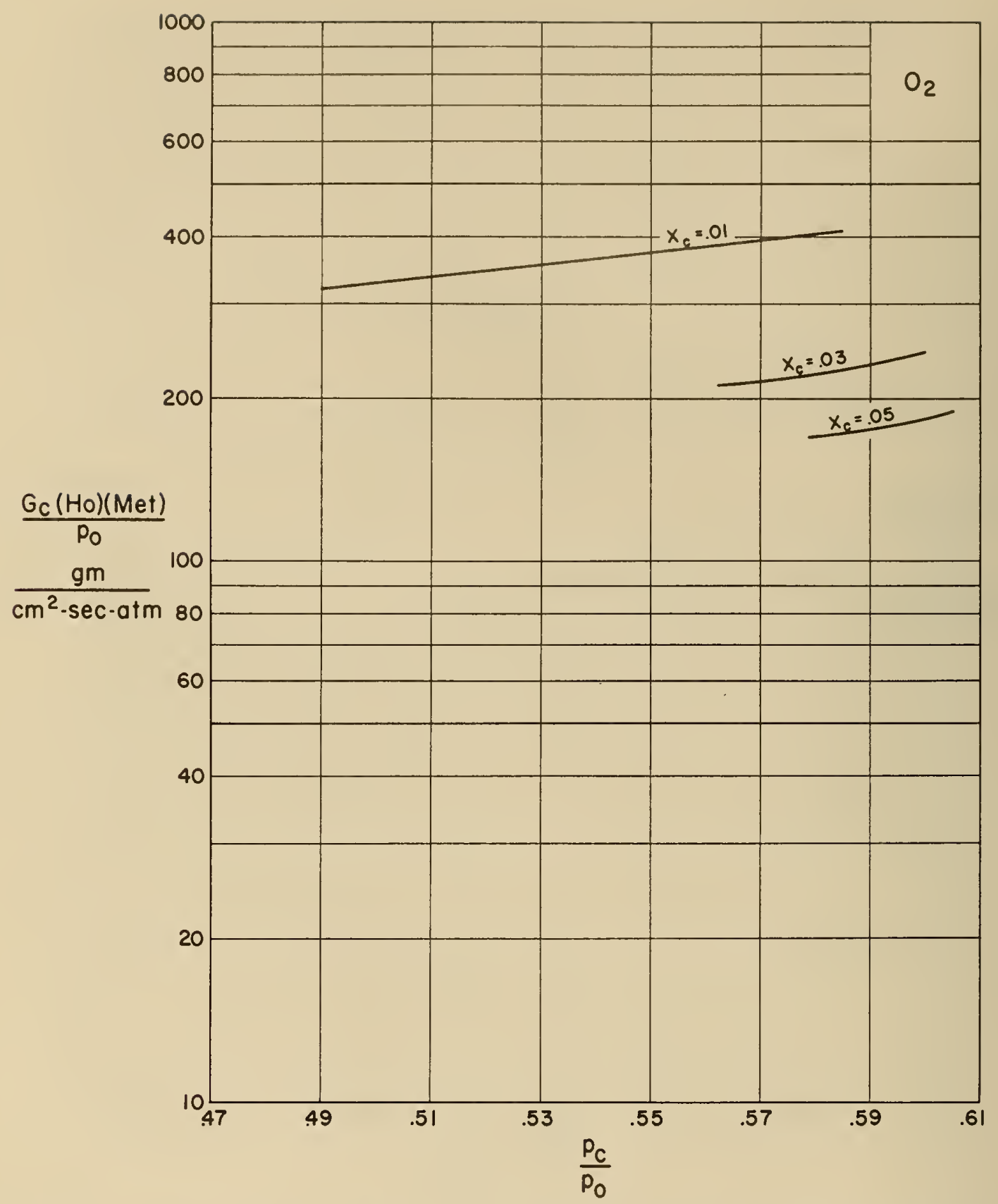

Figure 18c: Choking flow rate as a function of a critical pressure ratio for $\mathrm{O}_{2}$. Isentropic flow, homogeneous, metastable model for the flow process and at the point of choking. 


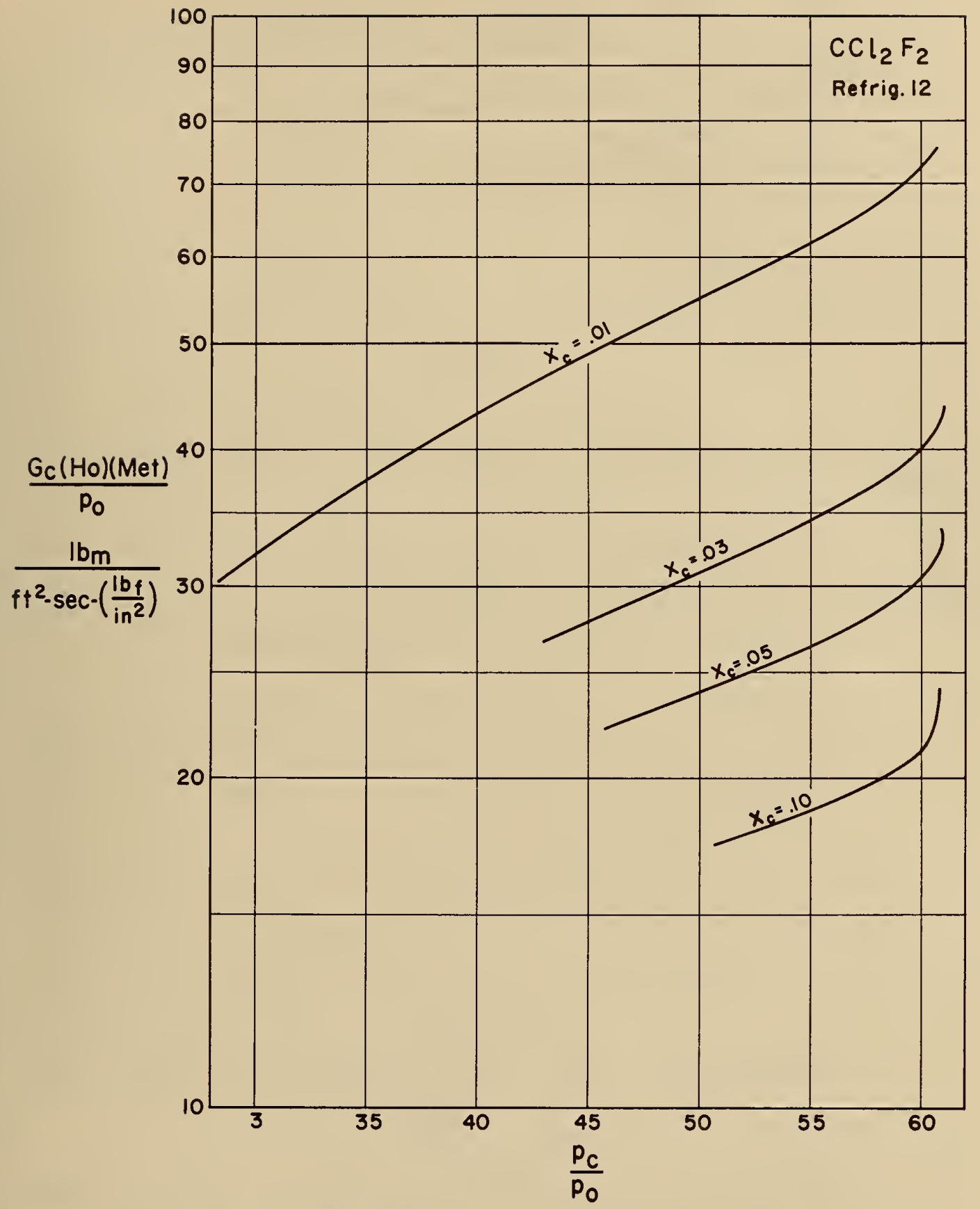

Figure 18d: Choking flow rate as a function of a critical pressure ratio for $\mathrm{CCl}_{2} \mathrm{~F}_{2}$. Isentropic flow, homogeneous, metastable model for the flow process and at the point of choking. 


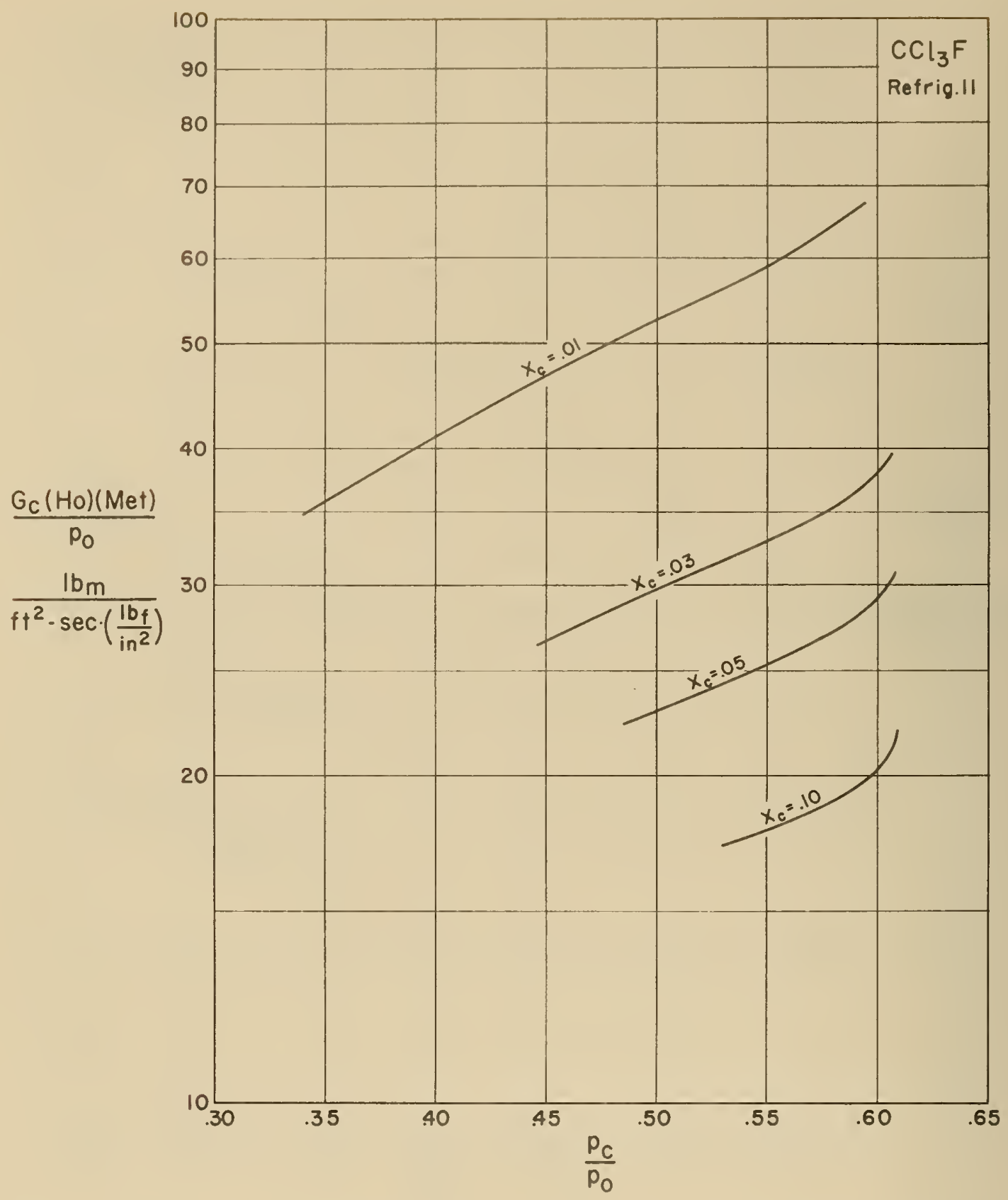

Figure 18e: Choking flow rate as a function of a critical pressure ratio for $\mathrm{CCl}_{3} \mathrm{~F}$. Isentropic flow, homogeneous, metastable model for the flow process and at the point of choking. 


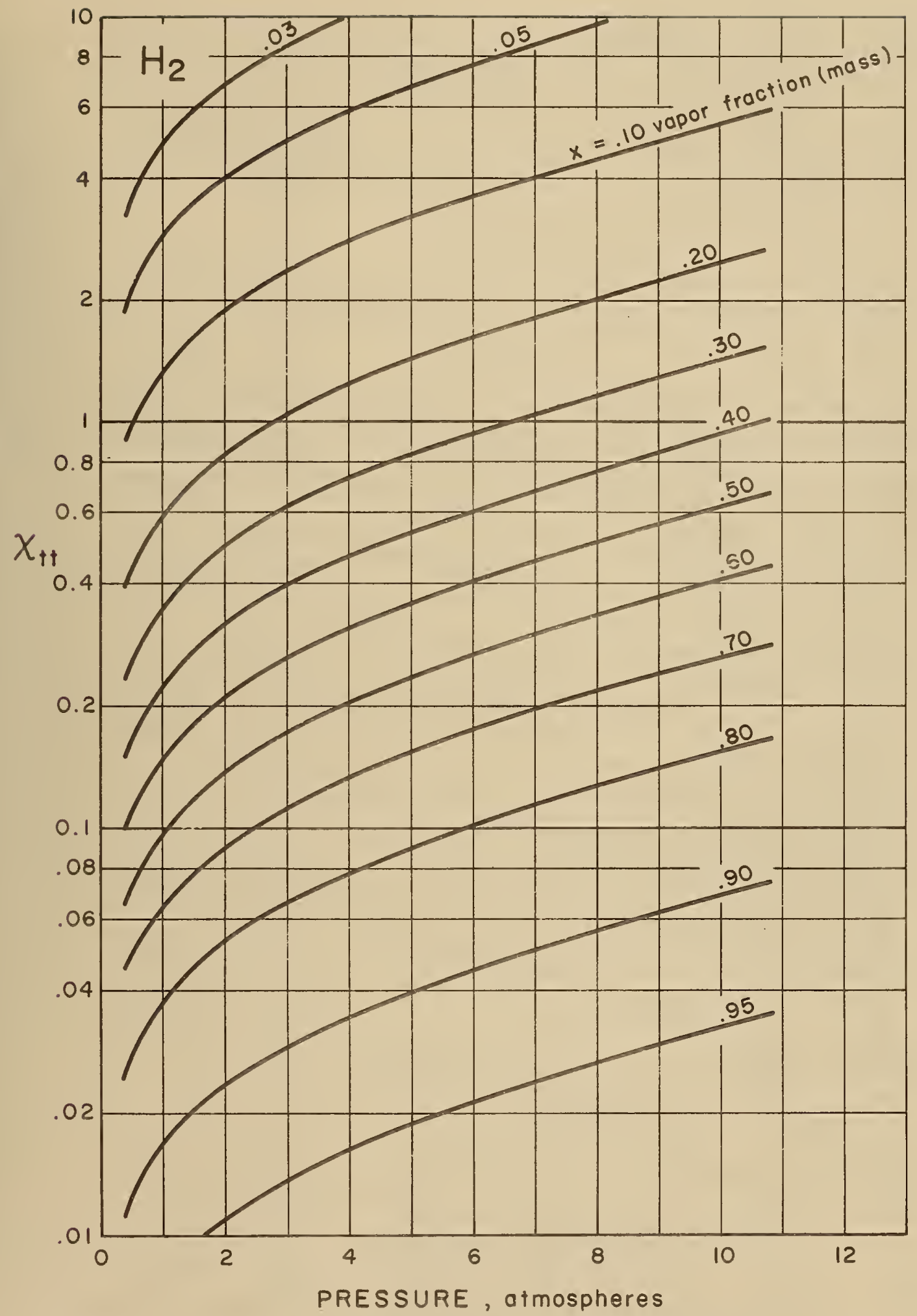

Figure 19a: Martinelli-Nelson correlating term $\chi_{t t}$ as a function of quality and pressure for $\mathrm{H}_{2}$. 


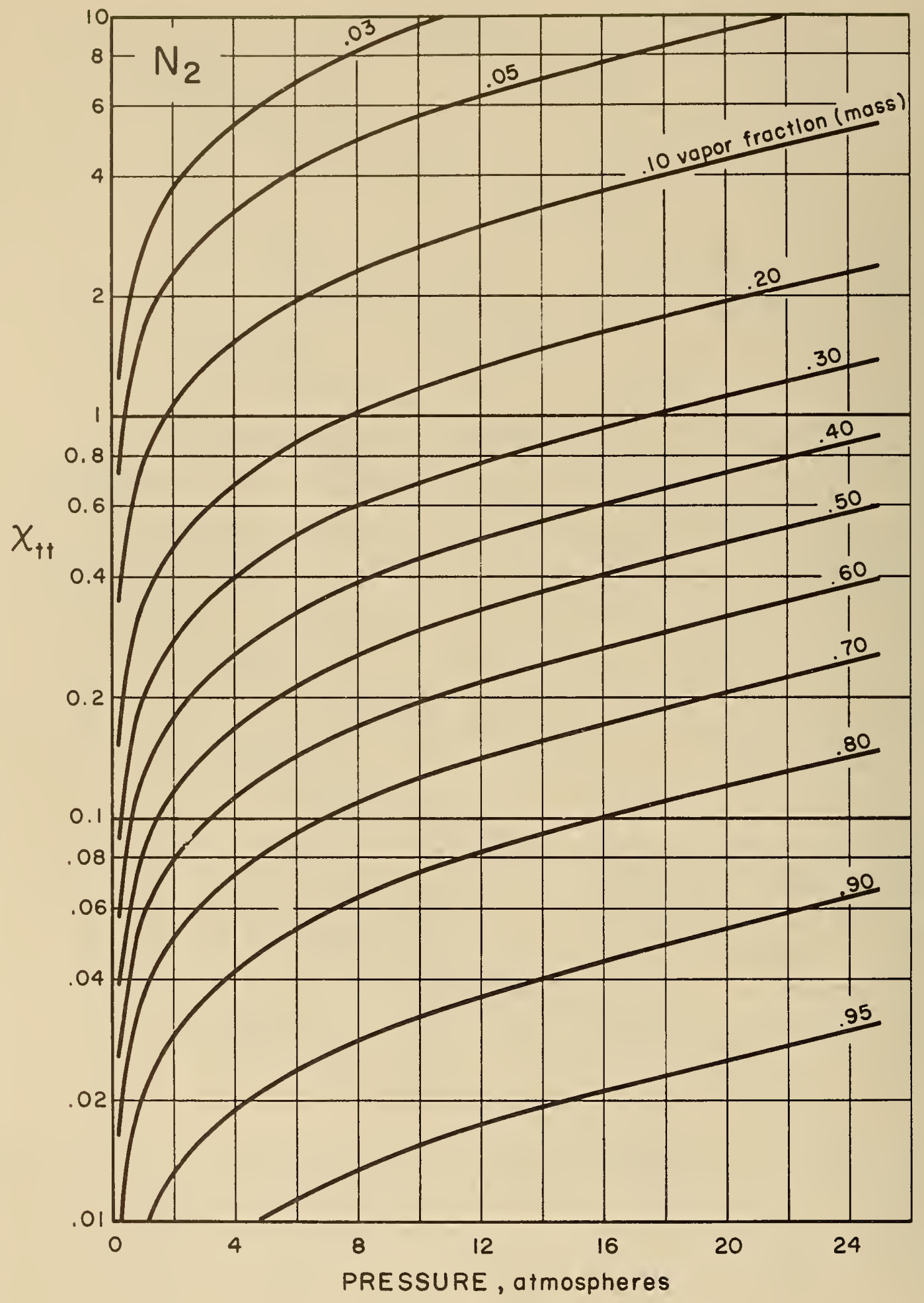

Figure 19b: Martinelli-Nelson correlating term $\chi_{t t}$ as a function of quality and pressure for $\mathrm{N}_{2}$. 


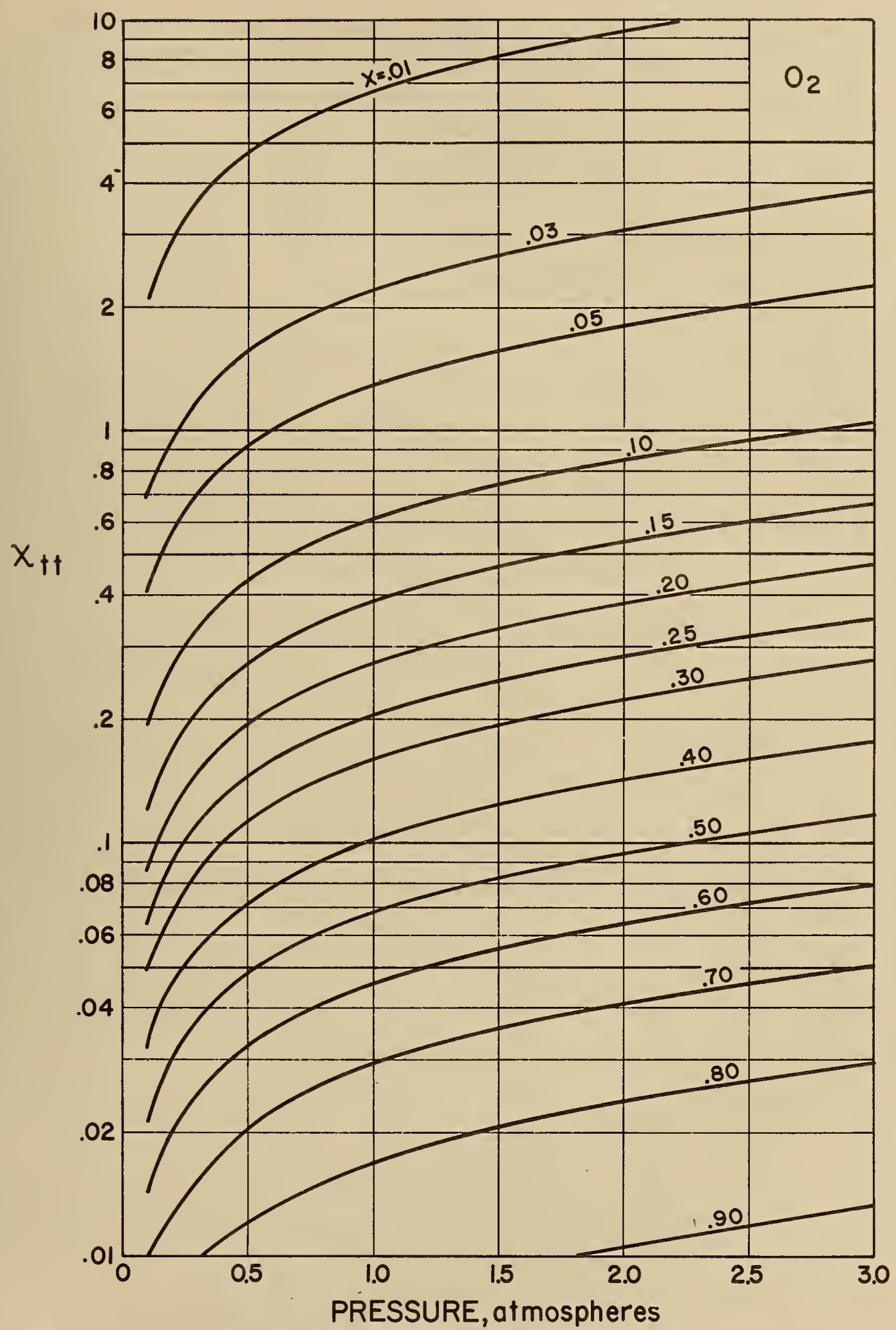

Figure 19c: Martinelli-Nelson correlating term $X_{t t}$ as a function of quality and pressure for $\mathrm{O}_{2}$. 101 


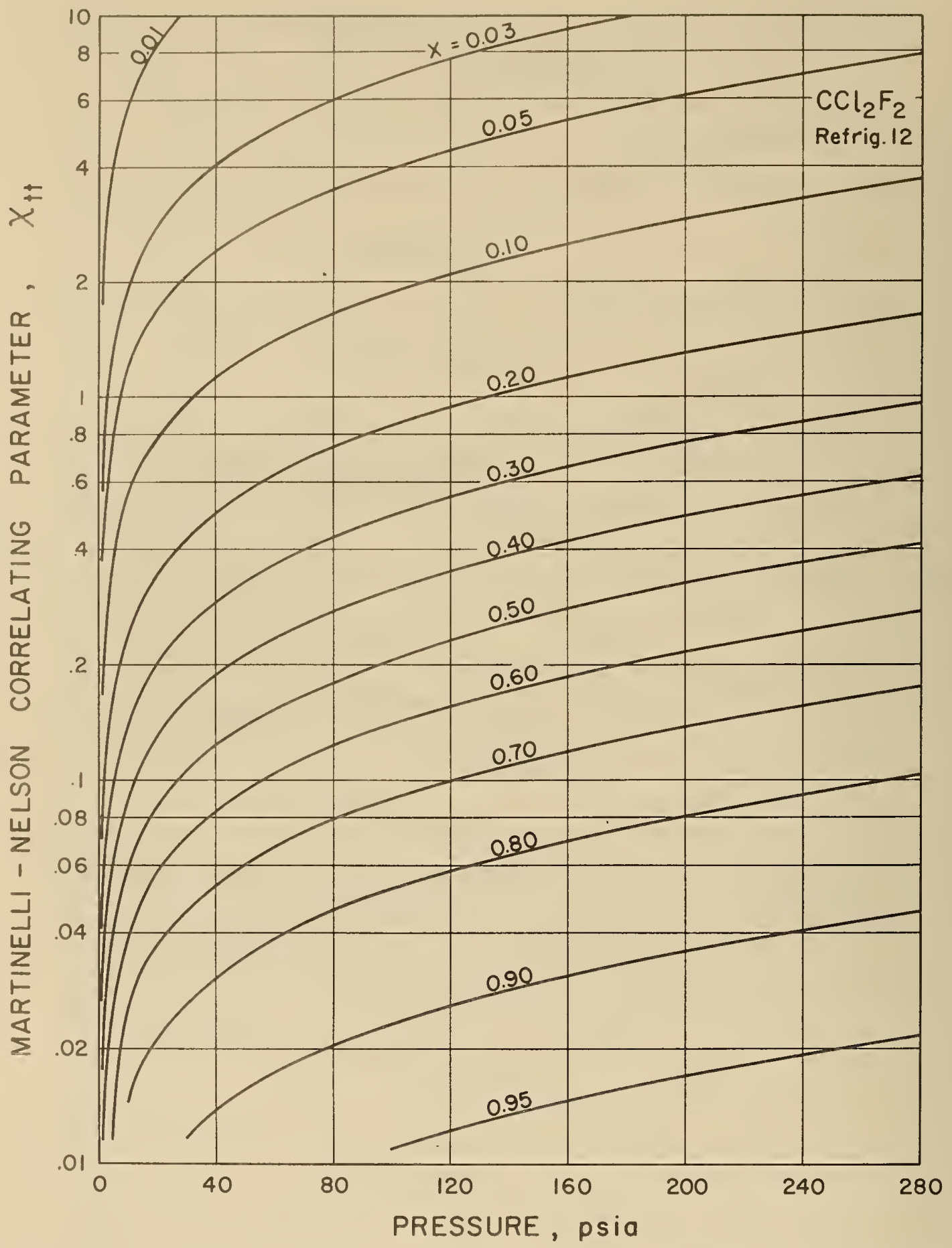

Figure 19d: Martinelli-Nelson correlating term $\chi_{t t}$ as a function of quality and pressure for $\mathrm{CCl}_{2} \mathrm{~F}_{2}$. 


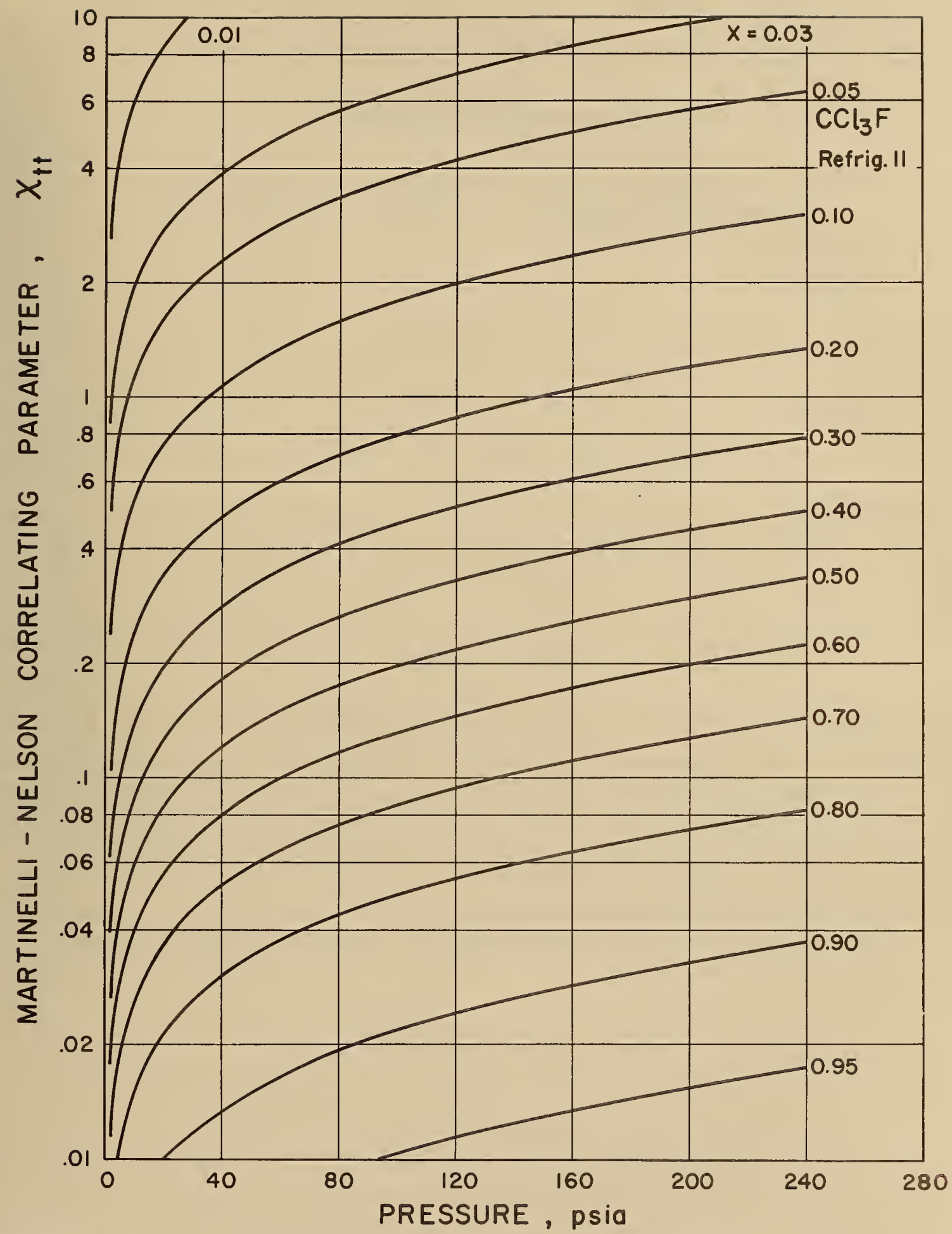

Figure 19e: Martinelli-Nelson correlating term $\chi_{t t}$ as a function of quality and pressure for $\mathrm{CCl}_{3} \mathrm{~F}$. 
The purpose of this section is to examine methods of approach and final expressions developed to predict choking in a single-component, liquid-vapor flow system.

\section{1 Homogeneous Mixture Flow Model}

For homogeneous mixtures, one may employ the conservation relationships ordinarily written for the gas phase. These expressions for one-dimensional, steady, adiabatic, horizontal flow are:

Momentum

$$
u d u+d p / p+\frac{f u^{2}}{2 D} d \ell=0 \text {; }
$$

Continuity

$$
\dot{m}=\text { Aup, or, } \mathrm{G}=\frac{\dot{m}}{\mathrm{~A}}=u p \text {; }
$$

Energy

$$
h_{0}=h+\frac{u^{2}}{2}=\text { constant }
$$

\section{2 Acoustic Velocity}

Choking flow velocity is often treated as equal to the velocity of a small pressure, or acoustic, wave. The mechanism described to support this approach is simply that the pressure signal cannot be transmitted upstream if the fluid velocity is greater than sonic velocity. Thus, the signals from pressure reductions downstream of the choking point cannot reach the choking point and effect an increase in flow rate at that point. The development of the expression for acoustic velocity is in many textbooks $[11,60]$.

In general, the authors apply the relationships in (2) and (3) to a differential pressure wave. The resulting expressions are:

$$
a^{2}=\left(\frac{\partial p}{\partial p}\right)
$$

and

$$
G_{c}^{2}=-\left(\frac{\partial p}{\partial v}\right)
$$


One may also approach the problem from the point of view that the mass flow rate is limited because a further increase in fluid velocity would produce a decrease in entropy in an adiabatic system. For an isentropic flow, one may use (2) and write the definition of choking flow, or flow at the exit of a converging flow system, or at the throat of a converging-diverging flow system, as:

$$
\left(\frac{\partial G_{c}}{\partial p}\right)_{s}=u\left(\frac{\partial p}{\partial p}\right)_{s}+\rho\left(\frac{\partial u}{\partial p}\right)=0
$$

or

$$
\left(\frac{\partial p}{\partial \rho}\right)_{s}=-\frac{u}{\rho}\left(\frac{\partial p}{\partial u}\right)_{s} .
$$

Also from (3),

$$
\mathrm{dh}+\mathrm{udu}=0 \text {, }
$$

and from relationships developed from the first and second law of thermodynamics,

$$
\mathrm{Td} s=\mathrm{dh}-\mathrm{dp} / \rho
$$

Combining (38), (39), and (40) results in an expression for the choking velocity which is

$$
u_{c}^{2}=\left(\frac{\partial p}{\partial \rho}\right)_{s}=a^{2}
$$

Thus, the same expression for the choking velocity results using either approach.

For the Fanno flow, or for a general flow process, one may conclude that, as the choking velocity is approached, the flow approaches the isentropic flow case, and (4) represents the choking velocity. This reasoning, although not rigorously developed here, may be supported by observation of a Fanno line on an h-s plot which indicates the entropy change approaches zero at Mach one.

A study of the flow, microscopically or molecularly, will also lead to the conclusion that the choking velocity is related to second law considerations. This conclusion may be reached by recognizing that in adiabatic flow, the molecular "disorder, " or entropy, is increased by the specific volume increase and reduced by the general, velocity-orientation of the massflow vector (see figure 20.) Then, as the flow approaches the isentropic and Mach one case the entropy-decreasing effect (relative to the specific volume or entropy increasing effect), will reach a value such that an increase in velocity would result in a net entropy decrease. Therefore, further velocity increase would violate the second law of thermodynamics. Again, a pressure-specific volume (or density) relationship is seen to produce the choking velocity, or mass-limiting condition, as these terms govern the net entropy change for the system. Again, the choking case is dependent on the second law of thermodynamics considerations. 


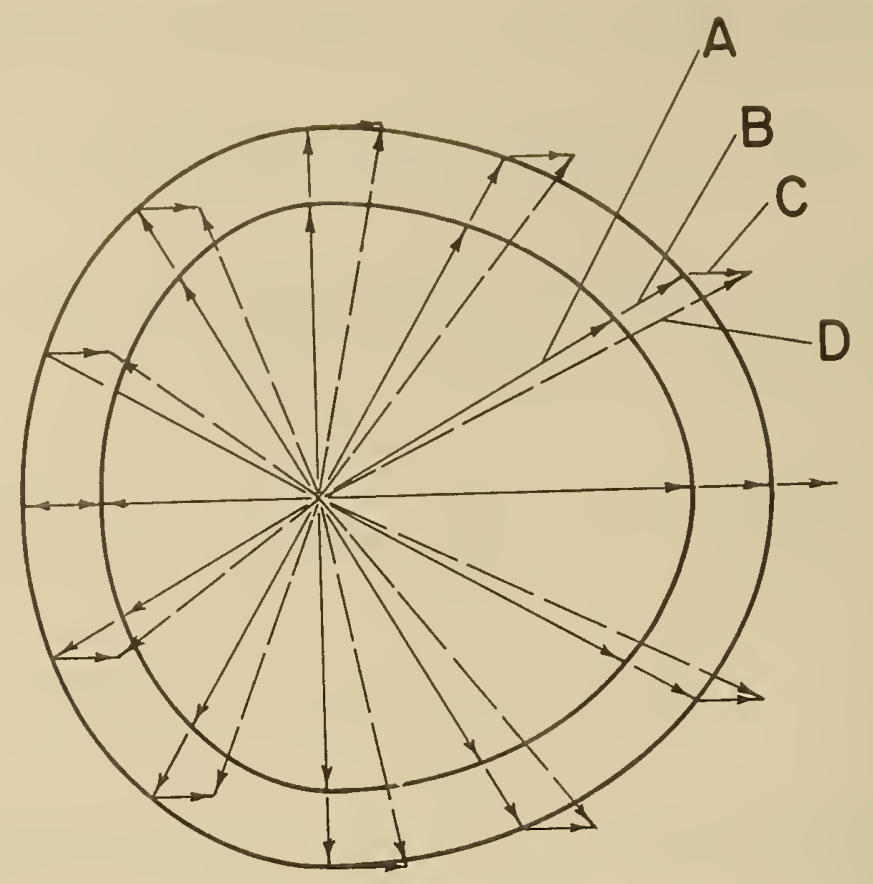

Figure 20: Effective molecular path vector before and after an accelerating pressure change.
A. Molecular path vector before accelerating pressure change.
B. Vector addition from increased specific volume after change - entropy increasing.
C. Vector addition from increased velocity after change - entropy reducing.
D. Final molecular path vector. 
The acoustic-velocity, pressure-signal model has definite limitations when used to study choking. For a single or two-phase case, it may be reasoned that it is possible for a pressure signal to travel upstream in a lower-velocity, boundary layer when all but that small portion of the flowing fluid is at the Mach one condition. Although it is very possibly negligible, this effect must be accounted for in the analysis. In a two-phase mixture, the value of "a" from (4) will be much lower than the value for either phase considered separately, even for the most extreme assumptions one may make regarding the liquid-vapor equilibrium or mass transport at the interface $[57,63,70]$. In this case, it may be possible for the pressure signal to travel upstream on a single-phase path at a velocity much higher than choking velocity. The possible effects of this signal on the choking phenomena must also be explained.

Also, sonic velocity has been shown to be frequency dependent in single-phase ${ }^{[54]}$ and two-phase, two component ${ }^{[64]}$ systems. This frequency dependence has been shown to be a function of the relaxation time, or the time necessary to distribute the energy among the degrees of freedom of the system. If the period of the propagating wave is much less than the relaxation time, then the complete relaxation process will not occur. In the single-phase system, this energy distribution is between the translational, rotational, and vibrational degrees of freedom of the molecules. Therefore, the relaxation time is short and the frequency dependence of the acoustic velocity will begin only at a very high frequency. In the two-phase system, the significant degrees of freedom affecting the relaxation time are the mass, momentum, and energy transport at the phase interfaces. These phenomena, obviously, will produce long relaxation times and low sonic velocities at low frequencies and high sonic velocities at high frequencies. The signal theory is particularly difficult to apply here as a pressure disturbance would be expected to contain a rather large spectral distribution of frequencies which would travel at different velocities through the fluid.

Some experimental data have been reported which indicate that measured sonic velocities can be quite different from those obtained from evaluating (4) assuming equilibrium between the phases. Karplus [32], working with low quality water mixtures, and Collingham [15], experimenting with the higher quality mixtures of water found in the center of liquid-vapor flow sections, both found pressure-wave velocities much higher than those predicted by computations assuming equilibrium. Collingham's work indicated that the entrained liquid in a liquid-vapor mixture had little effect on the pressure wave velocity. His measured velocities were very close to the sonic velocity values expected in the vapor alone. Equation (4) would predict this measured value only if the mass, momentum, and energy transport between the phases were negligible. Collingham did not report a frequency dependence for his pressure wave velocity. The curve representing $G_{c(H O)(M E T)} / G_{c(H O)(T H)}$ shows the change 
in values for the choking mass flow if zero mass and momentum transport are assumed in solving (5). The details for developing the $G_{C(H O)(M E T)}$ expressions have been previously reported $[63,70]$.

From the preceding discussion, it would appear that one must evaluate how strong and how general a pressure signal is necessary to be effective in changing the mass rate of flow and the velocity of those signals must be determined. The conclusion, therefore, is that although the pressure signal approach may be valid, it would be extremely difficult to apply to evaluate the choking velocity in a liquid-vapor mixture.

Examining the thermodynamic approach, the relaxation phenomena must be evaluated to solve (4), and this is probably not possible at this time for many flow cases because there are so many limitations of knowledge concerning the flow pattern and the transport phenomena at the interface. If this information is available, however, then the choking velocity may be determined. For a homogeneous mixture, the rate of heat and mass transfer (assuming no momentum transport) will allow an evaluation of (4) and (5). Specifically, the pressure drop is associated with a time, and that information will allow a determination of the density changes produced by the heat and mass transport at the liquid-vapor interface. Of course, if the time were very long (theoretically infinite), the processes would proceed to the equilibrium state. Although difficult, the thermodynamic (second law) considerations do provide the most reasonable approach to the problem. Some detailed procedures, using this method of analysis, are developed in the "Quantitative Solutions" section of this paper.

In the preceding summary of two-phase, choking-flow papers, it was found that almost all authors used a form of (4) or (5) to predict choking, but no author considered relaxation in the solution of the equation.

\section{5 Non-Homogeneous Models}

When the phases tend to separate, producing variable-density or separate-phase flow patterns, the analysis becomes even more difficult. Considering an extreme case of a separated-phase flow, in an annular flow pattern with the phases travelling at different velocities, in order to apply (4) or (5) for either the thermal equilibrium or the rate dependent case, one must assume an "effective" velocity for the fluid, where quite different velocities are known to occur. Considering an effective choking velocity for the mixture and probable slip velocities, the gaseous portion of the flow surely would be found to exceed the sonic velocity. The constant entropy condition prescribed by (4) and (5) for the liquid-vapor system would probably be achieved by a decrease in entropy of the higher-velocity gas phase, produced by that phase exceeding Mach one, equalling an entropy increase of the lower-velocity liquid phase. It is difficult to see how the actual flow could achieve these conditions. 
Many investigators, however, have used (4) or (5) with thermal equilibrium assumptions to predict choking flow, using a separated-phase model.

An approach that would appear to be more promising would be one in which the choking velocity of the vapor core or, in a variable density model, an average-density, higher-quality core would control the mass-limiting characteristics of the flow. The general ideal of this approach has been used in the separated-phase, vapor-choking model. [14,63] The results of this model compared to the homogeneous, thermal equilibrium model are shown in figure $8 \mathrm{~b}$. Agreement is good only at high qualities. However, the assumptions include the use of a separated model and slip velocities computed from the Martinelli-Nelson correlation. Perhaps neither of these assumptions are appropriate for many lower-quality flow cases. Examination of data from entrainment studies ${ }^{[13,32]}$ and flow pattern correlations [5] shows that separated-phase flow is improbable for choking conditions except for very high quality flows. The effectiveness. of the vapor choking model in the "middle" quality ranges is probably due to metastability rather than the accuracy of the model.

In summary, in considering non-homogeneous flow models the separated phase model presents very difficult problems when the relaxation (second law) approach is applied with (13) and (19). The required physical adjustment of the flow to suit the expressions appears highly improbable. If the choking flow condition is assumed to be controlled by a core which may be treated as homogeneous, the analysis becomes possible and use of the vapor-choking, separated-phase model for medium and high quality flow indicates this approach shows some promise.

\subsection{Qualitative Solutions}

One may apply the relaxation concept to simplified models to determine the choking behavior which would be generally expected. Also, these results may be used to explain, at least partially, the experimentally determined values shown in figure $8 \mathrm{~b}$.

For the two-phase mixture,

$$
v=(1-x) v_{f}+x v_{g}
$$

and

$$
d v=d v_{f}-x d v_{f}-v_{f} d x+x d v_{g}+v_{g} d x
$$

The first two terms on the right of (41) can be considered negligible with respect to the remaining terms by assuming liquids to be relatively incompressible. Then, to evaluate (5),

$$
\frac{1}{G_{c}^{2}}=\left(\frac{\partial v}{\partial p}\right)_{s} \approx x\left(\frac{\partial v}{\partial p}\right)_{s}+v_{f g}\left(\frac{\partial x}{\partial p}\right)_{s}
$$


In the following solutions, two cases will be considered: (1) the thermal equilibrium case, and

(2) the case where mass transfer is time-dependent but the other relaxation processes (energy and momentum transport) have small relaxation times and their time-dependence is negligible. Thus, the first term on the right of (42) will be the same for both cases, and the different values for $\left(\partial \mathrm{x} / \partial_{\mathrm{p}}\right)_{\mathrm{s}}$ will determine the different values obtained for $\mathrm{G}_{\mathrm{c}}$. The cases considered and the treatment which follows are intended to be illustrative of the relaxation method of approach. Complete or rigorous treatment is not intended.

\subsection{Qualitative Solutions: Thermal Equilibrium}

From the expression

$$
s=(1-x) s_{f}+x s_{g},
$$

and for the isentropic case, one may develop

$$
\frac{d x}{d p}=\frac{(x-1) d s_{f} / d p-x d s_{g} / d p}{s_{f g}}
$$

For the thermal equilibrium case, this relationship may be solved using thermodynamic, tabular data for the fluid. The results of this solution for water are shown as the thermal equilibrium curve in figure 21.

\subsection{Qualitative Solutions: Relaxation Considered}

In this approach the variables $d p$ and $d x$ are considered time-dependent. The desired ratio $\mathrm{dp} / \mathrm{d} \mathbf{x}$ may be determined from the following relationship

$$
\left(\frac{\mathrm{dx}}{\mathrm{dt}}\right)\left(\frac{\mathrm{dt}}{\mathrm{dp}}\right)=\frac{\mathrm{dx}}{\mathrm{dp}} .
$$

Figure 9 shows a typical pressure-distance relationship used to determine the values of the time-dependent terms in (44).

The bubble growth rate resulting from mass transport may be expressed as $d R_{b} / d t$. Then the change in bubble volume, $d V g_{g}$ related to $d_{R_{b}}$, is

$$
d R_{b}=\frac{d V}{4 \pi R_{b}^{2}}
$$


Then, analyzing a unit mass with $\mathrm{N}$ bubbles,

$$
\frac{d V}{d t}=4 \pi R_{b}^{2} N\left(\frac{d R_{b}}{d t}\right)
$$

This leads to the expression for the time rate of quality change as a function of bubble growth rate or

$$
\frac{d x}{d t}=\rho_{g} 4 \pi R_{b}^{2} N\left(\frac{d R_{b}}{d t}\right)^{*}
$$

For these computations, the previously reported asymptotic bubble-growth-rate data of $\mathrm{Z}$ wick and Plesset [76], $\left(\mathrm{dR}_{\mathrm{b}} / \mathrm{dt}=4 \mathrm{~cm} / \mathrm{s}\right)$, and Hammitt ${ }^{[24]},\left(\mathrm{dR}_{\mathrm{b}} / \mathrm{dt}=1.75 \mathrm{f} / \mathrm{s}\right)$, were used.

Although neither case is exactly applicable to the case considered, it is believed that these data are sufficiently representative for use to present quantitative curves as shown in figure 21. Also, since Hammitt's bubble growth rate is approximately thirteen times that of $\mathrm{Z}_{w i c k}$ and Plesset, the results, using the two values, show the effect of quite different rates of mass transport at the interface.

In figure 9, the slope of the curve at the choking point will produce a value for $\mathrm{dp} / \mathrm{d} \ell$ and with the choking velocity $\mathrm{d} \ell / \mathrm{dt}$, one may write

$$
\left(\frac{\mathrm{dp}}{\mathrm{d} \ell}\right)\left(\frac{\mathrm{d} \ell}{\mathrm{dt}}\right)=\frac{\mathrm{dp}}{\mathrm{dt}} .
$$

Using this method and the data of Faletti [19], the remaining value necessary for the solution of (44) is obtained. This method of evaluating $d x / d p$ from (44) is considered sufficiently accurate for qualitative comparisons. It is presumed that the density change from new bubble formation will be negligible. A more rigorous approach may not produce more accurate values, since so little is known of the mass-transfer, relaxation process. For one example, a more detailed study would consider the effect of surface tension on the effective vapor pressure in the vapor bubble. First of all, in such a study the bubble size is unknown. Probably an effective bubble size would be assumed and, with this, some crude estimates could be made The final conclusions of such a study would appear to be that both experimental and theoretical treatments indicate that surface tension has an effect, resulting in behavior tending toward the metastable case. Even if a proper bubble size were reasonably well known, one can see that

* This expression assumes that the term $V_{g}\left(\frac{d \rho_{g}}{d t}\right)$ is negligible compared to $\rho_{g}\left(\frac{d V}{d t}\right)$ 
the two processes play compensating roles, because, as the radius of curvature decreases, the "effective" vapor pressure will be increased and the mass-transfer driving force will be reduced. But, with smaller bubbles, the heat and mass-transfer area will be increased, tending to produce a compensating increase in the rate of these processes.

Figure 21 shows the evaluation of (44) for the cases considered. On the "relaxation" curves, which consider mass-transport rates, for points above the thermal equilibrium curve there is sufficient time to produce equilibrium. For points below the thermal equilibrium curve, metastability would be expected. Since only one curve crosses the thermal equilibrium curve, and that curve represents a relatively small bubble size $\left(R_{b}=0.01\right.$ in. $)$ and the extreme values for bubble growth rate (high) and pressure gradients (low), metastability would be expected for most low quality flow cases.

Figure $8 \mathrm{~b}$ shows that low quality choking flow tends to show metastable behavior by the $G_{C} / G_{C(H O)(T H)}$ values greater than one which has been reported. Although no curves are shown for a separated-phase model in figure 2l, the behavior of the curve for the largersized bubbles indicates that a long relaxation time and rather extreme metastable behavior would be expected from that model.

\section{9 Conclusions}

In studying choking for single-component, liquid-vapor mixtures, the use of the sonic velocity, pressure signal-approach appears to present more difficult problems than an approach which considers choking to be limited by the second law and which considers the relaxation time for the transport phenomena.

Some very approximate curves indicate metastable behavior should be expected for almost all low-quality, choking flows. It is recommended that, in the future, consideration be given to the relaxation (or transport) phenomena in solutions of (4) and (5) in two-phase, choking-flow studies.

\section{ACKNOWLEDGMENTS}

The author wishes to acknowledge the very valuable assistance of $H$. P. McDonough who programmed the idealized equations for solution on the NBS computer. The author is also indebted to Dr. R. B. Jacobs for his advice on the selection and development of the theoretical expressions and E. G. Brentari whose assistance was very valuable throughout all parts of the report. He also wishes to extend his thanks to Mrs. Mildred Birchfield, Mrs. Sallie Cunningham, Miss Gloria Hoffmire, and W. W. Bulla who patiently assisted through manuscript preparation. 


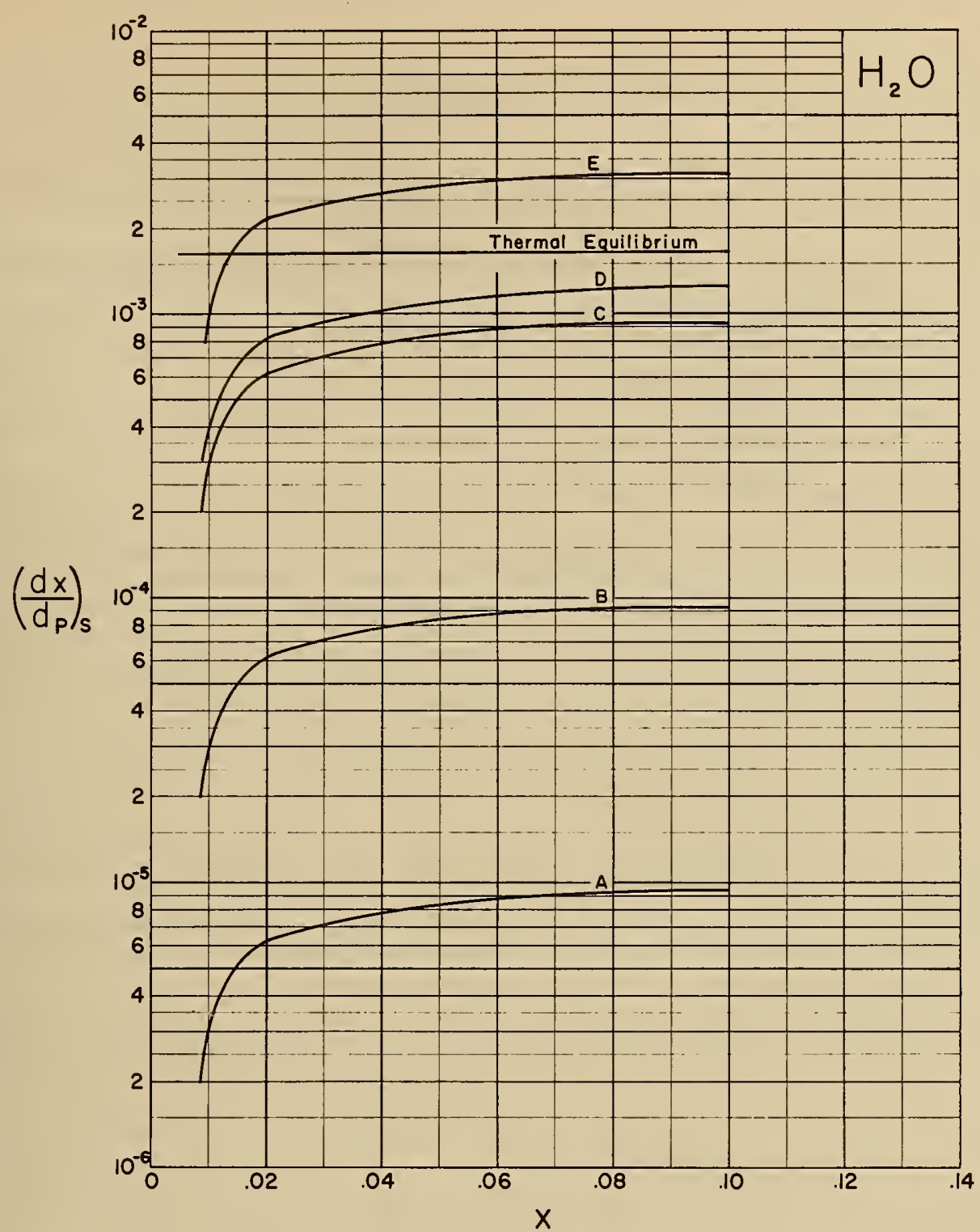

Figure 21:

Values of $(\partial \mathrm{x} / \partial \mathrm{p})_{\mathrm{s}}$ as a function of initial quality with constant values of $R_{b}, \dot{\mathrm{R}}_{b}$

and $(\partial \mathrm{p} / \partial \ell)_{\mathrm{s}}$ as parameters.
A. $R_{b}=0.1$ in., $\dot{R}_{b}=0.131 \mathrm{f} / \mathrm{s}[76] ;(\partial \mathrm{p} / \partial \ell)_{s}=600 \frac{1 b_{f}}{i n^{2}-f}[19]-$ mean value.

B. $R_{b}=0.01$ in., $\dot{R}_{b}=0.131 \mathrm{f} / \mathrm{s} ;(\partial \mathrm{p} / \partial \ell)_{s}=600 \frac{1 b_{f}}{i n^{2}-f}$

C. $R_{b}=0.001$ in., $\dot{R}_{b}=0.131 \mathrm{f} / \mathrm{s} ;(\partial \mathrm{p} / \partial \ell)_{s}=600 \frac{1 b_{f}}{i n^{2}-f}$

D. $R_{b}=0.01$ in., $\dot{R}_{b}=1.75 \mathrm{f} / \mathrm{s}[24] ;(\partial \mathrm{p} / \partial \ell)_{s}=600 \frac{\mathrm{lb}_{f}}{\mathrm{in}^{2}-\mathrm{f}}$

(Th. Eq.) curve obtained assuming thermal equilibrium

E. $R_{b}=0.01$ in., $\dot{R}_{b}=1.75 \mathrm{f} / \mathrm{s} ;(\partial \mathrm{p} / \partial \ell)_{s}=2401 \mathrm{~b}_{\mathrm{f}} / \mathrm{in}^{2}-\mathrm{f}[19]-1$ owest value. 
1. Agnostinelli, A., and V. Salemann, Predictions of flashing water flow through fine annular clearances, Trans. ASME 80, $1138-1142$ (1958)

2. Allen, W. F., Flow of a flashing mixture of water and steam through pipes and valves, Trans. ASME 73, 257-265 (1951).

3 ASME Research Committee on Fluid Meters, Fluid meters - their theory and application, fifth ed. (ASME, New York, 1959).

4. Bailey, J. F., Metastable flow of saturated water, Trans. ASME 73, $1109-1116$ (1951).

5. Baker, O., Simultaneous flow of oil and gas, Oil and Gas J. 53, 12, 185-190 (1954)

6. Benjamin, M. W., and J. C. Miller, The flow of saturated water through throttling orifices, Trans. ASME 63, 410-429 (1941); The flow of flashing mixtures of water and steam through pipes, Trans. ASME 64, 657-699 (1942).

7. Binnie, A. M., and M. W. Woods, The pressure distribution in a convergent-divergent steam nozzle, Proc. Inst. Mech. Eng. (London) 138, 229-266 (1938).

8. Bottomly, W. F., The flow of boiling water through orifices and pipes, Trans. North East Coast Inst. Eng. and Shipbuilders 53, 65-100 (1937).

9. Bridge, T. E., How to design the piping for conveying flashing hot water, Heating, Piping, and Air Conditioning, 69-73 (March 1949); 92-96 (April 1949); 98-100 (May 1949).

10. Burnell, J G., The flow of boiling water through nozzles, orifices, and pipes, Engineering 164, 572-576 (1947); The discharge of boiling water through a venturi tube, J. Inst. Eng. (Australia) 27, 7-8, 213 (July-August 1955)

11. Cambel, A. B., and B. H. Jennings, Gas dynamics (McGraw-Hill, Inc., New York, 1958)

12 Chisholm, D, The flow of steam/water mixtures through sharp-edged orifices, Eng and Boiler House Rev. 73, 252-256 (1958).

13. Collier, J G , and G. F Hewitt, Data on the vertical flow of air-water mixtures in the annular and dispersed flow regions, AERE (Great Britain) R3455 (1960).

14. Collier, J. G. , A review of two-phase heat transfer (1935-1957), AERE CE/R 2496, Harwell, England (1958)

15. Collingham, R E., Measurement of acoustic velocity in very wet steam, Master's Thesis, University of Washington (1960).

16. Coremans, J. M. J., H. Van Itterbeek, J. J. M. Beenakker, H. F. P. Knapp, and P. Zandenbergen, Physica 24 (1958).

17. DuCoffe, H. L., J. R. Bennet, and C. G. Ray, Subcritical and critical flow through straight-through, elbow and Tee A-N fittings and sharp edged orifices at elevated temperatures, Trans. ASME, 1349-1357 (1958).

18. Dukler, A. E., and M. Wicks, Entrainment and pressure drop in concurrent gas-liquid flow, AICHE J. $\underline{6}, 3,463-468$ (1960). 
19. Faletti, D. W., Two-phase critical flow of steam-water mixtures, Ph. D Thesis, University of Washington (1959), AIChE J. 8, 2 (1963).

20. Fauske, H., Critical, two-phase, steam-water flows, Proc. of the 1961 Heat Transfer and Fluid Mech. Inst., 79-89 (Stanford University Press, Stanford, California, 1961).

21. Friedman, A. S., unpublished (1954).

22. Goglia, G. L., and G. J Van Wylen, Experimental determination of limit of supersaturation of nitrogen vapor expanding in a nozzle, Trans. ASME 83, Ser. C, 1, 27-32 (1961)

23. Goodenough, G A., Supersaturation and the flow of steam, Power 66 , 466-469 (1927)

24. Hammitt, F. G., P. T Chu, V. F. Cramer, and C. L. Wakamo, Observations and measurements of flow in a cavitating venturi, Tech. Report 5 ORA Project 03424, College of Engineering, University of Michigan, Ann Arbor.

25. Harvey, F. F., and A. S. Foust, Two-phase one dimensional flow equations and application to flow in evaporator tubes, Heat Transfer Symposium, AIChE 49, Ser. 5, 91-106 (1953).

26. Hesson, J L , and R. E. Peck, Flow of two-phase carbon dioxide through orifices, AIChE J. 4, 207-210(1958).

27. Holtzman, D., The variation of sonic velocity in two-phase mixtures considering the effect of liquid compressibility, unpublished report, Aerojet-General Corporation, Azusa, California.

28. Hoopes, J. W., Flow of steam-water mixtures in a heated annulus and through orifices, AIChE J. 3, 268-275 (1957)

29. Isbin, H. S, et al., Void fractions in two-phase steam-water flow, AIChE J. 3, $136-142$ (1957); Two-phase, steam-water critical flow, AIChE J. 3, 361-365 (1957); Two-phase, steam-water pressure drops for critical flow, Symposium on Two-Phase Flow, Inst. of Mech. Engrs., London (February 7, 1962).

30. Johnson, H. A., and A. H. Abou-Sabe, Heat transfer and pressure drop for turbulent flow of air-water mixtures in a horizontal pipe, Trans. ASME 73, 977-987 (1951).

31. Johnston, H L., R. W. Mattox, and R. W. Powers, NACA Tech. Note 2546 (1951)

32 Karplus, H. B., Propagation of pressure waves in a mixture of water and steam, Armour Research Foundation, Rep. 4132-12.

33 Kays, W. M., and A. L. London, Compact heat exchangers (National Press, Palo Alto, California, 1955).

34. Kinderman, W. J., and $E$. W. Wales, Fluid flow through two orifices in series - 3. Parameters of metastable and stable flow of hot water, Trans. ASME 79, 1, 183-190 (1957)

35. Leppert, G., M. Jakob, and J. B. Reynolds, Pressure drop during forced circulation boiling, Heat Transfer Symposium, AIChE 52, Ser. 18, 29-36 (1955).

36. Linge, K. , Flow of boiling liquid refrigerants through throttling devices, University of Karlsruhe (unpublished).

37. Linning, D. L., The adiabatic flow of evaporating fluids in pipes of uniform bore, Proc. Inst. Mech. Eng. 1B, 64-75 (1952-1953). 

power riactors, AEC Research and Development Report ANL-6063 (1959).

39. Love, W. J., Critical pressure ratio for a nozzle with two-phase fog flow, Geners? Electric, HW-64269 (1960).

40. Magiros. P. G., and A. D. Dukler, Entrainment and pressure drop in concurrent gasliquid flow - II. Liquid property and momentum effect, Development in Mechanics, Vol. 1 (Plenum Press, New York, 1961).

41. Martinelli, R. C., and D. B. Nelson, Prediction of pressure drop during forced circulation boiling of water, Trans. ASME 70 (1948).

42. Massend, W. A, Steam-water critical flow using separated flow model, General Electric HW-65739 (1960).

43. Mellanby, A. L., and W. Kerr, The supersaturated condition as shown by nozzle flow, Proc. Inst. Mech. Eng. 2, pt. 2, 855-883 (1922).

44. Mendler, Rathbun, Van Huff, and Weiss, Natural circulation tests with water at 800-2000 psia under non-boiling, local boiling, and bulk boiling conditions, Trans. ASME 83 , Ser. C, 3, 261-273 (1961).

45. Monroe, E. S., Flow of saturated boiler water through knife-edged orifices in series, Trans. ASME 78, 373 (1956).

46. Mullins. J. C., W. T. Ziegler, and B. S. Kirk, Project No. A-593 Eng. Exper. Sta. Geo. Inst. of Tech., Tech. Report 1 (1961); Tech. Report 2 (1962).

47. Muraoka, J., Steam-water critical flow test design 1040, General Electric HW-69488 (1961).

48. Murdock, J. W., Two-phase flow measurement with orifices, ASME Paper No. 61-WA-27 (1961).

49. Pasqua, P. F., Metastable flow of freon-12, Refrig. Eng. 61, 1084 A-1088 (1953).

50. Perry, J. H., Chemical Engineer's Handbook, third edition, pp. 370-373 (McGraw Hill, New York, New York, 1950).

51. Rettaliata, J. T., Undercooling in steam nozzles, Trans. ASME 58, 599 (1936).

52. Roder, H. M., R. D. Goodwin, NBS Tech. Note 130, PB 161631 (1962).

53. Rogers, J. D., Two-phase flow of hydrogen in horizontal tubes, AIChE J. 2, 536 (1956).

54. Rossinni, F. D., Thermodynamics and physics of matter, pp. $692-704$ (Princeton University Press, 1955).

55. Rudenko, N. S., J. Expl. Theoret. Phys. (USSR) 9 (1939); Rudenko, N. S., and L. V. Shubnikov, Phys. Ziet. Sowjetunion 6 (1934).

56. Ryley, D. J., Flow of wet steam - I and II, Engineer 193, 332-333, 363-365 (1952).

57. Sajben, M., Adiabatic flow of flashing liquids in pipes, Trans. ASME 83, Ser. D. 4, 619631 (1961).

58. Schweppe, J. L., and A. S. Foust, Effect of forced circulation rate on boiling heat transfer and in a short tube, Heat Transfer Symposium, AIChE J. 49, 242-288 (1951). 
59. Scott, R. B., unpublished (1961).

60. Shapiro, A. H. The dynamics and the rmodynamics of compressible fluid flow - I, 45-49, 114-122 (The Roland Press Co., New York, 1953).

61. Silver, R. S., and J. A. Mitchell, Discharge of saturated water through nozzles, Trans North East Coast Inst. Eng, and Shipbuilders 62, 51-72 (1945).

62. Silver, R. S., Temperature and pressure phenomena in the flow of saturated liquids, Proc. Royal Society (London) 194, Ser. A, 464-480 (1948).

63. Smith, R. V., Some idealized solutions for critical (mass limiting) flow for two-phase flow of hydrogen, nitrogen, and oxygen, Advances in Cryogenic Engineering, Vol. 8, K. D. Timmerhaus, Editor (Plenum Press, New York, 1963).

64. Soo, S. L., Effect of transport processes on the attenuation and dispersion in aerosols, J. of Acoustic Soc. of Am. 32, 8, 943-6 (1960).

65. Strobridge, T. R., NBS Tech. Note 129, PB 161630 (1962).

66. Stein, R. P., et al., Pressure drop and heat transfer to nonboiling and boiling water in turbulent flow in an internally heated annulus, CEP Symposium Series 50, 11, 115-126 (1954)

67. Steltz, W. G., The critical and two-phase flow of steam, Trans. ASME. J of Eng. for Power, 145-154 (April 1961)

68. Stuart, D. O., and G. Murphy, Prediction of critical pressures for the two-phase flow of saturated water in pipes, ASME Paper No. 58-A-112 (1958).

69. Stuart, M. C., and D. R. Yarnall, Fluid flow through two orifices in series - II, Trans. ASME 66, 387-395 (1944).

70. Tangren, R. F., C. H Dodge, and H. S. Selfert, Compressibility effects in two-phase flow, J. of Appl. Phys. 20, 7, 637-645 (1949).

71. Thermodynamic Properties, General Chemical Division, Allied Chemical and Dye Corporation, New York.

72. Tippits, F. E., Water wall rupture in a high pressure reactor - hydraulic and heat transfer effects, General Electric HW-40388 (1955). SECRET

73. Van Itterbeek, A., W. Van Dael, and A. Cops, Physica 27 (1961).

74. Yellot, J. J., Supersaturated steam, Trans. ASME 56, 411-430 (1934).

75. Zaloudek, F. R., The low pressure critical discharge of steam-water mixtures from pipes, General Electric HW-68934 (1961).

76. Zwick, S. A., and M. S. Plesset, On the dynamics of small vapor bubbles in liquids, J. Math and Physics XXXIII, No. 4 (1955). 


\section{SUBJECT BIBLIOGRAPHY \\ FOR}

LITERATURE SUMMARY

\section{0 A SUMMARY OF REPORTED WORK}

\section{1 Theoretical Analyses}

\subsubsection{Theoretical Analyses which Predict Choking from Initial Flow Conditions; Homogeneous, Thermal Equilibrium Model}

Allen, W. F., Flow of a flashing mixture of water and steam through pipes and valves, Trans. A.SME 73, 257-265 (1951).

Bridge, T. E., How to design the piping for conveying flashing hot water, Heating, Piping, and Air Conditioning, 69-73 (Mar. 1949); 92-6 (April 1949); 98-100 (May 1949).

Burnell, J. G., Flow of boiling water through nozzles, orifices, and pipes, Engineering 164 , $572-576$ (1947).

Burnell, J. G., The discharge of boiling water through a venturi tube, J. Inst. Eng. (Australia) 27, 213 (July-Aug. 1955).

Love, W. J. , Critical pressure ratio for a nozzle with two-phase fog flow, Gen. Elect. HW-64269, (1960).

Sajben, M., Adiabatic flow of flashing liquids in pipes, Trans. ASME 83, Ser. D, 4, 619-631 (1961).

Steltz, W. G., The critical and two-phase flow of sieam, J. of Eng. for Power, 145-154 (1961).

\subsubsection{Theoretical Analyses which Predict Choking from Initial Flow Conditions; Separated Phase, Thermal Equilibrium Model.}

Linning, D. L., The adiabatic flow of evaporating fluids in pipes of uniform bore, Proc. Inst. Mech. Eng. 1B, 64-75 (1952-1953).

Stuart, D. O., and G. Murphy, Prediction of critical pressures for the two-phase flow of saturated water in pipes, ASME Paper No. 58-A-112, (1958).

\section{1.3 Theoretical Analyses Which Predict Choking from Initial Flow Conditions; Separated Phase, Metastable Model.}

Bailey, J. F., Metastable flow of saturated water, Trans. ASME 73, 1109-1116 (1951).

Silver, R. S., Temperature and pressure phenomena in the flow of saturated liquids, Proc. Royal Society (London) 194, Ser. A. 464-480 (1948).

Silver, R. S., and J. A. Mitchell, The discharge of saturated water through nozzles, Trans. North East Coast Inst. Eng. and Shipbuilders 62, 51-72 (1945).

2.1.4 Theoretical Analyses which Predict Critical Flow at the Point of Choking; Homogeneous, Thermal Equilibrium Model.

Agnostinelli, A., and V. Saleman, Prediction of flashing water flow through fine annular clearances, Trans. ASME $\underline{80}, 1138-1142$ (1958). 
Faletti, D. W., Two-phase critical flow of steam-water mixtures, Ph. D. Thesis, Univ. of Wash. (1959), AIChE J. 9,2 (1963).

Fauske, H., Critical, two-phase steam-water flows, Proc. of the 1961 Heat Transfer and Fluid Mech. Inst., 79-89 (Stanford Univ. Press, Stanford, 1961).

Holtzman, D. , The variation of sonic velocity in two-phase mixtures considering the effect of liquid compressibility, Commun. Aerojet-General Corp., Azusa, Calif.

Isbin, H. S., et al., Two-phase steam-water critical flow, AIChE J. 3, $361-365$ (1957).

Love, W. J., Critical pressure ratio for a nozzle with two-phase fog flow, Gen. Elect. Rep. No. HW-64269, (1960).

Sajben, M., Adiabatic flow of flashing liquids in pipes, Trans. ASME 83, Ser. D, 4, 619-631 (1961).

Steltz, W. G., The critical and two-phase flow of steam, Trans ASME, J. of Eng. for Power, $145-154$ (1961).

Zaloudek, F. R., The low pressure critical discharge of steam-water mixtures from pipes, Gen. Elect. HW-68934, (1961).

\section{1.5 Theoretical Analyses Which Predict Critical Flow at the Point of Choking; Separated, Thermal Equilibrium Model.}

Collingham, R. E., Measurement of acoustic velocity in very wet steam, Master's Thesis, Univ. of Wash. (1960).

Fauske, H., Critical, two-phase steam-water flows, Proc. of the 1961 Heat Transfer and Fluid Mech. Inst., 79-89 (Stanford Univ. Press, Stanford, 1961).

Isbin, H. S., et al., Two-phase, steam-water critical flow, AIChE J. 3 , $361-365$ (1957).

Ryley, D. J., The flow of wet steam, I and II, Engineer 193, 332-333, 363-365 (1952).

Massena, W. A., Steam-water critical flow using the separated flow model, Gen. Elect. HW-65739, (1960).

Zaloudek, F. R., The low pressure critical discharge of steam-water mixtures from pipes, Gen. Elect. HW-68934, (1961).

\section{2 Semi-Empirical Relationships}

\section{2. 1 Semi-Empirical Relationships for Adiabatic, Constant-Area Flow Systems}

Agnostinelli, A., and V. Saleman, Prediction of flashing water flow through fine annular clearances, Trans. ASME 80, $1138-1142$ (1958).

Benjamin, M. W., and J. C. Miller, The flow of flashing mixtures of water and steam through pipes, Trans. ASME 64, 657-669 (1942).

Burnell, J. G., The flow of boiling water through nozzles, orifices, and pipes, Engineering $164,572-576(1947)$.

Faletti, D. W., Two-phase critical flow of steam-water mixtures, Ph. D. Thesis, Univ. of Wash., (1959); AIChE J. 9, 2 (1963).

Muraoka, J., Steam water critical flow test-design test 1040, Gen. Elect. HW-69488, (1961).

Zaloudek, F. R., The low pressure critical discharge of steam-water mixtures from pipes, Gen. Elect. HW-68934, (1961). 


\section{2. 2 Semi-Empirical Relationships for Adiabatic, Variable Area Flow Systems}

\section{2. 2. 1 Adiabatic, Variable Area Flow Systems with Superheated or Saturated Vapor or High Quality Fluid Entering}

Binnie, A. M., and M. W. Woods, The pressure distribution in a convergent-divergent steam nozzle, Proc. Inst. Mech. Eng. (London) 138, 229-266 (1938).

Goglia, G. L., and G. J. Van Wylen, Experimental determination of limit of supersaturation of nitrogen vapor expanding in a nozzle, Trans. ASME 83, Ser. C, 1, 27-32 (1961).

Goodenough, G. A., Supersaturation and the flow of steam, Power 66, 466-469 (1927).

Mellanby, A. L., and W. Kerr, The supersaturated condition as shown by nozzle flow, Proc. Inst. Mech. Eng. 2, 2, 855-883 (1922).

Rettaliata, J. T., Undercooling in steam nozzles, Trans. ASME 58, 599 (1936).

Yellot, J. J., Supersaturated steam, Trans. ASME 56, $411-430$ (1934).

\section{2. 2. 2 Adiabatic, Variable Area Flow Systems with Subcooled or Saturated Liquid or Low Quality Fluid Entering}

Bailey, J. F., Metastable flow of saturated water, Trans. ASME 73, 1109-1116 (1951).

Benjamin, M. W., and J. C. Miller, The flow of saturated water through throttling orifices, Trans. ASME 63, 419-429 (1941).

Bottomly, W. F., The flow of boiling water through orifices and pipes, Trans. North East Coast Inst. Eng. and Shipbuilders 53, 65-100 (1937).

Bridge, T. E., How to design the piping for conveying flashing hot water, Heating, Piping, and Air Conditioning, 69-73 (Mar. 1949); 92-96 (April 1949); 98-100 (May 1949).

Burnell, J. G., The flow of boiling water through nozzles, orifices, and pipes, Engineering $164,572-576(1947)$.

Chisholm, D., The flow of steam-water mixtures through sharp-edged orifices, Eng. and Boiler House Rev. 73, $252-256$ (1958).

Hesson, J. L., and R. E. Peck, Flow of two phase carbon dioxide through orifices, AIChE J. 4, $207-210$ (1958).

Hoopes, J. W., Flow of steam-water mixtures in a heated annulus and through orifices, AIChE J. 3, 268-275 (1957).

Kinderman, W. J., and E. W. Wales, Fluid flow through two orifices in series III. Parameters of metastable and stable flow of hot water, Trans. ASME 79, 183 (1957).

Linge, K., Flow of boiling liquid refrigerants through throttling devices, Univ. of Karlsruhe, \{Unpublished).

Mendler, Rathbun, Van Huff, and Weiss, Natural-circulation tests with water at $800-2000$ psia under non-boiling, local conditions, Trans. ASME 83, Ser. C, 3, $261-273$ (1961).

Monroe, E. S., Jr., Flow of saturated boiler water through knife-edged orifices in series, Trans. ASME 78, 373 (1956).

Murdock, J. W., Two-phase flow measurement with orifices, ASME Paper 61-WA-27 (1961).

Pasqua, P. F., Metastable flow of freon-12, Refrig. Eng. 61, $1084 \mathrm{~A}-1088$ (1953).

Stuart, M. C., and D. R. Yarnall, Fluid flow through two orifices in series II, Trans. ASME $66,387-395$ (1944). 


\subsubsection{Semi-Empirical Relationships for Constant Area Flow Systems With Heat Added or Removed}

Harvey, B. F., and A. S. Foust, Two-phase one dimensional flow equations and application to flow in evaporator tubes, Heat Transfer Symposium, AICHE 49, Ser. 5, $91-106$ (1953).

Leppert, G., M. Jakob, and J. B. Reynolds, Pressure drop during forced circulation boiling, Heat Transfer Symposium, AIChE 52, Ser. 18, 29-36 (1955).

Rogers, J. D., Two-phase flow of hydrogen in horizontal tubes, AIChE J. 2 , 536 (1956).

Schweppe, J. L., and A. S. Faust, Effect of forced circulation rate on boiling-heat transfer and pressure drop in a short vertical tube, Heat Transfer Symposium, AIChE $\underline{49}$, $242-288(1951)$.

Stein, R. P., et al., Pressure drop and heat transfer to non-boiling and boiling water in turbulent flow in an internally heated annulus, CEP Symposium Series 50, 11, $115-126$ (1954).

\subsection{GRAPHICAL COMPARISONS OF REPORTED THEORETICAL AND EXPERIMENTAL DATA}

\section{1 Experimental Investigations for Adiabatic, Constant Area Flow Systems}

Agnostinelli, A., and V. Saleman, Prediction of flashing water flow through fine annular clearances, Trans. ASME 80, 1138-1142 (1958).

Benjamin, M. W., and J. G. Miller, The flow of a flashing mixture of water and steam through pipes, Trans. ASME 64, 657-669 (1942).

Burnell, J. G., The discharge of boiling water through a venturi tube, J. Inst. Eng. (Australia) 27, 7-8, 213 (July-Aug. 1955).

Faletti, D. W., Two-phase critical flow of steam-water mixtures, Ph. D. Thesis, Univ. of Wash. (1959); AIChE J. 9, 2 (1963).

Fauske, H., Critical, two-phase steam-water flows, Proc. of the 1961 Heat Transfer and Fluid Mech. Inst., 79-89 (Stanford Univ. Press, Stanford, 1961).

Hoopes, J. W., Flow of steam-water mixtures in a heated annulus and through orifices, AIChE J. 3, 268-275 (1957).

Isbin, H. S., J. E. Moy, and A. J. R. Cruz, Two-phase, steam-water critical flow, AIChE J. $\underline{3}, 361-365$ (1957).

\section{2 Experimental Investigations for Adiabatic, Variable Area Flow Systems}

\subsubsection{Adiabatic, Variable Area Flow Systems with Super- heated or Saturated Vapor or High Quality Two-Phase Fluid Entering}

Binnie, A. M., and M. W. Woods, The pressure distribution in a convergent-divergent steam nozzle, Proc. Inst. Mech. Eng. (London) 138, 229-266 (1938).

Goglia, G. L., and G. J. Van Wylen, Experimental determination of limit of supersaturation of nitrogen vapor expanding in a nozzle, Trans. ASME 83, Ser. C, 1, 27-32 (1961).

Goodenough, G. A., Supersaturation and the flow of steam, Power 66, 466-469 (1927).

Mellanby, A. L., and W. Kerr, The supersaturated condition as shown by nozzle flow, Proc. Inst. Mech. Eng. 2, 2, 855-883 (1922). 
Rettaliata, J. T., Undercooling in steam nozzles, Trans. ASME 58, 599 (1936).

Tippets, F. E., Water wall rupture in a high pressure reactor-hydraulic and heat transfer effects, Gen. Elect. HW-40388, (1955). Secret.

Yellot, J. J., Supersaturated steam, Trans. ASME 56, $411-430$ (1934).

\subsection{Adiabatic, Variable Area Flow Systems with Sub- Cooled Or Saturated Liquid or Low-Quality Two- Phase Fluid Entering}

Bailey, J. F., Metastable flow of saturated water, Trans. ASME 73, 1109-1116 (1951).

Benjamin, M. W., and J. C. Miller, The flow of flashing mixtures of water and steam through pipes, Trans. ASME 64, 657-669 (1942).

Bottomley, W. F., The flow of boiling water through orifices and pipes, Trans. North East Coast Inst. Eng. and Shipbuilders 53, 65-100 (1937).

Bridge, T. E., How to design the piping for conveying flashing hot water, Heating, Piping, and Air Conditioning, 69-73 (Mar. 1949); 92-96 (Apr. 1949); 98-100 (May 1949).

Burnell, J. G., The flow of boiling water through nozzles, orifices, and pipes, Engineering $164,572-576$ (1947).

Chisholm, D., The flow of steam-water mixtures through sharp-edged orifices, Eng. and Boilerhouse Rev. 73, 252-256 (1958).

Hoopes, J. W. Flow of steam-water mixtures in a heated annulus and through orifices, AIChE J. 3, 268-275 (1957).

Kinderman, W. J., and E. W. Wales, Fluid flow through two orifices in series -3 . The parameters of metastable and stable flow of hot water, Trans. ASME 79,183 (1957).

Linge, K., Flow of boiling liquid refrigerants through throttling devices, Univ. of Karlsruhe, (Unpublished).

Monroe, E. S., Flow of saturated boiler water through knife-edged orifices in series, Trans. ASME 78, 373 (1956).

Pasqua, P. F., Metastable flow of freon-12, Refrig. Eng. 61, 1084 A-1088 (1953).

\section{3 Constant Area Flow Systems With Heat Added or Removed}

Harvey, B. F., and A. S. Foust, Two-phase one dimensional flow equations and their application to flow in evaporator tubes, Heat Transfer Symposium, AIChE 49, 289-329 (1953).

Leppert, G., M. Jakob, and J. B. Reynolds, Pressure drop during forced circulation boiling, Heat Transfer Symposium, AIChE 52, Ser. 18, 29-36 (1955).

Rogers, J. D., Two-phase flow of hydrogen in horizontal tubes, AIChE J. 2, 536 (1956).

Schweppe, J. L., and A. S. Foust, Effect of forced circulation rate on boiling heat transfer and pressure drop in a short tube, Heat Transfer Symposium, AIChE 49, 242-288 (1951).

Stein, R. P., et al., Pressure drop and heat transfer to nonboiling and boiling water in turbulent flow in an internally heated annulus, CEP Symposium Series 50, 11, $115-126$ (1954).

\section{4 Fluids Other Than Water and Fluid Property Studies}

Faletti, D. W. , Two-phase critical flow of steam-water mixtures, Fh. D. Thesis, Univ. of Wash. (1959); AIChE J. 9, 2 (1963). 
Hesson, J. L., and R. E. Peck, Flow of two-phase carbon dioxide through orifices, AIChE J. $\underline{4}, 207-210(1958)$.

Linge, K., Flow of boiling liquid refrigerants through throttling devices, Univ. of Karlsruhe, (Unpublished).

Pasqua, P. F., Metastable flow of freon 12, Refrig. Eng. 61, 1084A-1088 (1953).

Rogers, J. D. , Two-phase flow of hydrogen in horizontal tubes, AIChE J. $\underline{2}, 4$, 536 (1956).

Tangren, R. F., Dodge, C. H., and H. S. Selfert, Compressibility effects in two-phase flow, J. of Applied Phys. 20, 7, 637-645 (1949). 


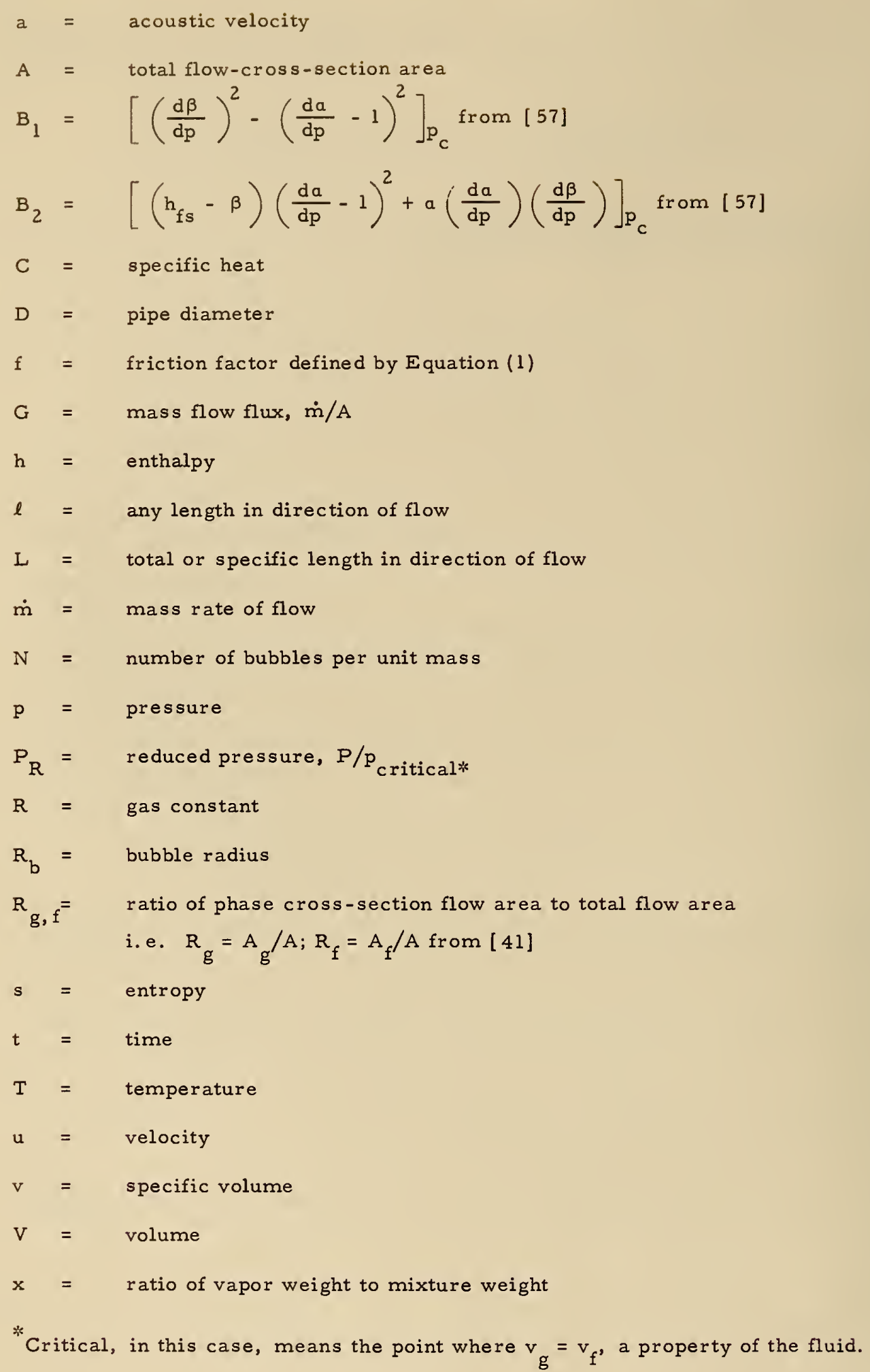




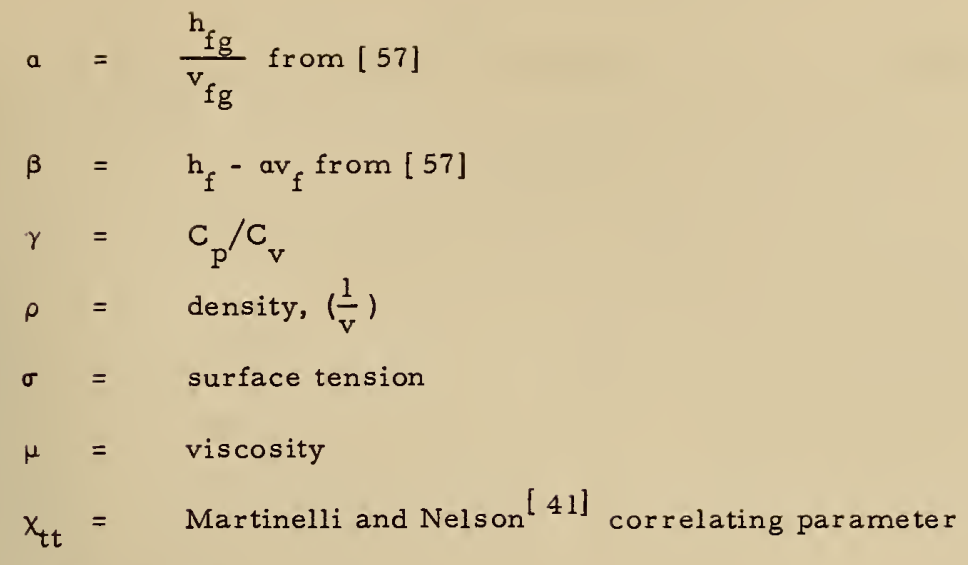

\section{Subscripts}

$1,2=$ station locations in direction of flow, 1 represents entrance conditions.

$c=$ critical (mass-limiting) conditions

$\mathrm{f}=$ liquid

$\mathrm{g}=$ vapor

$f g=$ difference between vapor value and liquid value i.e. $v_{f g}=v_{g}-v_{f}$

$(\mathrm{HO})(\mathrm{TH})=$ value obtained by use of a homogeneous, thermal equilibrium model

$(\mathrm{HO})(\mathrm{MET})=$ value obtained by use of a homogeneous, metastable model

$\ell=$ any length in direction of flow

$0=$ stagnation value

$s=$ saturated liquid point in the flow system or isentropic process

$\mathrm{VC}=\quad$ value obtained from a separated-phase, vapor choking model

tp $=$ two-phase

The first two letters of the author's name are used to denote special terms originated by that author. 
During the period of manuscript editing and typing, three more recent papers on choking two-phase flow have been prepared.

Mikol ${ }^{[1 \mathrm{~A}]}$ performed tests using $\mathrm{CCl}_{2} \mathrm{~F}_{2}$ in a small-bore, constant area system. He found his experimental choking data in good agreement with the homogeneous, thermal equilibrium model.

Starkman ${ }^{[2 \mathrm{~A}]}$ did experimental work with steam-water flow in a convergent-divergent nozzle. He found, in general, his experimental choking mass flow rate data fell between the predictions of a homogeneous, thermal equilibrium and a homogeneous, metastable model, somewhat nearer the metastable model predictions. For very low quality runs, he found the experimental data exceeded the mass flow rate predicted by his metastable model.

Fauske and $\mathrm{Min}{ }^{[3 \mathrm{~A}]}$ studied the flow of saturated $\mathrm{CCl}_{3} \mathrm{~F}$ through apertures and short tubes. They found that no vaporization or choking occurs in flow through apertures, but that a modified cavitation number is useful in determining the inception of two-phase flow and subsequent choking in short tubes. The work is in general agreement with that of Pasqua [49] The Fauske ${ }^{[20]}$ model can be used to predict critical flow rates for $L / D>20$ but underpredicts critical flow rates for smaller $L / D$ values. 
[1A] Mikol, E. P., Adiabatic single and two-phase flow in small bore tubes. To be published in ASHRAE $J$.

[2A] Starkman, E. S. , V. E. Schrock, K. F. Neusen, and D. J. Maneely, Expansion of a very low quality two-phase fluid through a convergent-divergent nozzle. ASME Preprint 63-AHGT-4.

[3A] Fauske, H. K. and T. C. Min, A study of the flow of saturated freon-11 through apertures and short tubes. ANL 6667, Argonne National Laboratory (1963). 

L. S. IDEPARTMENT OF COMIMERE

Luther 11. Hodges, Secretary

NATIONAL, BUREAU OF STANDARISS

A. V. Astin, Director

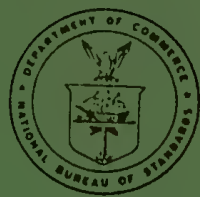

\section{THE NATIONAL BUREAU OF STANDARDS}

The scope of activities of the National Bureau of Standards at its major laboratories in Washington, D.C., and Bouldcr, Colorado, is suggested in the following listing of the divisions and sectionsengaged in technical work. ln general, each section carries out specialized research, development, and engineering in the field indicated by its title. $A$ brief description of the activities, and of the resultant publications, appears on the inside of the front cover.

MASIIINGTON, D.C.

Electricity. Resistance and Reactance. Electrochemistry. Electrical Instruments. Magnetic Measurements Dielectrics. High Voltage.

Metrology. Photometry and Colorimetry. Refractometry. Photographic Research. Length. Engineering Metrology. Mlass and Scale. Volumetry and Densimetry.

Heat. Temperature Physics. Heat Measurements. Cryogenic Physics. Equation of State. Statistical Physics. Radiation Physics. X-ray. Radioactivity. Radiation Theory. High Energy Radiation. Radiological Equipment. Nucleonic Instrumentation. Neutron Physics.

Analytical and Inorganic Chemistry. Pure Substances. Spectrochemistry. Solution Chemistry. StandardReference Haterials. Applied Analytical Research. Crystal Chemistry.

Mechanics. Sound. Pressure and Vacuum. Fluid Mechanics. Engineering Mechanics. Rheology. Combustion Controls.

Polymers. Macromolecules: Synthesis and Structure. Polymer Chemistry. Polymer Physics. Polymer Characterization. Polymer Evaluation and Testing. Applied Polymer Standards and Research. Dental Research.

Metallurgy. Engineering Metallurgy. Microscopy and Diffraction. Metal Reactions. Metal Physics. Flectrolysis and Metal Deposition.

Inorganic Solids. Engineering Ceramics. Glass. Solid State Chemistry. Crystal Growth. PhysicalProperties. Crystallography.

Building Research. Structural Engineering. Fire Research. Mechanical Systems. Organic Building Materials. Codes and Safety Standards. Heat Transfer. Inorganic Building Materials. Metallic Building Materials.

Applied Mathenatics. Numerical Analysis. Computation. Statistical Engineering. Mathematical Physics. Operations Research.

Data Processing Systems. Components and Techniques. Computer Technology. Measurements Automation. Engineering Applications. Systems Analysis.

tomic Physics. Spectroscopy. Infrared Spectroscopy. Far lltraviolet Physics. Solid State Physics. Flectron Physics. Atomic Physics. Plasma Spectroscopy.

Instrumentation. Engineering Electronics. Electron Devices. Electronic Instrumentation. Mechanical Instruinents. Basic Instrumentation.

Physical Chemistry. Thermochemistry. Surface Chemistry. Organic Cliemistry. Molecular Spectroscopy. Elleinc ntary Proccsses. Mass Spectrometry. Photochemistry and Radiation Chemistry.

Office of Weights and Measures.

\section{BOULDER, COLO.}

Cryogenic Ingineering Laboratory. Cryogenic Equipment. Cryogenic Processes. Properties of Materials. Cryogenic Technical Services.

\section{CENTRAL, RAUIO PROPAGATION LABORATORY}

Innosphere Research and Propagation. Low Frequency and Very Low Frequency Research. Ionosphere Research. Prediction Services. Sun-Earth Relationships. Field Engineering. Radio Warning Services. Vertical Soundings Research.

Radio Propagation Engineering. Data Reduction Instrumentation. Radio Noise. Tropospheric Measurements. Tropospheric Analysis. Propagation-Terrain Effects. Radio-Meteorology. Lower Atmosphere Physics.

Radio Systems. Applied Electromagnetic Theory. High Frequency and Very High Frequency Research. Frequency Utilization. Modulation Research. Antenna Research. Radiodetermination.

Upper Atmosphere and Space Physics. Upper Atmosphere and Plasma Physics. High Latitude lonosphere Pliysics. Ionosphere and Fxosphere Scatter. Airglow and Aurora. Ionospheric Kadio Astronony.

\section{RADIO STANDARDS LABORATORY}

Radio Physics. Radio Broadcast Service. Radio and Microwave Materials. Atomic Frequency and Time-Interval Standards. Radio Plasma. Millimeter-Wave Research.

Circuit Standards. High Frequency Electrical Standards. High Frequency Calibration Services. High Frequency Impedance Standards. Microwave Calilination Services. Microwave Circuit Standards. Low Frequency Calibration Services. 
